Portland State University

PDXScholar

\title{
Commercial Activities and the Geography of
} Movement in a West African Urban Market: A Study of Market-Stall Traders in Onitsha with Implications for Transport Policy

Krys Chukwuma Ochia

Portland State University

Follow this and additional works at: https://pdxscholar.library.pdx.edu/open_access_etds

Part of the African Studies Commons, Public Affairs Commons, and the Urban Studies Commons Let us know how access to this document benefits you.

\section{Recommended Citation}

Ochia, Krys Chukwuma, "Commercial Activities and the Geography of Movement in a West African Urban Market: A Study of Market-Stall Traders in Onitsha with Implications for Transport Policy" (1989).

Dissertations and Theses. Paper 1397.

https://doi.org/10.15760/etd.1396

This Dissertation is brought to you for free and open access. It has been accepted for inclusion in Dissertations and Theses by an authorized administrator of PDXScholar. Please contact us if we can make this document more accessible: pdxscholar@pdx.edu. 


\section{COMMERCIAL ACTIVITIES AND THE GBOGRAPHY OF MOVEMENT IN A WEST AFRICAN URBAN MARKET: \\ A STUDY OF MARKET-STALL TRADERS IN \\ ONITSHA WITH IMPLICATIONS FOR \\ TRANSPORT POLICY}

by

KRYS CHUKWUMA OCHIA

A dissertation submitted in partial fulfillment of the requirsments for the degree of

DOCTOR OF PHILOSOPHY

in

URBAN STUDIES : PUBLIC POLICY

AND ADMINISTRATION

Portland State University

1989 
TO THE OFFICE OF GRADUATE STUDIES:

The members of the Committee approve the dissertation of Krys Chukwuma Ochia presented June 6,1989.
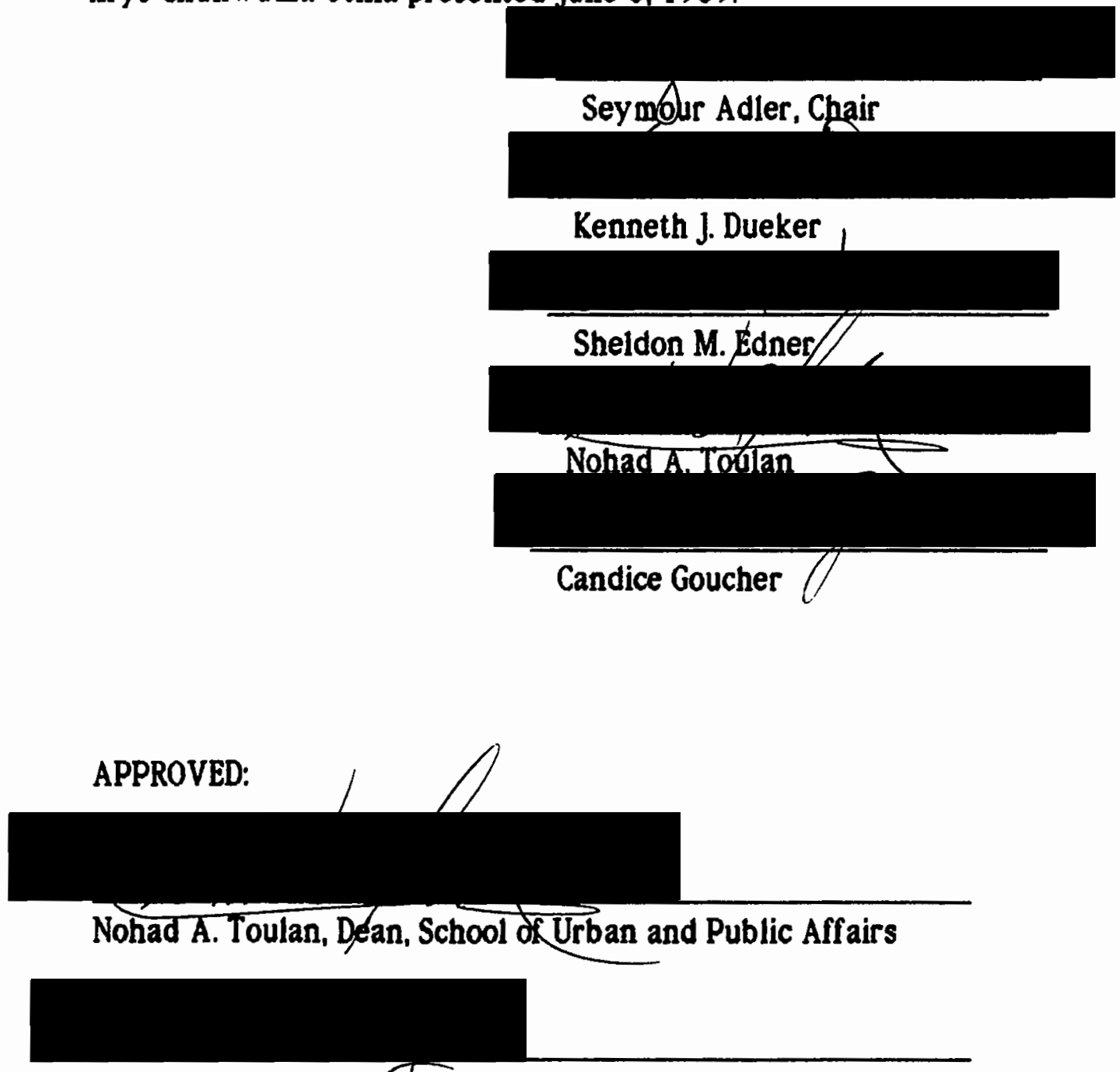

C. William Savery, Interim Vice Provost for Graduate Studies and Research 
AN ABSTRACT OF THE DISSERT ATION OF Krys Chukwuma Ochia for the Doctor of Philosophy in Urban Studies presented June 6, 1989.

Title: Commercial Activities and the Geography of Movement in a West African Urban Market: A Study of Market-Stall Traders in Onitsha with Implications for Transport Policy.

APPROVED BY THE MEMBERS OF THE DISSERTATION COMMITTEE:

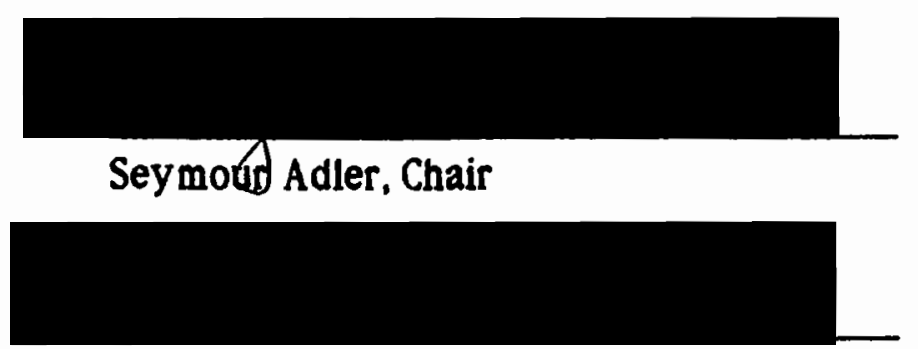

Kenneth J. Dueker
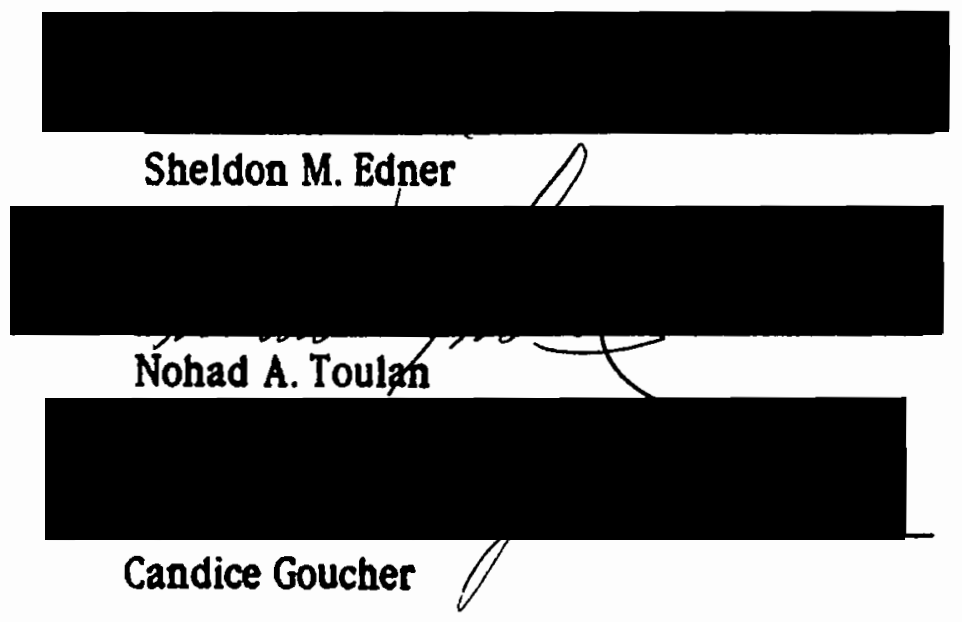
The purpose of this study is to understand the non-home-based travel behavior of urban market traders in Onitsha, Nigeria. Onitsha has one of the largest urban markets in West Africa with about 58-70 per cent of the labor force engaged in trading. Typically, researchers in the field of markets and marketing in the developing areas have provided useful studies in the organization and operation of markets but have paid little attention to traders. Moreover, studies in urban tripmaking behavior tend to concentrate on home-based trips because researchers of ten argue the importance of the work trip to planning and policy decisions. Implicitly, the trader has been ignored as a contributor to the daily non-home-based trip base even though traders of ten control the cash of the local economy. Therefore, there is an obvious lack of knowledge concerning how these important participants in the urban economy utilize and impact existing transport facilities and services.

A number of relevant trip-inducing variables were selected to assist in theorizing about the travel behavior of traders. These variables include gender, location, a means of personal transportation, the size of the stall, and, the type of good sold in the stall. Two hundred forty-six stalls were selected using a (non-random) systematic sampling methodology and the trip characteristics of occupants analyzed using a multiple linear regression model.

The results confirm that there is a direct relationship between stall size, the presence of a means of personal transportation, the number of vehicles, gender and total trips produced by a stall. In addition, CBD stalls tend to generate a greater number of trips than stalls in the periphery, and, stalls selling provision goods generate a greater number of trips than stalls specializing in other commodities. 
A typical stall in the sample is occupied by either one or two traders. There is a preponderance ( 3 to 1 ) of males in the trader population and a majority (89.4x) of stalls are occupied exclusively by either males or females. The mean trips produced by a stall in a typical business day is 2.7 trips although the number of trips varied between zero and ten trips. In the $\mathrm{CBD}$, an average stall produced 4.4 trips while stalls in the periphery generated an average of 2.1 trips. Small stalls (1-2 occupants) generate two trips, while medium (three occupants) to large (4 plus) stalls generate twice as many trips (4.3-4.5). While stalls occupied exclusively by males have a mean trip of 3.0, female-occupied stalls generate only 2.0 trips. Stalls which have a means of personal transportation generated more trips (4.5) than stalls where none existed ( 2.0 trips). Even though the maximum number of a personal means of transportation available to a stall for conducting daily business was two, sample results show a substantial difference between the number of trips produced by stalls with a maximum number of vehicles ( 5.6 trips) and stalls where vehicles were unavailable ( 2.0 trips). Finally, while provision goods stalls generated a mean of 3.3 trips, foodstuffs stalls generate about 2.1 trips; intermediate results exist for other commodities.

The significance of the findings are two-fold: Not only does it suggest emphasis in studying trip behavior of participants engaged in urban nonhome-based activities to assist in comparative transport planning in (West) Africa, there is empirical evidence to show that traders, unlike their counterparts in the retail business in the West, appear not to spend an entire business day consummating sales. Rather, together with consumers, they appear to contribute to the off-peak trips in the urban area and directly impact the urban transportation system. 
To transportation policy planners, the findings point to the need to encourage traders to use the public transportation system without explicitly encouraging additional use of a personal means of transportation. Moreover, walking should be encouraged by providing minimal road improvements and using the markets as the focus. Finally, storage facilities should be provided close to or within the markets to reduce the demand traders place on the urban transportation system thereby providing additional travel opportunities for consumers whose shopping habits sustain the economic importance of this commercial center in the îbo country. 


\section{DEDICATION}

This is dedicated to the memory of my father. He toiled in his farm to put me through school but passed away prematurely in 1980 while I was still studying in the United States of America. In addition this is dedicated to the other members of the family who, apart, from contributing financially to my education, continuously encouraged me to achieve the highest level of educational attainment. I also dedicate this to my wife. who had to put up with me while I spent endless hours preparing this document. 


\section{TABLE OF CONTENTS}

\section{PAGE}

DEDICATION.................................................................................... ii

LIST OF TABLES.................................................................................. vii

LIST OF FIGURES .............................................................................. ix

\section{CHAPTER}

I INTRODUCTION....................................................... 1

Study Problem..................................................... 1

II BACKGROUND OF STUDY AREA .......................... 12

The Development of Commerce

in Onitsha....................................................... 12

Spatial Organization...................................... 19

III A SOCIOLOGY OF URBAN MARKET TRADING ACTIVITY................................................................... 33

Years in Trading and Age Distribution...................................... 35

Market Supplies and Management............................................... 38

Government Relationship............................. 44 
IV LITERATURE, HYPOTHESES AND METHODS............ 51

The Literature ..................................................... $\$ 1$

The Hypotheses..................................................... 69

Sampling Methodology

and Procedure............................................ 72

Data Characteristics............................................. 78

Sample Size............................................................ 85

$\mathrm{V} \quad$ ANALYSIS OF SURVEY RESULTS................................ 88

Effect of Location...................................................... 89

Effect of Stall Size.................................................... 92

Effect of the Availability of a Means of Personal Transportation.................... 96

Effect of Gender-Males and Females...........100

Effect of Type of Commodity Sold............... 106

Characteristics of Trip Purpose................... 111

Characteristics of Mode Choice..................... 117

Constraints on Travel Behavior.................... 122

Significance of Findings.................................... 130

VI TRANSPORT POLICY IMPLICATIONS........................ 141

VII FURTHER RESEARCH.................................................... 146

A SELECTED BIBLIOGRAPHY............................................................ 150 


\begin{tabular}{|c|c|}
\hline & $\begin{array}{l}\text { SUMMARY OF STALL DATA AND } \\
\text { RELATED FREQUENCIES................................................... } 168\end{array}$ \\
\hline B & CORRELATION MATRIX TABLES.................................. 184 \\
\hline C & HSRRC MEMORANDUM \\
\hline & SURVEY MATERIAL \\
\hline & $\ldots$ \\
\hline & \\
\hline
\end{tabular}




\section{LIST OF TABLES}

TABLE

PAGE

I Percentage of Labor Force in Commercn............ 4

II Working Population by Place of Work and Means of Transportation.................... 29

III Age and Number of Years in Trading................. 36

IV Household Income by Occupation........................... 40

V Sources of Small Business

Finance in Onitsha............................................. 46

VI Overall Population by Age and Literacy............. 47

VII Overall Working Population by Sez/

Type of Employment, 1978.......................... 64

VIII Score for Each Dummy Variable............................... 68

IX Market Location, Total Stalls, Sample Size and Sampling Interval.................................. 74

X Mean Trips of Stalls and Stall Size........................ 94

XI Mean Trips of Stalls and Number of Stall Employees

XII Mean Trips of Stalls by Number of Vehicles..... 98

XIII Mean Stall Trips by Type of Good Sold.................. 108

XIV Trader Stall Trips by Type of Good Sold............... 109 
XV Stalls Producing Trips by Trip Purpose................. 111

XV1 Category of Traders Trip Purpose.......................... 116

XVII Type of Mode Selected

by Stalls Producing Trips................................. 118

XVIII Category of Traders by Mode Choice.................... 121

XIX Response Rate of Stall on Environmental

Constraints on Travel Behavior.. 123

XX Mean Trips by Category of Traders...................... 128 


\section{LIST OF FIGURES}

1. Market Zones, Main Market................................ 16

2. Nigeria: Distribution of Towns and Cities With Population of 50,000 or more....... 18

3. Urban Land Use ................................................... 21

4. Urban Road Network........................................... 27

5. Intraurban Bus Routes....................................... 30

6. Ogbete Market, Enugu, Nigeria, Showing a Typical Arrangement of Market Stalls............................................ 73 


\section{CHAPTER I}

\section{INTRODUCTION}

"[T]he fate of the city might hinge on how quickly and how wisely thle] urban movement problem can be or resolved or at least minimized"

- D.C.I. Okpala Nigerian Institute of Social and Economic Research

\section{STUDY PROBLEM}

The purpose of this study is to understand the (non home-based) travel behavior of urban market traders in Onitsha, Nigeria. Non home-based trips are characterized as those trips which do not have their origin or destination at the place of residence of the traveler. It is the intent of the study to offer researchers a better understanding of traders' travel characteristics, fill the void in current literature and provide a basis for comparing other (West) African market centers with the goal of maximizing the effectiveness of investment in transport facilities.

Typically, researchers in the field of markets and marketing in the developing areas have provided useful studies in the organization and operation of markets, but have paid little attention to traders (Hill,1970i. 
Even though market traders control the cash of the economy (Baker,1965:46), there is an obvious lack of knowledge concerning how (urban) traders in Onitsha and other cities in the developing areas utilize transport facilities and services. In other words, there appears to be no existing body of knowledge upon which we can base theoretical statements about their movements. For example, we do not understand the relationship between the number and the frequency of trips made by traders and the size of the trader's stall, or for that matter, the location of the stall. There may be a lot of opinions, but there are no facts. Indeed, Diandas (1984:204) has reminded scholars interested in conducting urban transport-related studies in the developing areas that "a useful study ... would be the careful assembly of facts about cities and the travel in them supported by discussion and diagnosis of problems aimed at seeking suitable combination of remedies." Obviously such a statement would not apply to cities in the West where a majority of work has been completed on urban activities, tripmaking and trip behavior of households.

Research in urban tripmaking in the developed and the developing areas has concentrated on home-based trips. As Stopher, Ohstrom, et al (1984:75) argue, the justification for the focus is primarily based on "the importance of the work trip in planning and policy decisions, and the appropriateness of the work trip for research." We know, for example, that about $\mathbf{8 0}$ per cent of all trips have their origin or destination at the family residence, while about 30-40 per cent of all those trips are work-related and about 10 per cent are additional trips made in the course of work, and, to and from school (Vickerman,1972:176-210; Olayemi,1977)). In addition, numerous data collected on travel and traffic have enabled the development of theories related to household tripmaking behavior. For example, such 
theories relate tripmaking to variables like age, the size of the household, family income, the number of automobiles available and the number of licensed drivers. Similar theories have also been developed to relate individual tripmaking behavior to non-work trips including shopping and recreational activities. Therefore, similar theories on the tripmaking behavior of traders in Onitsha and elsewhere could be developed if the data were available. Moreover, the data will foster proper planning decisions, and, as Starkie (1967:232-234) puts it, thought could be given to "balancing traffic with available road network (capacity) by means of economic, administrative and planning measures instead of endeavoring to increase road network in step with traffic," (cf: Olayemi,1980:129-142).

Generally, a significant proportion of those who find employment in the urban informal sector in the developing areas engage in the buying and selling of goods. As the population of cities in those areas continues to grow (see, Churchill, et al,1976:363-409), it is reasonable to assume that the number of traders will continue to increase (with greater impacts on transportation infrastructure) thereby reinforcing the need for researchers to refocus attention on understanding the travel behavior of the participants. This is particularly important since the urban centers in the developing areas continue to play an important role in over all economic development as the same centers continue to attract disproportionate amounts of investment in infrastructure in those areas. Table I illustrates the importance of commerce in the informal sector in some selected urban centers.

In Onitsha, even though traders constitute a significant proportion of the urban labor force, we do not understand their impact on the transport system. Because professional traders make up about 58 per cent of the 


\section{TABLE I}

\begin{tabular}{lc}
\multicolumn{2}{c}{ PERCENT AGE OF LABOR FORCE IN COMMERCE } \\
Urban Center & Percentage in Commerce \\
Freetown & $65.5(1963)$ \\
Mombasa & $40.7(1950)$ \\
Lima & $27.5(1970)$ \\
Ibadan & $71.0(1963)$ \\
Lae (Papua New Guinea) & $43.1(1977)$ \\
Hiniara (Solomon Islands) & $22.8(1978)$ \\
Dagupan & $22.0(1979)$ \\
ONITSHA & $57.5(1978)$ \\
Willmington, (U.S.A.) & $20.0(1970)$ \\
Sources: Silberman,1950:14-21; Mazumdar,1976:655-679; \\
Dannhaeuser,1977:471-503; Connell and Curtain,1982:119-136; \\
Onitsha Master Plan,1979:77
\end{tabular}

urban labor force, (or, by one account, Onyemelukwe, 1974:49-54, about 70 per cent of the total urban population claim trading as their occupation) and, those who conduct their business from sheds comprise about 80 per cent of the trader population, it is reasonable that we document the propensity of these entrepreneurs to make intraurban trips. The knowledge will be useful in establishing stall traders' contribution to urban tripmaking. The result will be useful toward establishing proper urban transport policies for creating an efficient system to benefit market operation.

In the judgement of some analysts, traders in Onitsha or elsewhere may not generate an appreciable number of business trips and impacts on the transport system to justify the present study (cf: Beveridge and 
Oberschall,1979:xiii). In fact, trading operations present characteristics to make us believe the opposite is true. For example, in analyzing the daily commuting behavior in Lagos, Nigeria. Olayemi (1977:19-27) found that intraurban movement is dominated by journey-to-work and school trips (79.3x), while business trips constitute only 9x of total urban trips. More important, however, Olayemi emphasized that while petty traders make only two trips daily (to and from the market), other professional traders often make many trips that, "it, no doubt, contributes to the heavy traffic characteristic of Lagos during off-hours." As a result, Olayemi argues that there is an unmistakable need for a very close examination of traders' travel behavior, especially in the urban areas of Nigeria and implicitly in other commercial centers in the developing nations.

What operational characteristics predispose the trader, in an urban environment, to make multiple trips during off-peak hours? According to Bauer (1965:26), "the activities of the trader represent a substitution of labour for capital." Beveridge and Oberschall (1979:107) observe that a majority of traders (in Zambia) have no telephones for placing orders to suppliers. Moreover, modern banking systems, including the use of checks to pay for orders, are not the norm. Furthermore, due to low levels of capital investment, businesses are unable to accumulate stockpiles. The alternative is to adopt less effective measures such as going in person to suppliers or to those with capacity to stockpile (p.153). In addition, African traders can not easily be classified as "retailers" or "wholesalers" (Bauer,1965:53; Hawkins,1965:23; Hodder and Lee,1974:145), and consumers have strong a preference for brand-name shopping (Pedler,1955:148; Baker,1965:46). The implication is that a typical stall would maintain a relatively large labor force to share responsibilities in order to maintain a smooth operation, 
especially when we consider the highly competitive conditions and the low profit margins (Pedler,1955:142). Finally, many traders who have the capability to stockpile have limited their storage facilities (Mushtaq,1968), since traders prefer to expand their business operation by increasing existing stock in the stall (Sada and McNulty,1981). Accessing storage locations outside the market will add to the propensily to make trips. Finally, there is a lack of refrigeration facilities, especially for those who sell foodstuffs.

Planned urban transport systems tend to characterize cities of developed economies. Moreover, advanced technologies have been applied in providing urban transport services in those areas. In contrast, the majority of urban centers in the developing countries, especially in Africa, grew as a result of their unique positions as centers of colonial administration. However, colonial attitudes toward (urban) development was essentially oriented to resource-based exploitation as illustrated by a statement attributed to Sidney Cain, the Undersecretary, Economic Development Division of the (British) Colonial Office, namely, that "there was nobody (at each colonial administrative office) whose particular business was to be a 'development chaser' in each territorial government (Lee,1967:140)." As a result, investment in the development of urban transport facilities, for example, was not a priority. One of the results is that there is no efficient relationship between land use and transportation. Perhaps the feeling was that the few automobiles plying the streets did not justify investing in urban transport planning. Those few automobiles belonged to the colonial administrators and their associates, the Warrant Chiefs (Isichei,1976). Wolpe (1974:64), for example, writing on (British) colonial administration in PortHarcourt, (Nigeria), emphasizes that the "official (colonial) and (the local) 
mercantile interests were not always coterminus. The colonial office had to concern itself with a wide range of problems that often had little to do with the requirements of the business community" which would have included developing an efficient system for moving people and goods. Therefore, a majority of population centers in the colonies grew without adequate provisions made for transport facilities.

Studies have shown that there is a positive correlation between the development and maintenance of an effective transportation system and an improvement in the local and regional economic system. In ex-colonial territories, the earliest phase of transport development was between the ports and the centers of economic resources in the hinterland. (The pre- and post-independence eras emphasized interconnectivity and expansion of the road network system. For details, see, Taaffe, Morrill and Gould,1972). It was argued that such port-hinterland linkage was a precursor to a total economic development of the areas. The era was characterized by the "leading sector," "bis push," and "big plan" paradigms (Rondinelli,1983) which tended to ignore the needs of local inhabitants. These residents, a majority of who found employment in the urban informal sector following migration from the rural areas, "muddled through" the economic system utilizing any available transport facilities.

Economists and planners have since recognized the difficulties involved with gathering data in the developing areas to assist in sound planning practices. As a result they have tended to "plan without facts" (Stolper,1966). The argument in current literature is that in making local development decisions, planners and policymakers should depend on local technocrats who possess detailed knowledge of local conditions (Rondinelli,1983). This study will respond directly to such a need by arming 
local planners with valuable information on local travel pattern of traders, a relevant ingredient in formulating a wise local plan.

Since 1975, World Bank transport experts have been arguing and urging policymakers in the developing areas to explore the maximization of existing urban transportation infrastructure rather than encouraging new capital intensive programs, as an option for addressing local urban transport problems (The World Bank,1975). To pursue and project this alternative, the Bank has, in its latest policy paper, reviewed and developed numerous strategies (The World Bank, 1986). My argument is that in order to intelligently explore the merits of the proposed options, there is the need, first, to assemble data on current urban travel characteristics in order to develop a handle for minimizing investments in transport facilities (see, Locklin,1959; Owen, 1959).Finally, realizing that the planning and management of transportation programs are still "compounded by lack of data" (Thompson,1983:Summary Page) in the developing areas, and in Nigeria specifically, transport "planning is still hampered by deficient and out-of-date data (Olanrewaju,1986:63)". Some experts (Ogunsanya,1985) have proposed simple models for generating simulated traffic data which could be applied in predicting urban traffic flows. It is anticipated that this study will contribute to the general understanding of the travel behavior of traders, at least in Onitsha, so that decision making will be based on empirical, rather than simulated data.

Finally, in order to facilitate the design and management of the urban transportation system to accommodate traders, the study also provides information on characteristics of trips generated and marketing activities toward future land use decisions involving market site selection, for example, would be made intelligently. Implicitly, the data obtained from this 
study would supplement data on residential trips of ten applied in planning and management of the urban transportation system for non-residential (trip) activities (Shuldiner,1965: Chapter II). Furthermore, it is anticipated that facts obtained from the study could be applied in educating traders and their leadership about the contribution of trading activities to the traffic system so that they could be persuaded to support the upkeep of the system. As several researchers (Hanna and Hanna,1977; Dike, 1982:85-94; Kilby,1969) have demonstrated, the concept of "improvement" to the African urban dweller is often interpreted to mean improwing the individual's hometown or place of origin even though the urban area provides the individual with a livelihood. Perhaps, traders could participate in the maintenance of the transport system by contributing financially should they realize that the transportation system actually promotes and sustains trading activities.

The following research questions, therefore, form the focus of study:

1. Which variables are statistically-significant in contributing to the total number of business trips generated from a trader's stall?

2. Which category of traders (masters vs non-masters) make the greatest number of intraurban trips after they arrive in the stall at the beginning of the business day?

3. What is the distribution of trip purposes?

4. The trip frequency? The mode choice?

5. Are the tripmaking patterns of traders in the CBD any different from those in the periphery?

6. What effects do the availability and the number of a means of personal transportation have on the propensity of traders to make trips? 
7. Finally, to what extent do the size of the stall, measured by the number of occupants, and the gender of stall occupants, have on the frequency and the number of trips generated from the stall? (Additional reasons for focusing on these questions are further examined in Chapter IV).

The effect of gender on trip production is particularly important since there is a preponderance of males over females in Onitsha market (see Chapter V for implications for study results), unlike in other West African urban markets. Answers to these questicns are explored by selecting a sample of stalls from the three major urban markets in Onitsha and analyzing the travel behavior of stall occupants using a multiple linear regression model. We expect to identify some relationships between the relevant variables and total trips generated from the stall. Furthermore, we expect a greater number of trips to be produced by stalls located along the express road, occupied exclusively by males, stalls which have a means of personal transportation, or which have a greater number of a means of personal transportation, stalls with a greater number of occupants and stalls selling provision goods than we expect for stalls in alternate categories (further details are included in Chapter IV).

The analysis is based on stall-level data and as a result, it was not practical to analyze trip information on individual traders except for trip purpose and mode choice. Data on trip distances, hourly trip rates and distribution or detailed information on trip destination are not included in the results. Based on the survey results, we are able to evaluate the difference between the trip purpose and mode choice of masters (stall owners/co-owners, temporary help or spouses) and non-masters (assistants and apprentices) to assist us in our understanding of relationship in the marketplace. 
The sample included about three per cent of stalis in the large markets (where all types of commodity are sold) so that other traders scattered in small shops, in residential areas, along business strips and in other small neighborhood markets were not sampled (Additional information is discussed in Chapter IV - Sampling Methodology and Procedure/Sample Size). In my judgement, however, those traders are expected to possess operational characteristics, including travel behavior, not dissimilar from stalls included in the sample. A similar argument would be extended to traders in other West African urban market centers whose operations are also small-scaled and who face similar economic and environmental constraints as stall-traders in Onitsha (Sethurman,1981). As a result, we expect the findings in this study to be relevant in understanding the travel behavior of traders in Onitsha and in other urban markets in West Africa and in the transportation system planning to accommodate the traders rather than expanding it for them (see also Chapter VII).

Having discussed the purpose of this study, the research questions, the expected results, and touched on the relevance of expected results to the trader population in Onitsha and elsewhere, the remainder of this report is organized into six major areas - a review of the general characteristics of the urban area studied; a sociology of urban market trading activity; the methodology applied in the study to assist in answering the research questions; an interpretation of the results of the survey: the transportation policy implications, and a proposal for further studies. 
CHAPTER II

\section{BACKGROUND OF STUDY AREA}

\section{THE DEVELOPMENT OF COMMERCE IN ONITSHA}

Onitsha is situated approximately 150 miles from the Atlantic Ocean. It is located on the bank of the River Niger at approrimately $6^{\circ} \mathrm{N}$ and $7^{\circ} \mathrm{E}$. It was founded in the 17th Century by immigrants from Benin. According to Ukwu, the original settlement was at Ndende on a low river terrace standing 30 feet above the river flood or 100 to 150 feet above sea level (Hodder and Ukwu, 1969:234). Originally, Onitsha has acted as an entrepot port between the Delta ports along the Atlantic Ocean and other trading stations on the upper Niger and Benue Rivers in the interior (Floyd,1969:284). During the high flood season (between July and October), the Niger is navigable from the Delta ports past Lokoja to Baro but during the low water season (January to June), Onitsha comes into its own as an entrepot when bulk cargo from the Delta ports and produce from northern Nigeria are transshipped at Onitsha (Floyd, ibid). The completion of irrigation dams upriver in the last two decades has diminished the amount of water flow in the lower Niger. In addition, during the 1980s', the significantly improved inter-city road system, combined with an aggressively expanding trucking business, have tremendously reduced the demand for river transport facilities and services as the major supply system, as trucks deliver foodstuffs from northern 
Nigeria at record levels or manufactured goods from Lagos and other Ocean ports.

The dominance of Onitsha as a commercial center began following the establishment of European factories in 1857 (Hodder and Ukwu, op cit). Prior to that date, the market was periodic and Onitsha had trade relations with various towns in the hinterland (Crowther,1970:179). On a typical trading day, there were about five hundred people in the market (Crowther, ibid). Prior to the mid-Nineteenth Century era, slave trading was the dominant trading activity in these areas. The European missionary traders who arrived by 1857 also brought with them Western education, Christianity, and the copper coins which replaced cowries as the medium of erchange (Crowther,1966:184). These factors hastened the replacement of slaves with palm produce as the principal commodity of trade (Isichei,1976:168). Moreover, several local traders switched from trading in fish, pottery, potash and beads to bulking palm produce for overseas markets. With the expanding commercial influence and trading activities in Onitsha, the market moved from its original location at Ndende to the Otu Okwodu site which today forms part of the inner central business district. Meanwhile, several British (including John Holt, the United African Company) and French trading firms, had established factories and were engaged in both retail and wholesale trade with indigenous traders acting as middlemen (Hodder and Ukwu,1969).

Several factors contributed to the growth of the commercial town. One of the factors was that "by 1911 the Resident British Administrator for Onitsha Province laid out Onitsha and gave it its first look as an urban settlement (Onyemelukwe,1974:51)." The structural improvements enhanced the commercial attributes of the center. Asther important factor was the 
introduction of municipal services following the implementation of the Nigerian Township Ordinance passed in 1917. According to Mabogunje (1969), the 2nd Class Township of Onitsha had a hospital by 1917, water supply by 1929 , and electricity by 1950 . These services attracted migrants to the center who also participated in the informal sector. In addition to these improvements, the local government authorities by 1928 erected permanent stalls at the site of today's Main Market in order to create order in the market place (Hodder and UKwU, op cit:238). This was an incentive because traders were assured of protected spaces for conducting business. Finally, the introduction of the lorry in the 1920s' and its proliferation in the 1930s' reduced the cost of movement in terms of time, money and human suffering. Ukwu reports that "records show that the journey from Agwu to Onitsha, (for instance), in 1927 took the greater part of two days, and (that) old traders in Bende Division report that it took three days from there. With motor transport this was cut down to between three and five hours, and no part of Eastern Provinces (now Anambra, Imo, Rivers, Cross River and Akwa Ibom States) was more than ten hours away, the rather slow speed - 20 to $30 \mathrm{mph}$ - and the frequent stoppages of the vehicles notwithstanding (Hodder and Ukwu, op cit:236)." The immigrants successfully transferred the concept of the village mini open-market system to the urban area, the forerunner to the multiplication in the number of market sites in the area despite government opposition. In Uganda, for example. Temple reports that the siting of markets was regulated (Temple, 1969:349).

Other developments which benefited the market in Onitsha were the construction of the Main Market and the Niger Bridge. The construction of a modern (Main) market by 1955 and the subsequent allocation of the stalls to 
the small traders and only to those lines which most needed to be in the market, on the advice of the indigenous traders themselves, was an important development. Perhaps, the preponderance of small traders and the desire to exclude the usually large foreign distributors and competitors from the collective market center might have affected such a decision. As a rule, according to Ukwu, the bigger traders stayed out of the markets and carry on their businesses in the shops (Hodder and Ukwu, op cit:239). One significant feature of the organization of the market is what has been described as "zoning." see, Figure 1. It is the grouping of kindred articles in a section of the market as is done in modern department stores (Nzekwu,1960:135). A similar feature characterizes several African markets (see, for example, Garlick, op cit:53).

The other development was the construction of the Niger Bridge (1.966) which linked the east (including Onitsha) and the west (including Lagos) directly by road for the first time. Prior to that, traffic across the Niger was handled by motorized ferries and the primitive but more efficient canoe ferry services (Udo, 1970:52). With the overland transport system, the direct importation of European and locally-manufactured goods was handled more efficiently because the total travel time and the inconvenience were significantly reduced; for example, loaded lorries took about forty minutes to cross the Niger, and without breaking bulk.

According to Udo, ferrying involved a huge waste of time with cars being delayed over twelve hours and lorries for five days at the Asaba end, opposite Onitsha. The protracted bridge construction contributed to the consolidation of the Nwadimkpa evening sauce market 1 adjacent to the

$1^{A}$ sauce market provides basic cooking ingredients and supplies mainly to neighborhood residents. Marketeers sometimes sell prepared food. 
headbridge. On the eve of the Nigerian civil war (1967), therefore, Onitsha

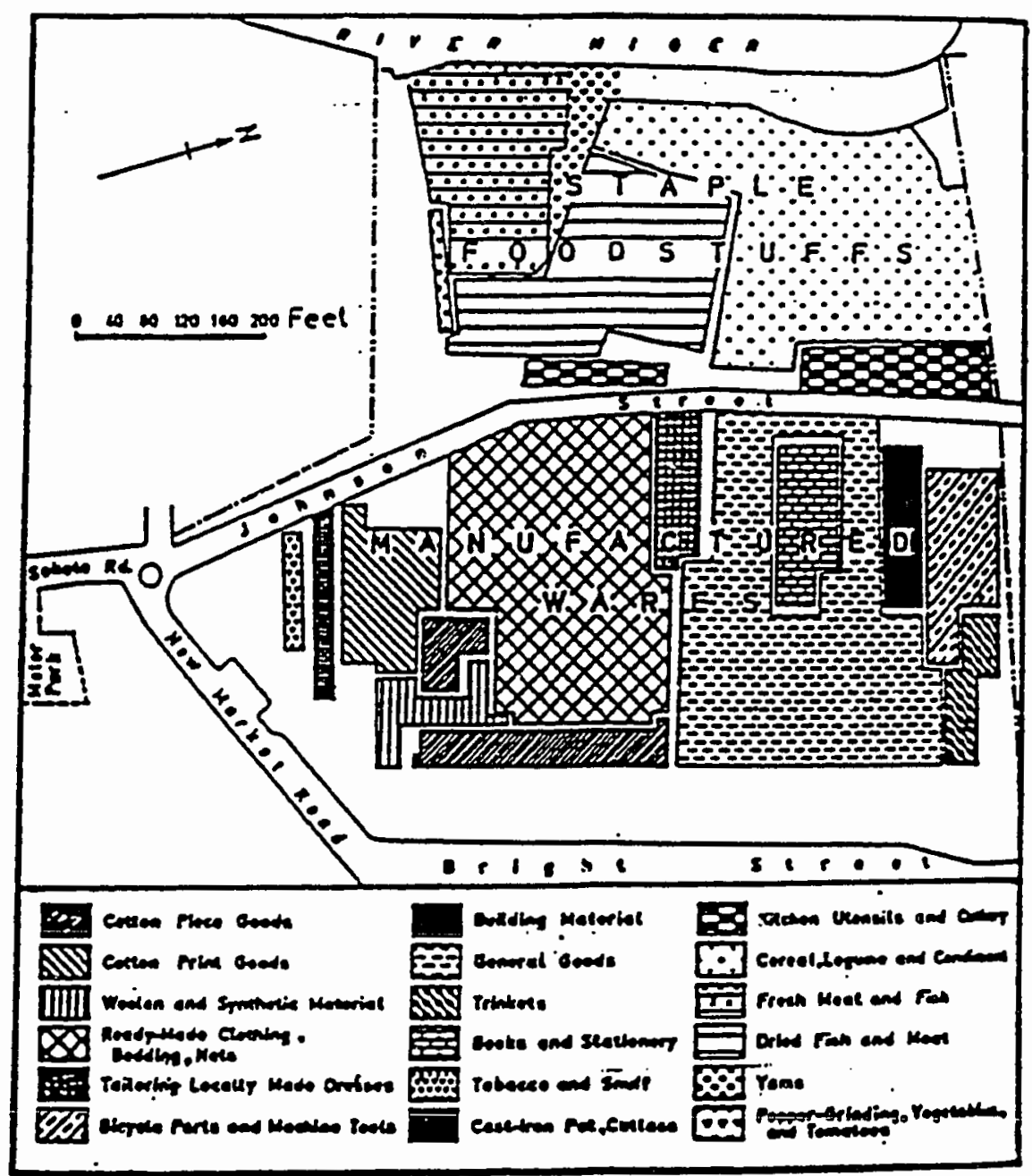

Eisure 1. Market zones, Main Market, Source:Onyemelukwe, 1970.

had large (the Main Market, Ose Okwodu) and medium-sized (Ochanja) markets and several sauce markets (Nwadimkpa, Ndende, Nkissi, Awka Road and Atani Road). Moreover, it had become a central place and a specialized city serving as a break-in-bulk for hinterland and distant markets. It had also become a cultural, social and administrative center in southern Nigeria, 
(see, Siddal,1961). Above all, "Onitsha town ... (has become) just one great market" (Nzekwu,op cit:147).

Since the cessation of hostilities (1970), Onitsha has recaptured and even surpassed its pre-war status. For instance, its population has increased from 163,000 in 1963 to about 250,000 in 1980 (O'Connor,1983:43). According to estimates provided by the Anambra State Ministry of Economic Planning in its 1987 population forecasts, Onitsha had about 500,000 residents in 1986. See Figure 2 for the distribution of population centers in Nigeria 2 . It is probable that more individuals are now engaged in trading. The increase in the trader population must have contributed to the evolution and growth of new markets to absorb new marketeers and to the structural changes at the older markets. For example, the Ochanja Market has been relocated to the Upper Iweka Road (with a vestige of the old market along the adjacent street with scantily-stocked sheds) and renamed the Ochanja Relief Market (adjacent to the Express Road) while the Nwadimkpa Market has been absorbed by the Headbridge Market. The two express road markets are larger in size than the original markets they replaced. Moreover, the Atani Road Market has been absorbed by the Headbridge Market although a vestige of the market, like the Ochanja Market, remains and is located adjacent to a motor park. The original market site and adjacent unimproved properties have been developed and is the site of a gas station, a number of distribution houses and light manufacturing plants in an area generally referred to as the Headbridge Development Layout.

2 According to Onyemelukve (1982:60), the 1963 Nigerian census "remains the latest official source for the population of the country." 


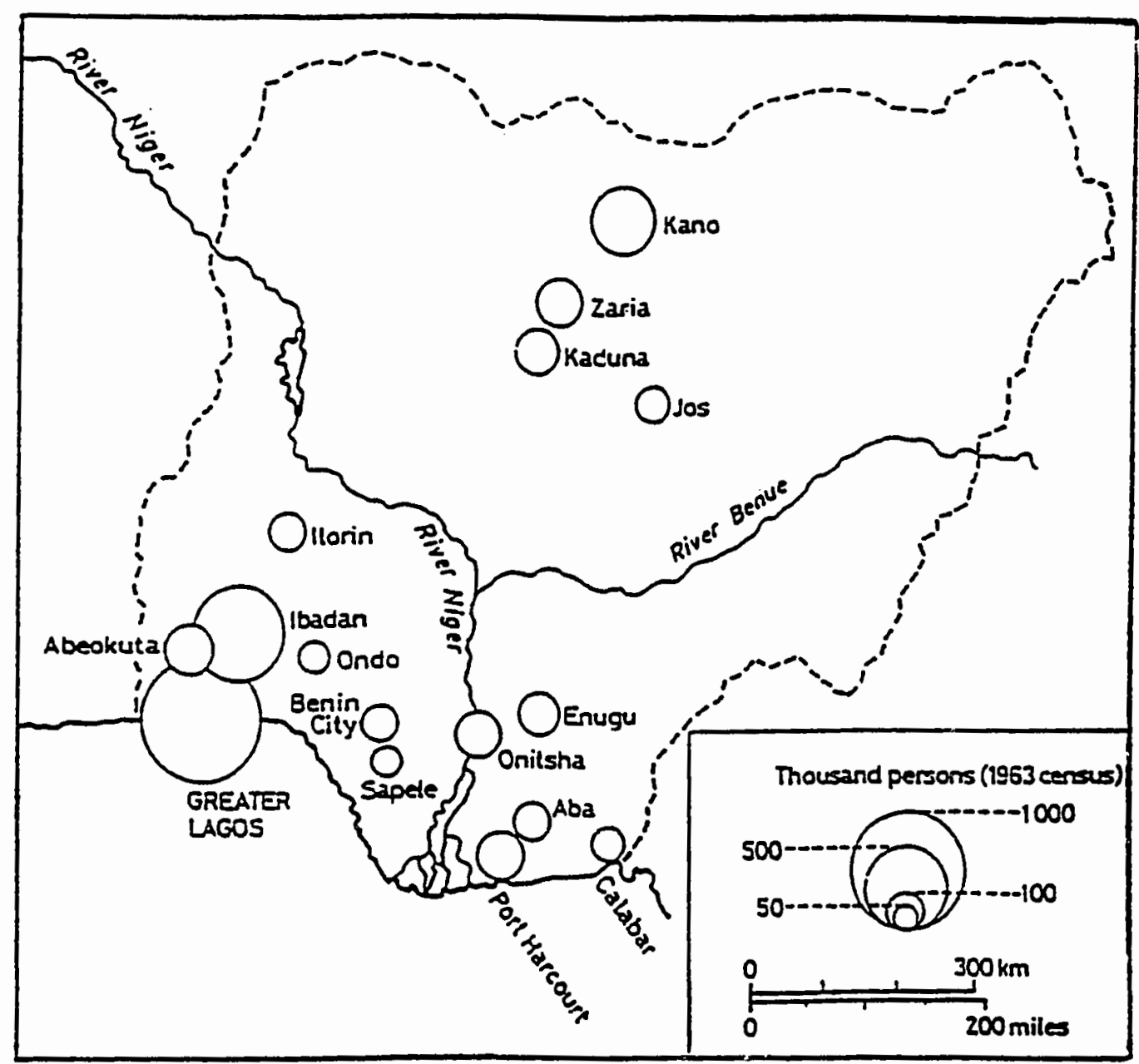

Fiqute 2. Nigeria: Distribution of towns and cities with population of 50,000 or more, Source: Ajaegbu, 1976. 


\section{SPATIAL ORGANIZATION}

\section{The Uses of Land}

Land use in Onitsha is mixed. However, the northeastern portion is mainly residential. This area is known as the Inland Town. The remaining parts of the town consist mainly of mixtures of residential, commercial and light manufacturing establishments. The markets have geographicallydefined boundaries. The evolution and growth of the Express Road Corridor markets were influenced by the delayed and protracted reconstruction of the Niger Bridge following the end of the Nigerian civil-war (1967-1970), and, more importantly, by the highway project extending to the Upper Iweka Road junction. Moreover, the establishment of industrial and housing properties and the construction of the Army Barracks on adjacent property played significant roles in promoting the growth and prominence of the corridor. The two markets, located on the corridor, are also served by motor parks.

The Fegge and the areas to the east and to the southeast of the Inland Town are residential with local shops and commercial strips serving pedestrian and adjacent residents. The administrative offices are located closer to the Inland Town, perhaps, the result of an early monopoly of the urban administrative machinery by the so-called Onitsha indigenes. They live mainly in the Inland Town around the palace of the Obi of Onitsha, their traditional ruler (Sklar,1963:151-157).

Following the formation of a new military government in 1985, it appears the enforcement of some aspects of the land use laws has been improved. For instance, traders have been forbidden to add the so-called "attachments" to their legal stalls. The attachments provide badly needed 
additional stall space. All offenders are routinely cited and their goods often confiscated by the Market Master. Increased enforcement of this and other laws affecting the environment of the trader could create additional intraurban trips by traders.

One significant feature of the land use pattern is the characteristic absence of major manufacturing establishments within the residential areas. Such establishments tend to surround the built-up areas. Perhaps, the original land tenure system in which land is held in trust for the family could have been a factor. In Onitsha, the indigenous population has laid claim to an extensive land area, and perhaps, were more inclined to parcel them in small holdings for the development of residential properties rather than for industrial purposes. Moreover, the early lead and continuous interest of Onitsha in commerce might have reduced interest in the manufacturing sector. Notice, for example, that a 1957 map of manufacturing establishments in Nigeria shows that there were none in Onitsha despite its regional importance (Federal Department of Commerce and Industry, Lagos,1957: Map Supplement). By 1965, Onitsha still had relatively few industries and they were based on processing agricultural and tree products (beverages, foodstuffs, rubber products, saw milling), and consumer goods (textiles and footwear). There were also other miscellaneous industries (gramophone records and printing; see Floyd,op cit:276-285). Perhaps industries have been late arrivals or a conscientious land use allocation system has placed them in the periphery of town ${ }^{3}$. (Figure 3 shows a generalized land use system in Onitsha). Regardless of what produced the present land use character, it is apparent that the spatial distribution of

\footnotetext{
3 For an excellent critique of the land use system in Nigerian urban centers, see, for example, Onokerhoraye, 1977
} 
activity centers would impact upon the intraurban movement of traders who need to interact with those centers as they

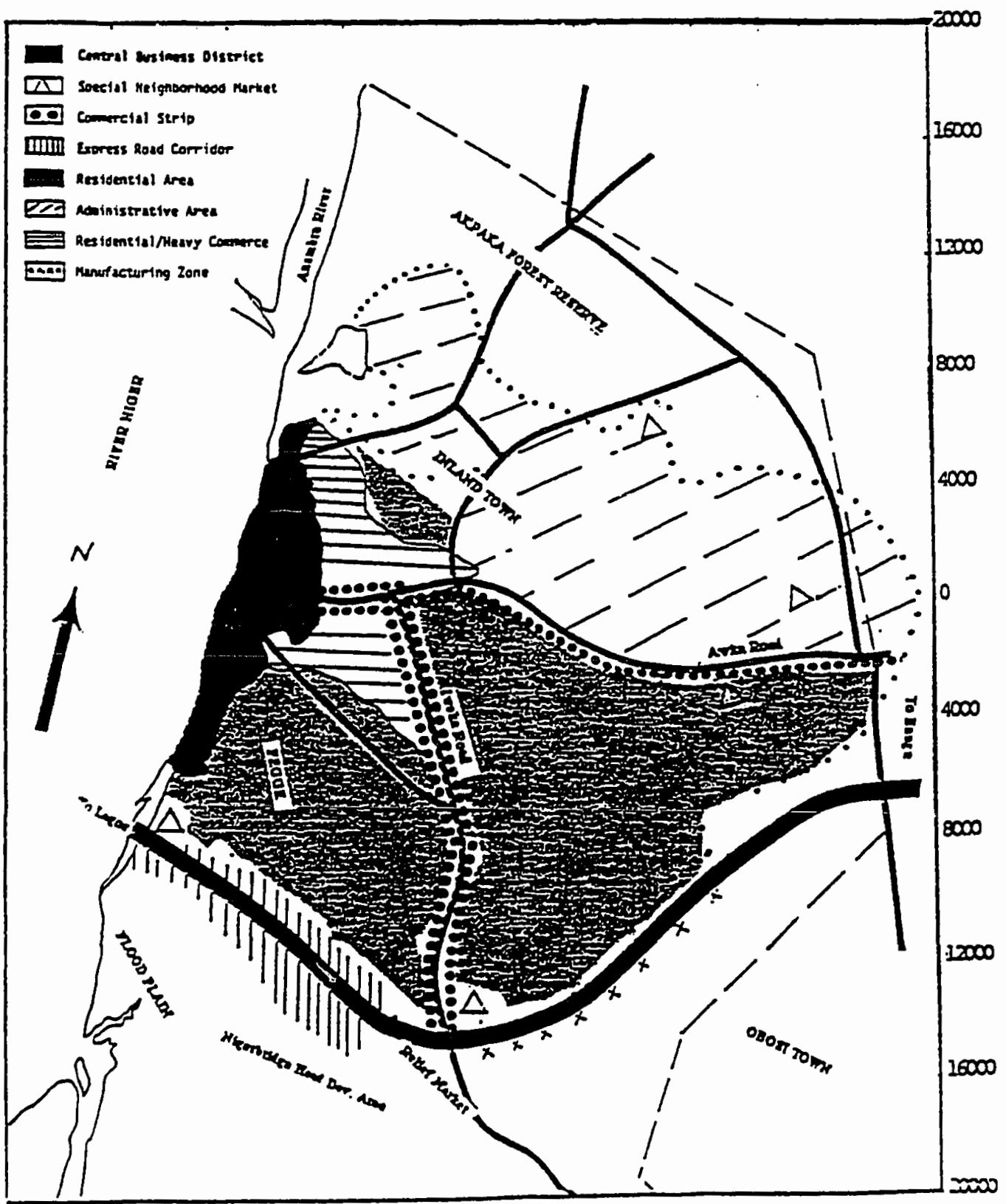

Eigure 2. Urban land use. 
participate in the urban economy.

\section{The Organization of Trade}

Any commercial transaction is made up of: (i) making available the resalable goods, (ii) the types of trading relationships and how they function, (iii) the mechanics of the exchange process, and (iv) the financial implications (Beajeu-Garnier and Dolobez,1979:rvii). This section will focus upon trading relationships.

Generally, the markets dominate the distributive system in West Africa (Pedler,1955:139). Baker describes the markets as collective areas because markets serve as the foci for the collection and distribution of goods. In Nigeria, as in many other countries in the developing areas, markets constitute the retail shopping center for the average individual (Baker,1965:45). But unlike markets in several other urban centers, the markets in Onitsha serve people of different socio-economic status (compare markets of Ibadan, Hodder and Ukwu,1969; Davis,1973: for Philippine markets; and Todd, Mulenga and Mupimpila,1979, for Lusaka markets). In addition, the goods sold within the markets are lower order goods which enter the rural market-place system (Hodder and Ukwu,op cit). Recall that Berry (1963:19-29) has argued that the central business district sells mainly high order goods. This is not the case in Onitsha.

In studying some of the factors responsible for the growth of the market town of Onitsha, Onyemelukwe (1974) discovered that eight out of ten times Onitsha has lower prices for manufactured goods than the other centers of Ibadan, Enugu, Port-Harcourt and Lagos. Even for agricultural food products, the prices at Onitsha are lower than what the producers receive in their village markets where, in addition, they have to attend various periodic 
markets and may sell on credit. Moreover, Onyemelukwe established that Onitsha has a wide areal trade influence in Nigeria. Elsewhere, Garlick (1971:75) confirms that to the African trader and consumer price was still the most important consideration, excluding the offer of credit. Other researchers (Baver,1965:62; Pedler,1955:148; Hawkins,1965:142) have reached similar conclusions. Onitsha appears to provide one of the best shopping opportunities to examine the travel characteristics of traders who provide the goods and services.

The retailing of goods and services, a tertiary activity, is closely tied to traffic flows (Simmons, 1964) whether marine or overland. In Onitsha, the development and concentration of early market sites close to the waterside was closely tied to the river transport system (Hodder and Ukwu,1969:232243). Similarly, the construction of a modern express road in the 1970s' linking Onitsha with some important Nigerian urban centers opened up an efficient intercity transport system. As a result, within a brief period (19761981), the segment of the express road in Onitsha became the "Route 128" 4 of markets in eastern Nigeria. Here two important markets are located at either end of an express road - the Headbridge Market to the west and the Ochanja Relief Market to the east - and compete for customers with the original and also transport-induced Main Market in the CBD. The traders in the study rent and occupy permanent stalls's.

4 This highvay in Massachusetts is known for its high concentration of high technology and research institutions $v$ ithin a relatively small land area.

5 Stalls are defined as "all independent retailing, vholesaling and service onterprises on public land (Bromley,1974:50). According to Bromley, such stalls provide additional advantages over the open stall - greater security, storage opportunity, space for the displgy of goods, a grealer onportunity to sell goods of high value and quality vith comfort and a better service to the customers (B̈romiey, i97î:iẑ)j. 
Commenting on the organization of trade in Onitsha, Katzin (1964:179198) notes that each stall generally consists of the principal trader, usually the owner of the stall, and a number of "boys" ranging in age from twelve years to the early twenties. The boys are usually in an apprenticeship program arranged with the owner of the stall. The boys conduct "market surveys" by ferreting out price information from competitors or by gathering information on the latest line of goods with potentials for fast turnover. These practices are beneficial due to limited marketing information and low levels of communication transfer techniques. In this market, "everything hinges on quick turnover," Hunter writes, " . . . a knowledge of prices in markets 100 miles around, and the extras to be earned by breaking bulk and selling small quantities down to a single cigarette (whenever considered profitable)" (Hunter,1962:134). The boys may also double as domestic servants to the principal trader, known locally as the "master." Very often, they are related by blood to the master and the arrangement tends to exclude the hiring of outsiders, a practice also common in Southeast Asia (Wigglesworth and Brotan,1966).

Apprentices are usually diligent in rendering their services in return for some form of remuneration. Observes Onyemelukwe (1970:126), "Quite often the master may decide to remunerate the outgoing apprentice in a more concrete way - by finding him a stall and stocking the stall with goods worth as much as, if not more than, the 'boy' would have hoped to receive." Generally, the duration of an apprenticeship program is determined by a number of factors including age at entry, economic conditions, the availability of vacant sheds at prime locations, the number of apprentices serving the master, the level of mastery of the line of business as gauged by 
the master and the availability of seed money to stock a new stall. Finally, the boys may also participate in the daily operation of the stall.

\section{The Transport System}

The earliest pre-colonial river front market developed in Onitsha in response to an excellent river transport connecting Onitsha with its trading partners nested along the Niger and Benue Rivers and those located overseas. With the advent of the forry and other improvements in overland transport system, the intercity transport network contributed to the growth in the market area of Onitsha and conceivably to the level of intraurban movement due to increased commercial activity.

Onitsha, like many Nigerian urban centers, "developed from historical nuclei which are still evident in the twisting narrow streets and old fashioned business premises . . (especially) in the downtown districts," observes Floyd (1963:63). But unlike the urban centers of Kano, Zaria, Ile Ife, Ibadan, where a high density of urban footpaths supplement motorable roads (Musisi.1986:142-143) all residential buildings in Onitsha would be accessible by an automobile, assuming the roadways are properly maintained. Floyd also acknowledges the unplanned street system but recognizes that "only south of the Otumoye Creek is there a clear indication of urban planning in Nupe Square and associated streets," including the residential districts of Fegge.

According to the Chief Engineer, there are about 60 miles of improved road in Onitsha. The Chief Engineer also indicated that no new roads are being built because no new residential developments are contemplated (Interview, June 13.1988) within the urban growth perimeter. 
The road system was developed in an era of expanding trade assisted by absence of vehicle weight restrictions on the use of local roads. The policy, a part of the weakly-enforced land use laws, encouraged traders to locate indiscriminately since they were assured their supplies would always reach them. An examination of the map of the urban road system, Figure 4, indicates a dense network closest to the river and a pyramid of roads to the east. In the post-colonial era, keeping roads properly maintained is, indeed, a perennial problem (see, Green, 1975; Hope, 1983; Rondinelli,1983) and it contributes to congestion and reduction in available road space.

Since 1985, however, efforts have been initiated to reduce the level of congestion, a reflection of change in urban policy formulated as part of the 1981-85 national development plan to focus attention on maintenance of urban roads while de-emphasizing road construction. For example, a Task Force of able-bodied citizens has been (i) organizing cleanup campaigns of travelways and neighborhoods. All residents also participate in the monthly (last Saturday) exercise; (ii) enforcing the no-litter laws, especially on roadways; and (iii) enforcing laws prohibiting individuals from erecting business stalls on public rights-of-way which tend to reduce available travelway and contribute to congestion. An auto parking structure has been constructed adjacent to the Main Market and on-street parking banned from contiguous streets. It costs only one naira to park all day in the lot. Such a low fee tends to reinforce the desire of motorists to drive to the $C B D$ which further increases congestion during business hours. Moreover, property owners often lease the front yards of some CBD properties to private car owners for daily parking which adds to the clutter. It is doubtful whether the measures, as currently instituted by the government to deal with the environment, would survive any change in government, even 


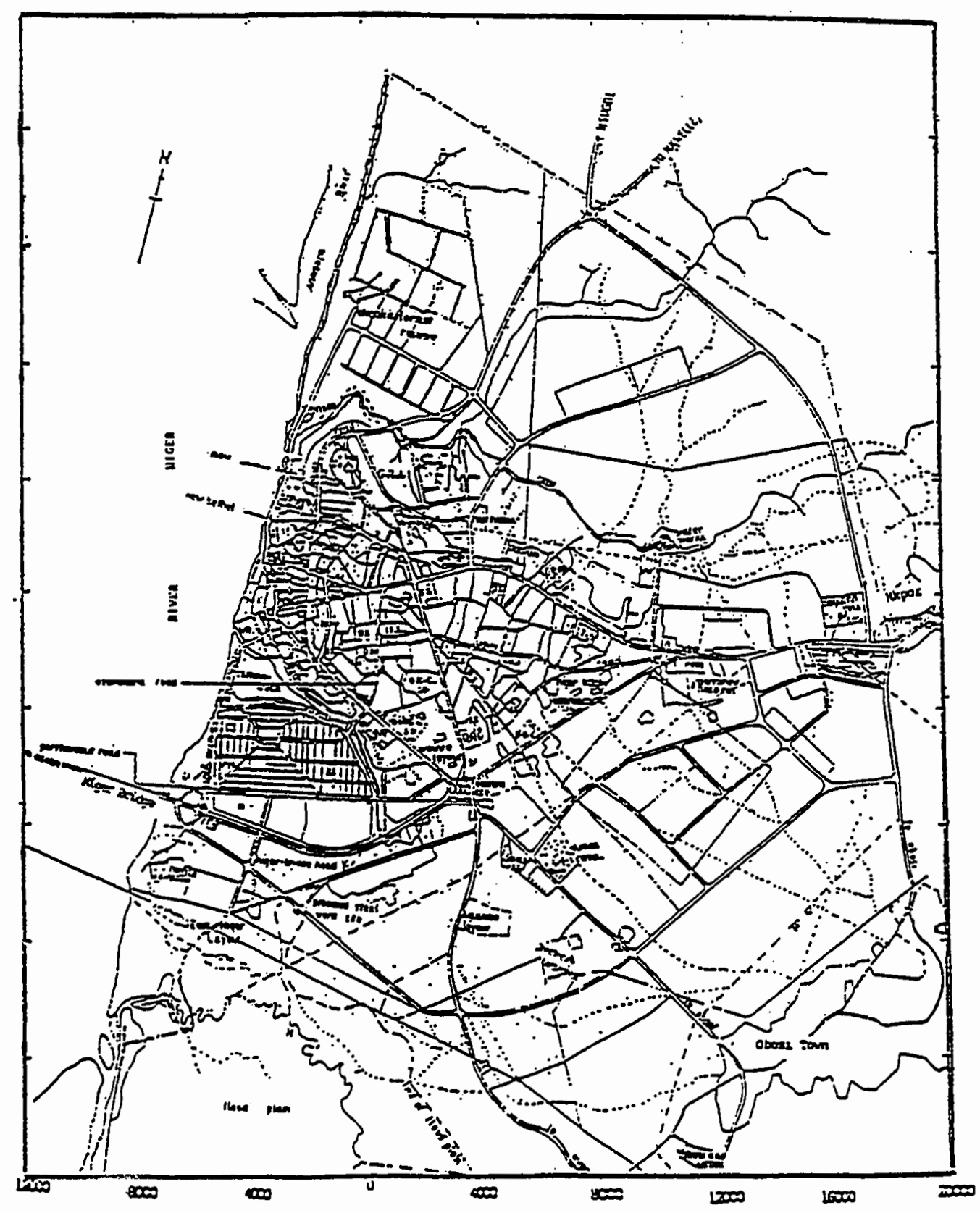

Figure 4. Lrban road network. 
though such measures may appear effective in the short run. The perception is that non-institutionalized laws, especially those by a non-elected military government, are fads. Moreover, there have been eye-witness accounts of military personnel forcing private citizens out of their private cars and ordering them to load garbage with their hands into the car because the individuals happened to be riding in the car on a clean-up day. People resent such an enforcement process, the program, and the administration associated with it.

By Western standards, the general traffic system is chaotic. There is no separation of traffic by mode, no traffic lights or signs, and traffic density is high. There are no sidewalks or adequate shoulders for pedestrians. Road users are expected and often apply common sense or intimidation to obtain and/or share the right of way.

In a Master Plan for Onitsha prepared for the Anambra State Ministry of Finance and Economic Development, the consultants interviewed 3,684 respondents or about one-and-a-one-half per cent of the urban population to determine mode choice for journey-to-work trips. Based on the survey, it appears that the major travel modes include walking, taxi, the private car, motorcycle and bus, with almost one-half of the population depending on foot to get to their work place. Table II. Individuals are willing to walk greater distances (Mera,1970:26) here than in the developed countries. Perhaps this is due to their inability to afford transit fares or simply because there may be more patrons than available seats on existing transit services at any given time, or, because traffic is so slow (about 10-15 mph, cf:Sarkar, 1980:92) that walking may be a quicker mode. Moreover, in certain instances, tazi cabs may refuse to accept passengers whose destinations are located in those areas of town notorious for worst road 
TABLE II

WORKING POPULATION BY PLACE OF WORK

AND MEANS OF TRANSPORTATION

Place of

Means of Transportation

Work

Foot Bike M/Cycle Tazi Pr. Car Bus Other Total

$\begin{array}{lrrrrrrrr}\text { Otu } & 743 & 14 & 270 & 381 & 243 & 128 & 3 & 1782 \\ \text { Odakpu } & 313 & 0 & 33 & 70 & 31 & 17 & 1 & 465 \\ \text { Woliwo } & 8 & 1 & 1 & 10 & 6 & 7 & 0 & 33 \\ \text { Fegge } & 295 & 0 & 56 & 99 & 32 & 43 & 23 & 534 \\ \text { Inland Town } 189 & 0 & 13 & 43 & 23 & 7 & 1 & 275 \\ \text { GRA } & 60 & 3 & 11 & 65 & 47 & 2 & 0 & 188 \\ \text { Onitsha } & 41 & 1 & 18 & 44 & 17 & 16 & 5 & 142 \\ \text { Other } & 56 & 3 & 26 & 84 & 30 & 30 & 36 & 265 \\ \text { Total } & 1.704 & 22 & 428 & 796 & 429 & 250 & 55 & 3684 \\ \text { Percent } & 46.3 & 0.6 & 11.6 & 21.6 & 11.6 & 6.8 & 1.5 & 100.0 \\ \text { Total Sample) } & & & & & & \end{array}$

Source: G \& G International:Onitsha Master Plan, Vol. 2,1979

surfaces. Another reason is that the bus mode serves only selected routes, Figure 5 , thereby leaving a majority of the urban area without services, even on a limited basis. (Note that the base fare for riding a bus or a taxi is only fifty kobo, 50k; 147k = 1 US \$. October 1988).

The existing bus route has succeeded in connecting mainly the three major markets and the Ose-Okwodu Market, north of the Main Market. A means of personal transportation typically includes personal automobiles, vans, pick-up trucks, and motorcycles, are also used in moving people and 


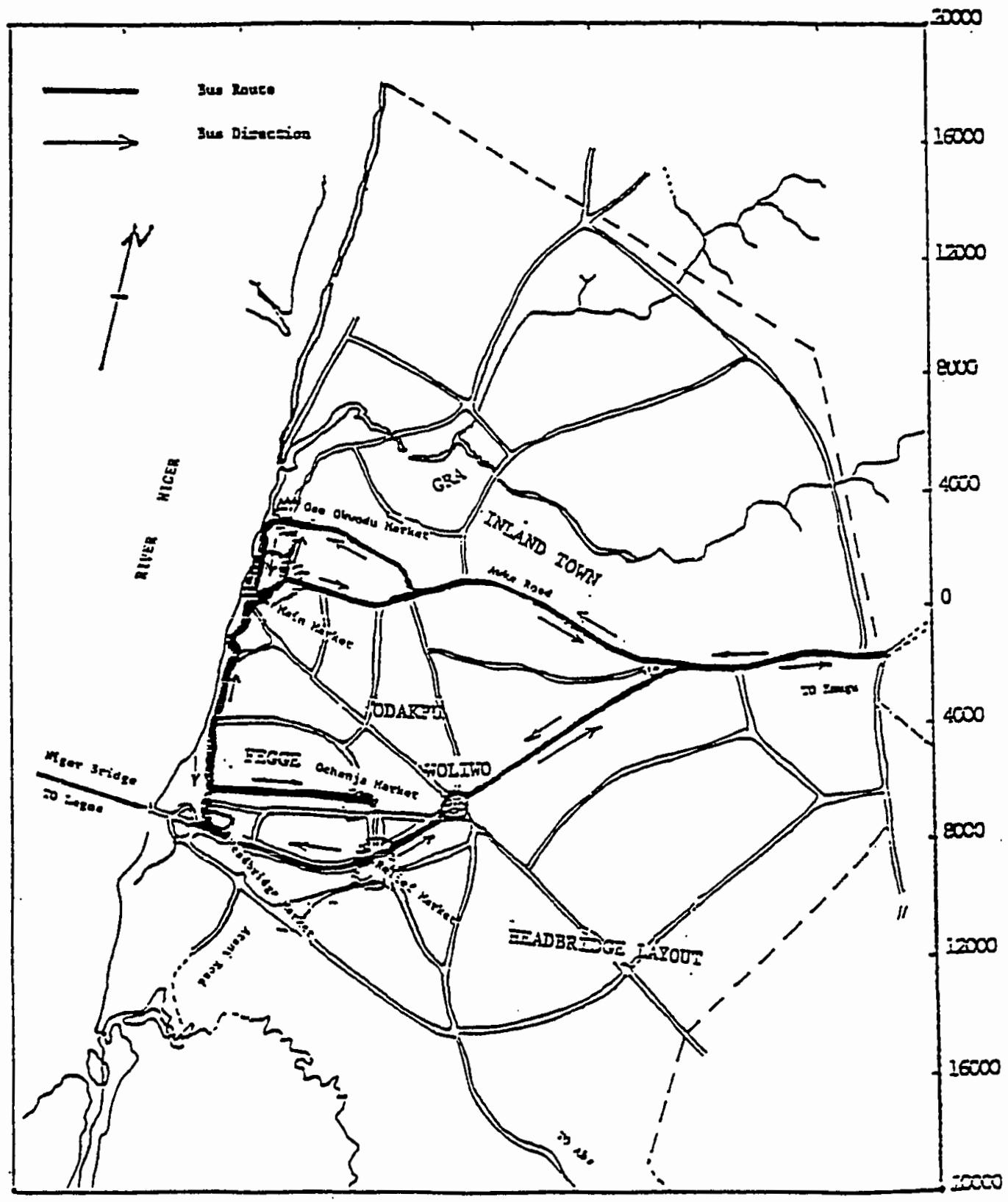

Figure 5. Intraurban bus coutes. 
and goods. The motor cycle mode may be falling out of favor because of the level of fatal accidents associated with its use (Oyebanii, 1984; West Africa, December 26-january 8, 1989). Irrespective of this, as the roads have become less passable, a motorcycle taxi system has been introduced (1985). The operators are licensed and are required to wear protective helmets and appear knowledgeable about how to handle the machine in terms of dodging potholes and weaving through the dense urban traffic. Although their base fare is one naira, (100 Kobo) they appear not to compete for patrons with either the bus or the taxi mode because they accept passengers for all areas including those areas often avoided by taxi and bus operators. (For similar services elsewhere in Nigeria, see, Obadofin and Olowu, West Africa, January 30-Feb.5,1989). Finally, wheelbarrows have replaced the wooden, hand-pushed truck for moving small quantities of goods as the roads become more congested and as more teenagers enter the manual goods-moving business.

In the next chapter, the sociology of urban market trading is examined to provide a broad background regarding the behavior of traders in the marketplace. Typically, urban market traders are small-scale operators and are of ten uneducated. As a result, they tend to possess poor accounting skills which would ordinarily assist business operators in sound financial management. In addition, traders often combine personal with business finances. One of the results is that both domestic and market financial decisionmaking would suffer in case of rapid market fluctuations. Moreover, traders will be expected to develop other inter-personal market relationships to assist them to acquire goods to maximize their income which is shared between personal and business expenditures. It could mean that the trader would remain small since he/she finds it difficult to qualify for 
bank loans for business expansion. How the trader juggles these relationships in order to survive in the marketplace forms the focus of our discussion in the nert chapter. 


\section{CHAPTER III}

\section{A SOCIOLOGY OF URBAN MARKET TRADING ACTIVITY}

The purpose of this chapter is to provide an overview of market trading as an urban activity. To achieve this, an attempt will be made to put in perspective the interdependence between the trader and a number of urban institutions. In addition, we will examine how the trader behaviorally functions and/or adapts in the marketplace, given the constraints of available resources. As Hodder and Lee (1974:144) put it, "it cannot too often be emphasized that markets in the towns of the developing countries (will continue to) 'play the vital role ... as media in the social and economic life of the people', (including traders)."

There appears to be a debate in current literature (Muller,1982; Breman, 1985) about the classificatory position of urban market-stall traders: Does the operation of permanent market stalls place trading in the formal or the informal sector of the economy? Consider that these traders have permanent structures; operate legally-sanctioned business, that are often registered, in a highly regulated market, even though the size of operation may be small and the stall is often operated mainly by members of the household or individuals who may be related. Micreover, in Onitsha, for example, the State has stipulated fixed trading hours (Muller, op cit). Whether all members of the stall show up at about the same or varying times is a business decision stall operators are most qualified to make. Faced 
with the dilemma of how to avoid applying the all-encompassing "formal" or "informal" label without misrepresenting the true characteristics of this group (and not necessarily quelling the controversy surrounding the debate), Muller selected the term "small scale." To Breman, however, it appears selecting a new label would not add to the solution of the problem. To her, "it is rather a continuum in which borderlines between the composite parts are drawn almost arbitrarily and are also difficult to locate in actual situation." In other words, the difference, Breman concludes, between the two sectors would actually be that of "structural inequality." This is indeed the milieu in which the Onitsha market trader operates.

The structural inequality emphasizes the oifference between the subsystems in the two business types - a small-scale operator and a large business. In fact the small scale operator has no "subsystems" while a typical big business has different components which function cooperatively to facilitate the efficiency of the system. The difference means that while the small scale operator is responsible for all phases of the operation, the large operator has different sections or departments responsible for different activities relevant for the management of a modern business. Furthermore, while the typical small-scale trader, for example, must compete with big trading houses in obtaining bank loans or government support, at another level it will queue with other urban residents to seek access to bureaucratic services. In addition, the trader must make business and personal family financial decisions, the former which would be the province of a board of directors (for a big business) consisting of experienced businesspersons. The typical trader solicits operational or working capital from acquaintances and accepts and trains apprentices and is responsible for the success or failure of the business. In other words, while big businesses are organized, for 
example, with separate divisions to deal with recruitment, training, shipping and receiving, advertising, sales, and public relations, and assisted by non face-to-face techniques to accomplish some activities, the structural inequality existing in the marketplace means that the small-scale trader is responsible for an array of activities facing a iodern entrepreneur. Moreover, in the case of the small-scale trader, these activities must oiten be completed by a face-to-face contact. In order to economically survive, therefore, the trader must develop several survival mechanisms to respond to the myriad demands associated with operating a stall.

\section{YEARS IN TRADING AND AGE DISTRIBUTION}

There is a great diversity in the age distribution of traders which corresponds with diversity in number of years individuals have been in trading, Table III. The significance of the diversity in age distribution will become obvious later in the discussion as we realize that trip making activities, for example, are age-related, i.e older adults make more trips than the younger stall members. What the data show is that:

1. Over one-half of traders have been in business for less than ten years;

2. Only 10.5 per cent of the trader population is 15 years or younger;

3. Over fifty per cent of traders are thirty years or younger, even though a little over 70 per cent of the urban population is in the same age category;

4. Generally, traders are represented at a higher proportion in each category than they occur in the general population, except for children 
TABLE III

AGE AND NUMBER OF YEARS IN TRADING

Number of Years in Trading, $x^{*}$

\begin{tabular}{|c|c|c|c|c|c|c|c|}
\hline Age & Under 5 & $5-9$ & $10-14$ & $15-19$ & $20^{+}$ & * & $\begin{array}{l}\text { * in Urban } \\
\text { Population* }\end{array}$ \\
\hline $15 \&$ under & 10.5 & 0.0 & 0.0 & 0.0 & 0.0 & 10.5 & 43.7 \\
\hline $16-30$ & 24.9 & 15.3 & 5.3 & 4.0 & 0.0 & 49.2 & 30.4 \\
\hline $31-40$ & 0.5 & 4.5 & 6.5 & 5.5 & 2.0 & 19.0 & 11.6 \\
\hline 41 \& over & 0.5 & 0.5 & 1.5 & 2.5 & 16.3 & 21.3 & 14.3 \\
\hline Total & 36.4 & 20.3 & 13.0 & 12.0 & 18.3 & 100.0 & 100.0 \\
\hline
\end{tabular}

fifteen years and younger;

5. The greatest proportion, $49.2 \%$, of traders are between sixteen and thirty years of age, even though they constitute the second largest component of urban population; (Notice that in the cultural milieu of the developing areas, the 15 years-and-under category constitute a segment that is often included in discussing the labor force, unlike the norm in the West (see Helmore, August 3,1987 ). As a result, the 16-30 category becomes the second largest category in our table and,

6. Of those 41 years and older, a majority have been in business for over twenty years while the distribution is much more diffused for those between 31 and 40 years of age. Only about $9.0 \%$ of traders between 16 and 30 years have been in business for over ten years suggesting a deiayed 
entry of this category into trading, perhaps, due to the Nigerian civil war. The age distribution affects who is responsible for what activity, including decision-making, in order to maintain a smooth operation of the shed.

Although trading may be considered by those in academe as a profession, some individuals who currently may claim it as their primary occupation may use it as a staging ground for other endeavors. Typically, the availability of opportunities in other areas of the economy will influence the propensity of traders to leave the occupation (Beveridge and Oberschall, 1977:67).

The general ease of entry and exit into this occupation is shown by the declining trend in the number of years of trading as one reviews the row total. Notice, for example, that while $56.7 \%$ of traders have been in the business for less than ten years, only $25.0 \%$ have been trading for ten years but no more than nineteen years. The diffused distribution for the 31-40 category could be attributed to the fact that this group constituted the older teenagers following the end of hostilities. The ravages of the war left people destitute and slowed recovery. Oblivious of the magnitude of property and income loss during the war, the group rationalized that staying in a profession which offered some level of stability and income was an attractive alternative. It appeared their perseverance in war has been transiormed into perseverance in keeping trading as a profession. Put differently, they tend to exhibit a low functional mobility (Sada and McNulty, 1984:71).

It seems that individuals who were traders before the civil war (the 41 plus category) returned to it following the cessation of hostilities. As older adults their perception of stall operation might differ from those of young Turks. Finally, it does not appear older adults participate in an 
apprenticeship program at the same rate as younger individuals, given the proportion of older adults who have been trading for less than five years. This is the period typically associated with teaching new entrants "about sources of supply, coping with market fluctuations, assessing quantity and shifts in fashion (Peil and Sada, 1984:254)". Perhaps adults feel uncomfortable learning such fundamentals from other adults and may choose to remain in their other, non-trading, occupations.

\section{MARKET SUPPLIES AND MANAGEMENT}

Foodstuffs sellers often obtain their supplies from local food producers located in the hinterland, or from sellers who may prefer to bring their produce for quick sales in Onitsha. For those selling manufactured goods, stock acquisition occurs either by buying from distributors located in town or elsewhere. Supplies may also be acquired from out-of-town manufacturers, mainly in Lagos. In order to understand the behavior associated with acquiring supplies, let us start by briefly examining household income distribution. Reliable data to construct business income distribution are traditionally very difficult to obtain (Davis, 1973; Sada and McNulty, 1981). Table IV shows the distribution of incomes for wage earner and self-employed households in Onitsha.

Traders appear to have the highest proportion of households in the middle income category, while they are second to public servants in the upper income category. Relatively, a smaller proportion of traders are in the low income category in comparison with other occupational groups in the self-employed category. 
In reviewing indigenous enterprises in distributive trades in Nigeria, Olakanpo (n.d.:55) writes: "The assessment of profitability of the business (of trading) is further rendered difficult by the tendency to mix up family and household expenses of the proprietor with business expenses." Since the two accounts merge for the trader, what transpires at the household level would have a tremendous impact on the financial status and stability of the business. Lowder (1986:184), for example, in explaining the propensity of traders to accept loans from the banks writes: "The acceptance of credit requiring interest payments and collateral is seen by many (traders) as unjustifiable risk for the family's resources," confirming the inseparability of both accounts. What emerges is that a typical trader mixes and balances business with household finances daily while conducting business. The trader has to juggle revenues and expenditures to ensure each arm of the operation is in good financial standing. This would, for example, affect the methods and behavior employed for acquiring stock for the shed.

As Olakanpo (op cit) sees it, apart from suffering from financial problems, a trader's managerial deficiencies would also affect the capacity to determine what, where, and when to buy, and the quantities to purchase; the ability to keep the size of the business within limits dictated by available capital, existing knowledge and experience; the wherewithal to competentlfin assess ris and develop strategies to reduce or preferably eliminate them; and the conviction that accurate record-keeping is as important as buying the gight merchandise at the right price and quantity. The smallness of the operation and the neglect to track all transactions heightens the trader's inability to deal, for example, with economic uncertainties related to irregular supplies, the failure to meet payments on schedule, sagging customer demand and declining sales revenues (Muller, op 
TABLE IV

HOUSEHOLD INCOME BY OCCUPATION

Occupation

Income Group Total

Lower Middle Upper

Public service

38

25

23

86

Contracting

14

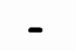

1

15

TRADING

120

63

28

211

Teaching

7

2

3

12

Farming

6

-

6

Driving/Touting

24

1

25

Laborer

9

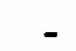

9

Salesman

2

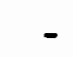

2

Tailoring

10

-

10

Mission worker

Hotel industry

No information

Total

235

92

56

383

Source: G \& G International: Onitsha Master Plan, Vol 2,1979

Note: Lower income $=\mathrm{N} 1,999 /$ year

Middle income $=\mathrm{N} 2,000-3.599 /$ year

Upper income $-\mathrm{N} 3,600$ and above/year (1.6 US $\$-\mathrm{N} 1.0,9 / 76)$ 
cit). These would combine to affect the financial health of the business (and the family) and the over all operation of the shed.

Lowder (op cit:186-197) has outlined various market distributive systems - simple to complex, fairly organized to highly organized and rationalized systems - in various cities in the developing areas, although the emphasis is on foodstuffs. Schwimmer (1979), using vegetables, fish and yam as distinct commodities, has identified and analyzed three modes of social organization existing in the distribution of commodities in a Ghananian central market. There is pure competition, ethnic monopolization and associational monopolization underlying the social and distributional relationships in the market place. Like their counterparts in Suhum, Ghana, foodstuffs sellers in Onitsha, for example, tend to exhibit similar characteristics (Onyemelukwe, 1970). The result is that traders in Onitsha may seek out suppliers, be they local or out-of-town sellers, to obtain stock on a competitive basis to improve their bottom lines. There is also a tendency of certain ethnic groups to monopolize the distribution and sale of certain food items. In Onitsha market, Onyemelukwe (1970:125) writes: "The majority of dealers in the mangala fish lines came from Ichida-Igbo Ukwu district of Awka Division, whereas the foodgrains sellers were mainly from Orlu Division." On yet another level, the trader could belong to a market trade association.

The associational relationship is even more frequent among traders selling other types of good even though one would wonder about the wisdom of a trader developing known associational relationships in such a competitive marketplace. Trager (1976/77) has pondered a similar question and theorizes that it fulfills a trader's need, as a middleman in the 
distributive system, to develop coping mechanisms to deal with poor communication between suppliers and buyers. The poor communication, Simms and Dumar (1976/77) explain, is a direct result of the dependency of traders in the enclave economy, a colonial handiwork, which is controlled by big distributors and manufacturers. In fact, Olakanpo (op cit: Chapter Five) identifies as a major problem the dependency of indigenous traders on big distributors and manufacturers as one of the problems hindering the growth and expansion of indigenous trading in Nigeria. The big distributors and manufacturers often impose differing standards or terms of purchase which a majority of traders independently may find difficult to meet. The result is that the "barefoot managers," as Michael van den Bogaert refers to them, would often source salable merchandise from third parties (Lowder, Chapter Six, see charts on page 192, for example), often at higher prices with a potentially deleterious impact on both the business and familial balance sheets.

Trager (op cit) identifies two levels of relationship - "groups formed by middlemen (traders) functioning at the same level of trade, and dyadic ties formed between people operating at different levels of trade (p.6)." The dyadic tie is formed between the trader and suppliers, and between the trader and customers. Each mode of relationship enhances the acquisition and processing of information, on pricing, demand and other markets. Indeed, traders often "may join together to buy a larger quantity of goods than any one could on ... (their) own who buy separately but share in transport costs (Trager, op cit:7). This minimizes total supply cost and boosts marginal working capital while the shared financial burden tends to extend the half-life of available financial resources improving liquidity. Moreover, when a member is bereaved or a member dies, traders in a line of trade or 
zone have been known to shut down their sheds and attend the funeral enmass. Perhaps the ethnic monopolization of some lines of trade reinforces this organizational behavior.

The trader-to-trader relationship strengthens the bond between traders selling similar commodities in the same market zone and an additional, albeit, informal relationship exists between those located along the same row of stalls. In the end, traders tend to watch out for each other and this solidarity extends to providing support in stall operation including counseling and disciplining younger traders.

A different and a higher level of coping mechanism is based at the trade association level, which plays a regulatory role (Trager, op cit:7) in controlling the behavior of traders either within the market or in sourcing salable stock. The largest umbrella organization in Onitsha is the Onitsha

Markei Traders Association which has established a recognizable code of ethics and operational guidelines and enforces etiquette among traders through zone leadership committees in cooperation with elected officers. For example, as Mr. F. U. Akaogu, the Market Master at the Main Market, explained to me, "OMATA helps (the government) to get things done. It is constantly interested in promoting the welfare of traders, for example, by hiring guards and enforcing the no-smoking laws in the markets (Interview, May 19, 1988)." Often it adjudicates between members and enforces membership-adopted market rules (Lowder, 1986:185). In the end, the social field of "an accomplished entrepreneur (trader)," to borrow from Yusuf (1975) involves a complex web of relationships with other urban institutions and entities - friendship, courtship, religious, political and entertainment which would influence how decisions in stall management are made. In the long run, as Lawson (1971) has determined in Accra, Ghana, "the supply of 
marketing services ... (by traders) approximates a perfect elasticity" with the price of goods sold by traders remaining consistently lower than elsewhere even though Onitsha, like Accra, is by no means the geographical center for the production or manufacture of those products (p.392). By and large traders profit from market operations that maintain or improve the occupation's proportionality in each income group in the urban area. The need to maintain or improve the status quo would influence, for example, the percentage of (household) income traders spend on internal movement to support business operation.

\section{GOVERNMENT RELATIONSHIP}

Eades (1985: Chapter 12) observes that in West Africa governments have applied various direct and indirect methods, including market fees and regulations (p.210), and, we may quickly add, allocation of measured (minimum) business space in the markets, as tools in controlling traders and trading. Apart from building and assigning market stalls, traders are required to maintain other relationships with the State. One result of the inadequate provision of market stalls, in terms of number and floor size (a typical stall measures 6 \& 8 feet), is that small scale traders continue to remain small operators as they are forced to share space. This is compounded where an apprentice has graduated but is unable to separate and start on his/her own stall operation.

Until the advent of non State-controlled banks in the late seventies/early eighties, banking institutions were owned and managed as a government subsidiary but never paid any special attention to supporting small businesses, including traders. The attitude of the banking industry to 
generally de-emphasize financial support for traders has not changed with the introduction of private banks, implying that traders may continue to be small-scale operators. As a result, traders have learned to accumulate startup capital from sources other than commercial lending houses, (see Table V). Notice that even though the chart refers to all types of small business in Onitsha, the results are still valid, especially when trading constitutes the major type of occupation.

As Olakanpo (op cit:36) has observed, "These methods of financing tend to build a highly personal financial relationship and social relationships (with relatives and friends) that conflict with both independence and business." As the business appears to prosper, all affected individuals would prefer to participate in sharing the profit. One of the results is that the financial position of the trader is indeterminate when the trader applies for a bank loan. Banks have often lost money in the past on unsecured trader loans and naturally have grown cautious.

As can be seen from the table, personal savings constitute the largest source of finance for business. This often includes money from relations, spouse and friends. Other sources - money lenders who often charge high interest rates, co-operatives and institutions and government - also provide some source of financial assistance (see also Onyemelukwe, 1970). Typically, "The small indigenous trader does not invest in freehold or leased property (Olakanpo, ibid:28)" which could serve as collateral for obtaining bank loans. For those in business, they are not keen on proper record keeping for accounting purposes. Moreover, a majority of traders lack managerial capacity which could assist them in preparing business plans, including loan packages. All these are attributable to traders' low level of education, 


\section{TABLE V}

\section{SOURCES OF SMALL BUSINESS FINANCE IN ONITSHA}

Source

Personal savings

Money lenders

Cooperatives and Institutions

BANKS

Share issue

Government

More than one source

Total $x$ of all establishments

\section{2}

1.0

5.7

0.2

1.0

8.0

100.0

Source: G \& G International:Onitsha Master Plan, Vol 2,1979

Table VI.

Although the highest literacy rates occur in the 10-19 (41.3x) and 20$29(25.9 x)$ age ranges (accounting for $67.2 \%$ of the total literate population), it is not likely that a majority of stall ownership and decision-making responsibilities would be coter minus with members of those groups for cuitural reasons. Because they could be excluded in other decisions related to disbursement of funds this could exacerbate the illiquidity of traders. Their oxclusion provides an additional dimension of why records may often be poorly-kept to help track, guide and direct expenditure. We have also pointed out the non-separation of business and personal accounts, facts banks need in order to inielligently assess the creditworthiness of an 
TABLE VI

\begin{tabular}{rrcrc}
\multicolumn{5}{c}{ OVERALL POPULATION BY AGE AND LITERACY } \\
Age & Literate & Illiterate & Total & * \\
$0-9$ & $613(9.5 \%)$ & $2,158(48.7 \%)$ & 2,771 & 25.4 \\
$10-19$ & $2,673(41.3 \%)$ & $792(17.9 x)$ & 3,465 & 31.8 \\
$20-29$ & $1.679(25.9 x)$ & $689(15.5 \%)$ & 2.368 & 21.7 \\
$30-39$ & $815(12.6 \%)$ & $424(9.6 \%)$ & 1,239 & 11.4 \\
$40^{+}$ & $694(10.6 x)$ & $371(8.4 x)$ & 1,063 & 9.7 \\
Total & $6,474(100.0)$ & $4,434(100.0)$ & 10,906 & 100.0
\end{tabular}

Source: G \& G International: Onitsha Master Plan, Vol 2,1979

applicant. So, it appears the two groups, small scale traders and bankers, may not have developed a common ground, a working formula, to mutually promote the business of each other. Traders, therefore, have tended to distrust banks so that even though some traders may have income which could be deposited in the bank to yield interest, a majority may elect to save with a rich or older relative or simply leave it at home.

One of the results of the unhealthy relationship between banks and traders is that certain traders have developed alternative methods for raising money. This is accomplished by engaging in multiple economic activities (Mueller,1982:11; Garlick,1973). Some traders own farms where they grow foodstuffs for consumption and the excess is sold for cash, while others engage the services of sharecroppers who are full-time farmers, while still others may develop and rent real estate or own transit vehicles. The 
8oal, according to Mueller (ibid) is to "integrate and control their various enterprises (and use) ... internal financing as a rational instrument in the absence of a banking system that could provide quick, short term loans," (cf: Simms and Dumar, op cit:52). As a result, some principal traders have developed the habit of terminating trading early and taking off on Saturday afternoons to attend to those businesses from which they usually return directly to the market on Monday mornings.

\section{The Market Masters and Traders}

Located close to or within the principal markets is the Market Master's Office. A market master answers to local elected officials. In separate interviews $(5 / 19 / 88$ and $6 / 10 / 88)$ held with two of the officers, it was revealed that the major responsibilities of the office which relate to traders are the enforcement of the right-of-way laws which require that no articles of trade be displayed in any manner that could impede pedestrian or vehicular movement, and, the "collection of stall fees for the State." To them, the leadership at OMATA is too militant because occasionally, it tends to take the laws into its hands and appeal directly to elected officials instead of working with the market masters to channel complaints and concerns to resolve issues. In administrative terms this would affect the (potential) relationship between the two groups, including joint discussions on how to deal with urban transport problems.

Owners of confiscated goods are required to pay a fine before repossession. During the field study I had the opportunity to observe policy implementation first hand in the office of one of the officers. It was akin to an open court and the presiding "judge" was the government official. As usual the implementation stage is perhaps the first time, theoretically, these 
(affected) individuals are aware of and are in contact with the bureaucratic system which makes policies affecting the welfare of traders. Each trader's name was called amidist comments from others waiting their turn. The trader would approach the "bench" pleading his or her case. At the end the individual was "led away" to the storage room by an assistant. A majority of traders understand what should occur between the hearing and the storage rooms, assuming the trader were interested in leaving with the confiscated merchandise. As would be expected, there was an obvious exhibition of what Theodore Thomas labels "bureaupathologies." According to Schaffer and Wen-Hsien (1985:258), these include the difficulty and uncomfortableness officials have in playing "servant, ... the lack of eagerness to satisfy the applicant or provide the putative service with speed and objectivity." In accessing these services the trader does not possess either the "voice" or "exit" capacity and is therefore at the mercy of the officer behind the counter. As a coping mechanism, traders have devised methods for obtaining administrative services with a minimal amount of abuse from the officers of the State. This includes the familiar payment of bribes or offering of gifts and gratuities. My assumption from this state of events is that to individuals who receive services from the bureaucratic system, the greater the amount of expected payoff and inconvenience, the less likely the service receiver, including traders, would intentionally expose him- or herself to circumstances which would precipitate visiting a state office. In conclusion, a trader is not only concerned about how to maximize profits and pay off debts on schedule and stay in business, but the sociology of trading requires that the trader responds to other demands to provide a cushion for intelligently balancing daily needs of the stall with those of the bousehold.

The implications of the tripmaking by traders are: 
1. The small scale character of Onitsha traders might influence the tendency of participants to engage in business trips;

2. The age range of occupants in a typical stall could influence not only the propensity of individuals to make trips (given how each age group is expected to behave for cultural reasons) but it could also affect the trip purpose of individuals;

3. The various complex interpersonal relationships traders establish in order to assure market supplies could affect the number and frequency of trips;

4. The variety and characteristics of different supply systems may mean that younger stall occupants could be delegated the responsibility of collecting/delivering merchandise, thereby forcing that group to participate in a greater number of trips for that purpose. It could also influence the type of mode selected;

5. The difficulty with which funds are secured for start-up and operating capital could further exacerbate the need for older adults, perhaps the stall-owners, to engage in money-related trips; and,

6. Traders would be expected to limit the volume of contacts with state officials, and, therefore, trips associated with visiting government offices. 


\section{CHAPTER IV}

\section{LITERATURE, HYPOTHESES AND METHODS}

This chapter will focus on literature review of relevant variables affecting travel behavior, followed by a number of hypotheses postulated to test the relationship between total trips produced from stalls in our study area. Our interest is on evaluating the travel behavior of stall traders and the impact of such an activity on the urban transportation system. The last part of the chapter will deal with the methods applied in collecting the sample data and the types of data collected.

\section{THE LITERATURE}

At this point, it will be relevant to briefly explore the theoretical explanation of an individual's decision to travel. Whether or not to make a trip, according to Marble (1967), involves decisions which are classified as "games" with associated risks, uncertainties and payoffs. To Nysteun (1967), the utilities available at the destination provide the incentives or the payoffs for undertaking a trip. The individual has to deduct the cost associated with friction (distance), the mode of travel, congestion, nuisance during the line haul and the opportunity cost in order to justify the movement. This is similar to what Stuart F. Chapin (1968) describes as the "puli" versus the "push" factors in theorizing about movement behavior. The goal is to ensure that the tripmaker maximizes return on the travel, since "the effort 
required to reach an opportunity is part of its cost and consequently the attractiveness of it to the consumer (Starkie, 1967:51)." Abler, Adams and Gould (1971) argue that "if the time and money costs of traversing a distance are too large, the movement will not take place" despite what Ullman (1955) describes as complementarity or areal differentiation. This factor triggers the demand for a movement in order to complement activities in other subareas. The distance covered during interaction is measured in real times of transfer and time cost or the friction of distance. This is what Ullman labels "transferability." In fact, it was Stouffer (1940) who introduced the concept of "intervening opportunities" to account for the distance moved. According to Stouffer, "the number of persons going a given distance is directly proportional to the number of opportunities at that distance and inversely proportional to the number of intervening opportunities." In Onitsha the existing intervening opportunities at different subareas or destinations motor parks, warehouses, banks, public agencies - induce interaction.

\section{Location}

Typically, individuals at locations with attractive trip-inducing qualities will make more trips relative to other individuals whose locations have poor qualities (Kansky,1967). The attractive qualities include an excellent road surface, service availability and frequency, (Prashker, 1979; Wohl,1970) and benefits associated with business opportunities (Wilson, 1972). Prashker (ibid) and Wohl (ibid), for example, have confirmed the positive relationship between ridership and service frequency. Regarding transit service: the knowledge that the waiting time is short could serve as a positive reinforcement to the tripmaker. Regarding road surface conditions: the poor road surface in the central business district in Onitsha has led many 
taxi operators to refuse patrons whose destinations are in the CBD, but away from market locations, or have accepted them if they were willing to pay for the inconvenience of the operator and the additional wear and tear on the vehicle. For Onitsha traders, therefore, location, might be a variable affecting the number of trips generated from a stall.

The effect of location on business-related tripmaking activities in the developing areas has also been recognized (Sethurman,1977; Sada McNulty, 1981). In Lagos, for example, Sada and McNulty (ibid:73) determined that "there was an observed flow of traders to the sites with expanding opportunities for sale." The markets frequently favored by traders, the researchers found, "were large markets located in the main transport routes associated with high demands and they were also highly rated by the traders in terms of growth potentials." This is why Sethurman (ibid) recommended that in relocating informal sector enterprises in Africa, the correlation between market potentials (in terms of volume of business) and location must be taken into consideration. In other words, improved access could contribute significantly to the success of an enterprise, and, therefore should be given a top priority in relocating displaced businesses. The relevance here is that small-scale entrepreneurs, having selected locations which satisfice their capacity to make trips in order to service their customers, should not be randomly relocated to areas with unattractive tripmaking qualities. The cumulative effect would be felt in declining revenues for the entrepreneur.

We are theorizing that the express road markets, which are spatiallydifferentiated from the CBD market lonly the three principal markets in 
Onitsha have been selected for study6), will be associated with a greater number of trips because of their attractive locational qualities. The selection of spatially-differentiated markets will be useful in exploring whether market location is a significant factor influencing the number of trips generated from a stall. The number of intraurban trips made by traders will directly affect the level to which traders contribute to off-peak traffic. The fewer the number of trips, the higher the level of travel opportunities reserved for customers whose shopping habits contribute to sustain the commercial significance of Onitsha.

Additional evidence in the literature suggests that a peripheral location will generate a greater number of trips than a location in the central business district.

Weisman (1975), for example, observes that city size tends to influence the number of activity centers and travel opportunities. The CBD, he continues, has been declining as a center of commerce and employment opportunities especially since the early 1960s' (Muller, 1976). With the loss of employment and economic resources to the suburbs, one of the results is that the existing (suburban to CBD) transit system is failing to satisfy current demand. Moreover, with over 80 per cent of jobs created in most metropolitan areas occurring outside the CBD, "the centers of metropolitan areas could continue to lose importance as a destination for the work (business) trip," according to Spielberg, Weiner and Ernst (1981). With only one-sixth or less of trips ending in the downtown (Muller, op cit) it seems

6 "Markets", as defined in this study and as it is generally used in these areas, means a geographically-bounded aggregate of stalls used by traders while buying and selling of merchandise. Cf:Bromley, 1974:51; Hill, 1\%6:55; Tait 1\%1:2; Hill,1966:248 
less likely that the central business district would generate more non homebased trips than the periphery.

Wong (1969) has evaluated urban travel behavior in Chicago by analyzing fifty-seven travel zones. One of the independent variables applied in the study was the distance from the center of the city. Without necessarily segregating trips into home-based and non home-based categories, the results of data analyses, using both regression and factor analysis modeis, suggest that trip generation rates increase with distance from the CBD. In other words, non-CBD land uses would generate more trips than similar land uses close to (and/or within) the CBD. (See also Chapter V, Starkie, 1967). This could become even more pronounced as the population of the urban area increases, as is the case in Onitsha in the last decade.

Hebert S. Levison (1978) of Wilbur Smith and Associates, in a transportation planning manual prepared to assist planners in the "real world" emphasizes that "It may seem that as an urban population rises, the central business district will usually grow relatively more slowly than the (suburban) region as a whole in terms of . . trip generation (p.57)." Adding to the debate, what this tends to suggest is that we would expect non homebased trips by employees to occur at a greater rate and frequency outside the $\mathrm{CBD}$ as centers of employment and commerce shift to the periphery.

The two peripheral markets in Onitsha along the express road would tend to confirm the image of an evolving satellite with an increasing proportion of employment and commerce. The expectation is that the trip making frequency of traders along this corridor would be greater than those of other traders in the CBD. Gihring (1984) has conducted a study of out-ofoutlet contact by urban entrepreneurs in Zaria, Nigeria. (A preponderance of respondents in the sample were traders). The author indicates that the 
dominant market center is located in Sabon Gari. (Our assumption is that this is located within the CBD, see, Gihring,1984:22). The research results show that "entrepreneurs who (are) located in major market centers (including Sabon Gari) ... actually ... participate in significantly fewer number of outof-outlet contacts for all purposes (p.24)." Gihring, it should be added, took pains to remind his readers that the level of spatial nucleation found in southern Nigerian urban centers (Onokerhoraye,1977) may not measure up to those existing in the north. Irrespective of the observation, the study results tend to corroborate other findings in the West regarding the disparity in the frequency of non home-based trips found between the CBD and nonCBD locations, with more trips produced by the latter.

To be included in the model, the two spatial locations must be quantified: they could be measured with reference to the center of the city, i.e., the population center; or by determining the distance from the administrative center or from the intersection of a major arterial. Alternativeiy, location could be entered as a dummy rabiable. Determining the population center or defining the geographical center in Onitsha could be unrealistic in view of uncontrolled peripheral growth in the last decade, especially to the north and southeast. On the other hand, since the express road is the major traffic arterial, defining location linearly would yield only two scores, including a zero score. A similar dichotomous value will be obtained by scoring locations as dummy variables. The preferred choice by this researcher is to score location, LOC, as a dummy variable, given that a powerful model will be used in the analysis. Stall location was entered as a dummy variable and scored 0,1 ( 0 for $\mathrm{CBD}$ and 1 for the peripheral location).

The expectation is that the (partial) regression coefficient of location will be positive. Because of the nominal nature of the variable, we can not 
statistically increase or decrease its value in tandem with TOTRPS. However, the positive value could be interpreted to mean that should $C B D$ traders move to the periphery markets, they would increase their propensity to generate business trips.

\section{Size of Stall}

For trip generation, the number of individuals in a stall is an appropriate surrogate to measure the size of a trip-generating unit. Daniels and Warnes (1980:192) argue that in the same way that household size (cf:Ayeni,1975) and composition influence the number of trips generated in a given period, the size of a factory or office, as measured by the number of employees, affects the volume of trips generated, particularly for non-work trips involved with the collection and distribution of services. In the oftquoted work by Hurst (1970) on traffic generated by non-residential land use, the analysis showed that the "total traffic generated does seem to bear a strong relationship to land use measured by floor space and the number (of people) employed." According to Hurst, however, in the regression analysis, "in all cases the correlation coefficients show(ed) that inhabitants and workers are more closely related to trip production than floor area appear(ed) to be." Although the analysis focused on vehicular trips, the findings are instructive because they clearly confirm the statistical significance of applying the number of employees in defining the size of the business and relating the variable to the frequency and number of trips generated, (see also, Cheng, 1970).

Three stall sizes have been selected for this study to assist in an additional analysis:

1. small - all stalls occupied and managed by one or two traders; 
2. medium - all stalls having three occupants, and,

3. large - all stalls having four or more occupants.

The selection of these "sizes" is based on the possible number of occupants in the shed (Onyemelukwe,1970; Katzin, 1964; Baker,1965). Since a majority of stalls are occupied by no more than four persons, it is reasonable to limit the sizes selected for our study within that range to avoid a preponderance of empty cells.

Other surrogates, however, have been used to define the size of a stall. For instance, Bromley (1974), studying Quito's urban markets, classified stalls into two sizes - small and large - based on daily turnover: large stalls had daily turnover of over 1972 US $\$ 10.00$, while small stalls had daily turnover of less than US $\$ 10.00$. Moser $(1980)$, on the other hand, identified and ranked five sizes of puestos (stalls) from largest to smallest based on relative values within Bogota's Plaza San Juan. Moser, however, failed to provide any information on the criteria used in selecting the sizes.

In Africa, Katzin (1964:138) has observed that "insufficient information exists on which a classification according to size of the business can be used, such as amount of invested capital or volume of business." This is partially due to poor record-keeping habits of traders who might be inclined to hide their real worth from relatives and from taxing authorities. This characteristic has not changed. In addition, there appears to be no separation between capital investment, profits and funds reserved for business and non-business purposes, information which could be applied in classifying businesses. Not only that, attempts to obtain income-related data have often met with serious disappointment and sometimes have even threatened the progress of a research project (Garlick,1971; Davis,1973; Sada and McNulty, 1981). 
The amount of rent paid could be a better surrogate, assuming stalls occupying larger floor areas pay higher rents. Current rent schedules in Onitsha indicate that at the Main Market (in the CBD), there is a one-time development fee of $\mathrm{N} 480.00$ in addition to a monthly rent of $\mathrm{N} 120.00$. $\mathrm{A}$ development fee of $\mathrm{N} 360.00$ and a rent of $\mathrm{N} 120.00$ are paid by traders at the Headbridge and the Relief Markets. This structure does not provide any form of relief and, hence, the alternative specification selected above.

At the interval data level, the size of a stall was measured by counting the number of occupants or employees, NEMP. The expectation is that there will be a positive relationship between the number of employees and TOTRPS. In other words, the regression coefficient for NEMP will be positive. Moreover, multicollinearity was not expected to be a problem because it has been determined that in Africa, the number of assistants employed might reflect little more than the trader's family responsibilities (Garlick, 1971:41). As a result, this variable would not highly correlate with other factors associated with business operation and trip production (Ohadike, 1971).

\section{Availability of a Means of Personal Transportation}

A means of personal transportation provides the convenience, (perceived or real) time savings, the freedom to choose preferred routes and an opportunity to exhibit the individual's social status (Brog, Heuwinkel, et al, 1977:23). The implication is that stalls with a means of personal transportation will be associated with a greater number of trips. For example, traders prefer to use a means of personal transportation despite the potential for (real) increased travel times. As a result, stalls which have a means of personal transportation will house traders who are more mobile (Hertz,1982) and whose business operation would be characterized by a 
greater variety in terms of business contacts completed in a typical business day. Secondly, as the number of means of personal transportation increases, there will be a corresponding increase in the number of trips generated from the stall, ceteris paribus.

This attribute was selected for study because we know that in a status-conscious culture, Onitsha traders regard very highly a personal means of transportation. Therefore, possession of an automobile could contribute to trips generated from a stall. We also know that the competing public transit (bus) and paratransit (taxi service) modes are of poor quality which places a premium on a means of personal transportation as a way of completing business contacts.

It would be a misconception to assume that traders belong to the poorest income group in Nigeria, and, therefore could not afford a means of personal transportation. Income studies (Fajana,1976; Etim and Erontimi,1976; Peil and Sada,1984:249) have shown that not only do traders receive a greater than proportionate share of income, but their income is relatively high in comparison with other sectors. Moreover, there are marked differences in income distribution between traders with stalls and those without stalls, with the former earning more than the latter. Therefore, some traders can be expected to own and maintain a means of personal transportation (see Household Income Distribution, Chapter II).

As Okpala (1981) has indicated, a private car, for instance, apart from providing convenience, privacy and flexibility, may be applied in identifying a person's socio-economic status. This is consistent with user attitudes in West Germany where it is indeed considered prestigious and reinforces an individual's self-esteem to own and operate a private automobile (Brog,et al,1977:23). In Onitsha it also symbolizes business 
success. The inference is that it is more likely that traders with a means of personal transportation, in their effort "to show off," could make more trips than those who do not have a personal means of transportation. Many car owners may not ride buses because most buses are small. They carry both goods and passengers and are congested; many buses tend to be unclean and noisy. The same car owners, it was found, (Okpala,ibid) seldom walk (6.6x) because walking may be considered demeaning and enervating.

Ogunsanya (1982) has analyzed the spatial pattern of intraurban freight flow in Lagos and concluded that small parcels are often transported in passenger cars and buses. Given the inconvenience and out-of-pocket cost associated with riding a bus, a trader would prefer to move small freight using a personal means of transportation. Moreover, since a majority of West African residents may conceive the opportunity cost of time as zero (Brindley, 1972), private cars would be preferred despite low travel speed. In fact, $31.2 \%$ of respondents in Okpala's survey indicated that they use their car because it is faster. Perhaps this is a question of perception? However, for those riding their motorcycles, intraurban trips could be completed in a relatively shorter time, depending on the dexterity of the rider. The "socioauto-fact" (K.Oludaro,1977:7, cited by Okpala, ibid) in Nigeria may mean that stalls with a personal means of transportation would generate a greater number of trips. In a Dutch study (Van der Hoor,1979), however, it was found that "car ownership and availability have a rather limited influence on the number of trips made (in a total activity pattern for home-based and non home-based activities) ... . The effects of those variables are only relevant in distribution (distance traveled) and mode split." Perhaps the psychological perception of a private means of transportation in Onitsha could yield results to the contrary? 
In evaluating this variable, it was relevant to distinguish between stalls with and without a means of personal transportation, on the one hand, and between stalls with different numbers of a means of personal transportation. The purpose was to evaluate, in the first case, whether a statistical difference existed. If it did, a second model would assess tripgeneration capacities of stalls based on the number of a means of personal transportation available to the stall.

The first model applied the attribute, the presence/absence of a means of personal transportation. PETRPS, as a dummy variable (0-no; 1-yes). The expectation was that the value of the regression coefficient would be positive. In the second model, the effect of the number of a means of personal transportation available, VEHAVA, was modeled. Again, the regression value was expected to be positive. The implication is that trips generated will increase with an increase in the number of means of personal transportation available to the stall. In both models, multicollinearity was not expected to pose a problem.

\section{Gender - Number of Males and Females}

In a study of adult trip makers in New York State, Brunso and Hartgen (1984:70) found that men make more trips per day than women in all categories of income and employment. To take this a step further, we hypothesize that the greater the number of males in a stall, the greater the number of trips generated from the stall. In African markets, though, females generally tend to predominate.

Typically, women start participating in trade and commerce at an early age and accumulate experience before marriage, realizing that they will assume responsibility of maintaining the daily livelihood of their 
families (White,1981). In Ghana, for example, "among the Ga families it is traditionally the women who trade," (Garlick,1971:31). As a result, about 85 per cent of stall holders in Accra (markets) are women. Nationally, 83 per cent of traders in Ghana are women (Lawson,1971). They also dominate the large Kumasi market (O'Connor,1983:149). According to Baker (1965:46), the great majority of market traders in Nigeria are women, and Vagale (1974:3) tends to concur by observing that in Nigerian markets, there is a preponderance of women over men in selling as well as buying. In Lagos, for instance, there is a continued dominance of women in urban marketing activities (Sada and McNulty, op cit:76): out of the estimated 63,000 traders, 85 per cent were women; in 1950, it was 80 per cent (Hodder and Ukwu,1969:50). Irrespective of this, note that our emphasis is on stalls as a surrogate for individuals for assessing the number of trips generated in a typical business day.

In discussing the characteristics of African urban (small scale) economy, O'Connor (op cit) recognizes the importance of trading and emphasizes that, in fact, women participate at a higher rate in West Africa than in East Africa, where a majority of them cultivate the land or engage in the craft industry. In Onitsha, however, men have come to dominate the distribution of imported and locally-manufactured goods for which the (Main) market is known. A consultant's survey of 3,934 participants in the labor force further confirms the preponderance of males over females in sales (trading), Table VII, with a ratio of almost three males to one female. (The implications of this finding is discussed in Chapter VII). Ukwu, for example, refers to a "typical Onitsha trader" as a man (Hodder and Ukwu, ibid:236), while the Crowther expedition of 1857 recorded that canoes brought "men from neighboring tribes to Onitsha ... market" (cited by 
Hodder and Ukwu, ibid). Perhaps, because women participate vigorously in the agricultural economy of the Iboland, unlike Yoruba women, female traders in Onitsha are more often found selling foodstuffs. Unlike in Zambia where they dominate all sales of foodstuffs, their dominance in Onitsha may be limited to retailing some food items (Onyemelukwe,1970). They may also be found selling other commodities. My hypothesis is that women may not

\section{TABLE VII}

\section{OVERALL WORKING POPULATION BY SEX/} TYPE OF EMPLOYMENT, 1978

Type of Employment

$\begin{array}{lrrrr} & \text { Male } & \text { Female } & \text { Total } & \text { * } \\ & & & & \\ \text { Professional technical } & 37 & 10 & 47 & 1.2 \\ \begin{array}{l}\text { Administrative executive and } \\ \quad \text { management }\end{array} & 225 & 72 & 297 & 7.5 \\ \text { Clerical } & 91 & 29 & 120 & 3.5 \\ \text { SALES (TRADING) } & 1,656 & 605 & 2.261 & 57.5 \\ \text { Farming/Fishing } & 4 & 3 & 7 & 0.2 \\ \text { Transport and communication } & 85 & 1 & 86 & 2.2 \\ \text { Produce processing/labor } & 132 & 22 & 154 & 3.9 \\ \text { Services } & 236 & 118 & 354 & 9.0 \\ \text { School/college } & 46 & 147 & 193 & 4.9 \\ \text { Others } & 262 & 153 & 415 & 10.5 \\ \text { Total } & 2,774 & 1,160 & 3,934 & 100.0\end{array}$

Source: G \& G International: Onitsha Master Plan,Vol.2,1979 
be making as many trips as men, even though women are subjected to similar marketing conditions as men. In other words, women may still fail to make an active use of the urban transportation system to support their businesses, as suggested by the fewer number of trips they would make. Stalls occupied by a greater number of women may not even generate a larger number of trips.

For each stall, gender was measured by enumerating the number of males and females and scored on an interval scale. The attributes, NMALES, NFEMS and MAFEMS were each expected to have a positive regression coefficient. Furthermore, we expected NMALES to have the largest $b_{\mathrm{i}}$ value.

\section{Commodity Groups}

Since traders buy and sell different types of goods, it seems reasonable they would respond differently to the need for making business contacts, for example, in sourcing saleable goods and efficiently servicing their customers. As a result, even thouglir all traders face similar broad operational constraints, the type of good sold in a particular stall might exert some influence that would make a trader behave differently, trip-wise, from traders selling other types of commodities. The expected result was that for a trader (or a group of traders) in a particular stall, total trips generated would be a function of type of good sold. Ross (1982) has determined that villagers have a propensity to borrow grains from their neighbors during periods of unforeseen shortages. The practice might have been transferred to market operations. It is, in fact, common knowledge that Onitsha traders borrow merchandise to be repaid in cash or replaced. Accomplishing the activity would impact upon total trips generated from the borrower's stall. 
The following constitute the groups of commodities sold at each market:

1. General Goods/Provisions and Articles - sugar, perfumery, patent medicine, toiletries including pomade, imported and locally-manufactured packaged grocery, watches, sewing accessories, school supplies, books, canned goods.

2. Textiles - piece goods including cotton, bafts, printed cotton, wax block prints, woolen and synthetic materials.

3. Readymade Clothing - men's and women's apparel and accessories, children's dresses, bedding and mosquito nets.

4. Hardware - bicycle and bicycle parts, small hand tools, kitchen utensils, farm equipments, small electrical supplies including batteries, nails, enamel wares and plates; and.

5. Foodstuffs - yams, garri, beans, dried fish and meat, onions and local food items, vegetables, plantains, fruits and other food ingredients.

The hypothesis is that commodity type will influence the number of trips generated. For example, goods that are more likely to be borrowed will be associated with a higher number of trips so that the provision group is the most qualified in this category. Other groups of commodity, for example textiles, which come in bales and which could not be easily borrowed, will be associated with stalls with fewer trips. From another perspective, realize that it is only after an individual satisfies the need for food would additional, if any, income be spent on a "luxury" such as textiles. This phenomenon may further diminish the propensity of those stalls to generate trips as traders in such stalls make fewer sales. Hardware goods come in small pieces and may fit the characteristic of provision goods and are also sold in small quantities, for example, nails. Our expectation is that the trip rate of stalls in this 
category would resemble those of stalls selling provision goods.

Finally, for foodstuffs sellers, the expectation is that relatively fewer trips could be made. Over time consumers have come to realize that foodstuffs differ in quality based on their place of origin (Onyemelukwe,1974). Sellers often take turns announcing the origin of their goods to attract buyers who demand a lot for their money. Consumed in this activity or exhausted by it, foodstuffs sellers may avoid making multiple trips in exchange for a possible increase in sales volume.

To include commodity groups in the analysis, each group could be ranked according to suspected propensity of members to make trips; or, commodity groups could be scored as dummy variables. As dummy variables, the provision group (expected to generate the highest rate of trips) was used as the reference or comparison group. Table VIII shows the resulting scores (Nie, Hull, et al. 1975:374). 
TABLE VIII

SCORE FOR EACH DUMMY VARIABLE

Number of Dummy, Variables

$\begin{array}{llllll}\text { Commodity Groups } & D_{1} & D_{2} & D_{3} & D_{4} & D_{5} \\ \text { Foodstuffs } & 1 & 0 & 0 & 0 & 0 \\ \text { Hardware } & 0 & 1 & 0 & 0 & 0 \\ \text { Readymade } & 0 & 0 & 1 & 0 & 0 \\ \text { Textiles } & 0 & 0 & 0 & 1 & 0 \\ \text { Provisions } & 0 & 0 & 0 & 0 & 0\end{array}$

By referencing the number of trips for each group to the comparison group. in causal terms, according to Blalock (1979), the score might be interpreted as the increments or decrements in the number of trips that the other group members will generate, assuming the comparison group members were to change into that line of trade.

Alternatively, the groups could be ranked from lowest to highest, based on suspected propensity of members to make trips. Oberschall and and Beveridge (1979:Chapter IV and Appendix III) applied a similar reasoning in a multiple linear regression analyses of business success in Zambia. The commodity groups could be scored from 1 through 5 (foodstuffs through provisions), or, according to Clark and Hosking (1986:9), commodity groups are "ordinally classified" because the magnitude of the difference is not specified. However, commodity group is scored as a dummy variable (PROVIS $=0$; other variables -1 ) to assist in the model building and interpretation of statistical results associated with each commodity group.

It should be added that in comparing the statistical results obtained 
from scoring a variable ordinally and as a dummy, Lewis-Beck (1984) found no difference in the regression coefficients. Beveridge and Oberschall lop cit:341) seem to allude to a similar conclusion when they write that "in no case (as a result of their own comparison) were results (of the tests of significance) affected."

\section{THE HYPOTHESES}

The following hypotheses are postulated to test the relationship between the frequency of interaction, as measured by the number of trips, and the selected independent variables. The attributes were determined to be appropriate based on literature search and prevailing local conditions in the study area.

1. Stalls located along the express road will generate more trips than stalls located in the central business district.

2. Stalls with a higher number of occupants will generate a greater number of trips.

3. Stalls which have a means of personal transportation will generate more trips than stalls where none are available.

4. Stalls with a greater number of means of personal transportation will generate a greater number of trips.

5. Stalls with a greater number of male occupants will generate a greater number of trips; and,

6. Stalls specializing in the sale of provisions, which can be easily borrowed, will generate a greater number of trips. Further explanations supporting the derivation of the hypotheses are provided shortly. 
Specification of Attributes

The relationship between the attributes selected for study and total trips generated from a stall was examined by applying a multiple linear regression model. This model was selected because it has a powerful capacity to depict linear relationships, where they exist, and has been extensively applied by researchers in studying home-based (Marble,1957; Ayeni,1975; Sada and McNulty,1981) and non home-based (Hurst,1970; Wong,1969; Shuldiner,1965) travel behavior. Based on the same material, my assumption is that a linear relationship exists between total trips (TOTRPS) generated from a stall and its location, the type of commodity sold in the stall, the size of the stall, means of personal transportation and gender. In other words,

$$
\begin{array}{r}
\text { TOTRPS }=\quad f(\text { location, gender, personal transportation, } \\
\text { size of stall, commodity sold })+ \text { disturbance term }
\end{array}
$$

Two spatial sites, the periphery and the central business district, make up the locations studied while gender consists of comparing the effects on total trips generated by males for stalls exclusively occupied by the group. by females for similar stalls, and for stalls occupied by both males and females. Similarly, we explored the propensity of stalls to generate trips, given the presence/absence of a personal means of transportation and the effect on trips produced, given the number of vehicles available to the stall for completing business contacts. The size of the stall was measured by the number of employees while the type of commodity sold was measured on a binary scale for each of the five commodity components - Foodstuffs, Hardwares, Readymade. Textiles, and Provisions. The provision category 
does not appear in the models because it is the comparison group in a series of binary variables (Nie, Hull, et al:1975). The following is a list of variables used in the study:

LOC - location of the stall;

NMALES - number of stalls exclusively occupied by males; NFEMS - number of stalls exclusively occupied by females;

MAFEMS - number of stalls exclusively occupied by both males and females;

PETRPS - measures the presence/absence of a means of personal transportation;

VEHAVA - measures the number of vehicles available to the stall, 1-2;

NVEH - measures the number of vehicles available to the stall, including zero vehicle;

NEMP - measures the number of stall occupants;

FOODS - foodstuffs commodity group;

HARD - hardware commodity group;

READY - readymade commodity group;

TEXTI - textile commodity group; and

PROVIS - provision com modity group.

\section{Summary}

There is paucity of data and information in the literature on non home-based trip studies and the problem is more acute in the developing areas. We do know, however, that the location, the size of an establishment, (measured by the number of occupants), the availability of a means of personal transportation, the number of means of personal transportation, the 
number of males and the number of females affect total trips generated from an activity area. These attributes have been selected for further study and evaluation in an African market conditions. The type of commodity sold in the stall was also included since traders in different commodity groups were expected to behave differently which could impact upon total trips produced from the stall.

The expectation is that LOC, NMALES, NFEMS, NEMP, PETRPS, and VEHAVA will have positive unstandardized regression coefficients. Moreover, it is expected that the $b_{i}$ value of NMALES will be larger than the $b_{i}$ for NFEMS. For the type of good sold, the comparison was linked directly with the PROVIS (comparison) group because of the scoring method. Finally, by applying critical judgement and a priori knowledge (Ferguson, 1978:36) in reviewing the independent variables and the probability that they would highly correlate with each other, multicollinearity (Poole and Farrell, 1971; Chalmer,1987:240-254; Ebdon,1985:111; Norusis,1983) was not expected to pose any problems.

\section{SAMPLING METHODOLOGY AND PROCEDURE}

A systematic (non-random) sampling methodology was used to select stalls, the units of observation and analyses, as reflected in the hypotheses. Market stalls are used as surrogates for traders. Typically, stalls are arranged in rows and back-to-back, see Figure 6, for an example. They are also numbered by block and individually.

A spatial sampling frame consisting of all registered stalls at the time of the survey was used. "A spatial sampling frame is one in which location is 


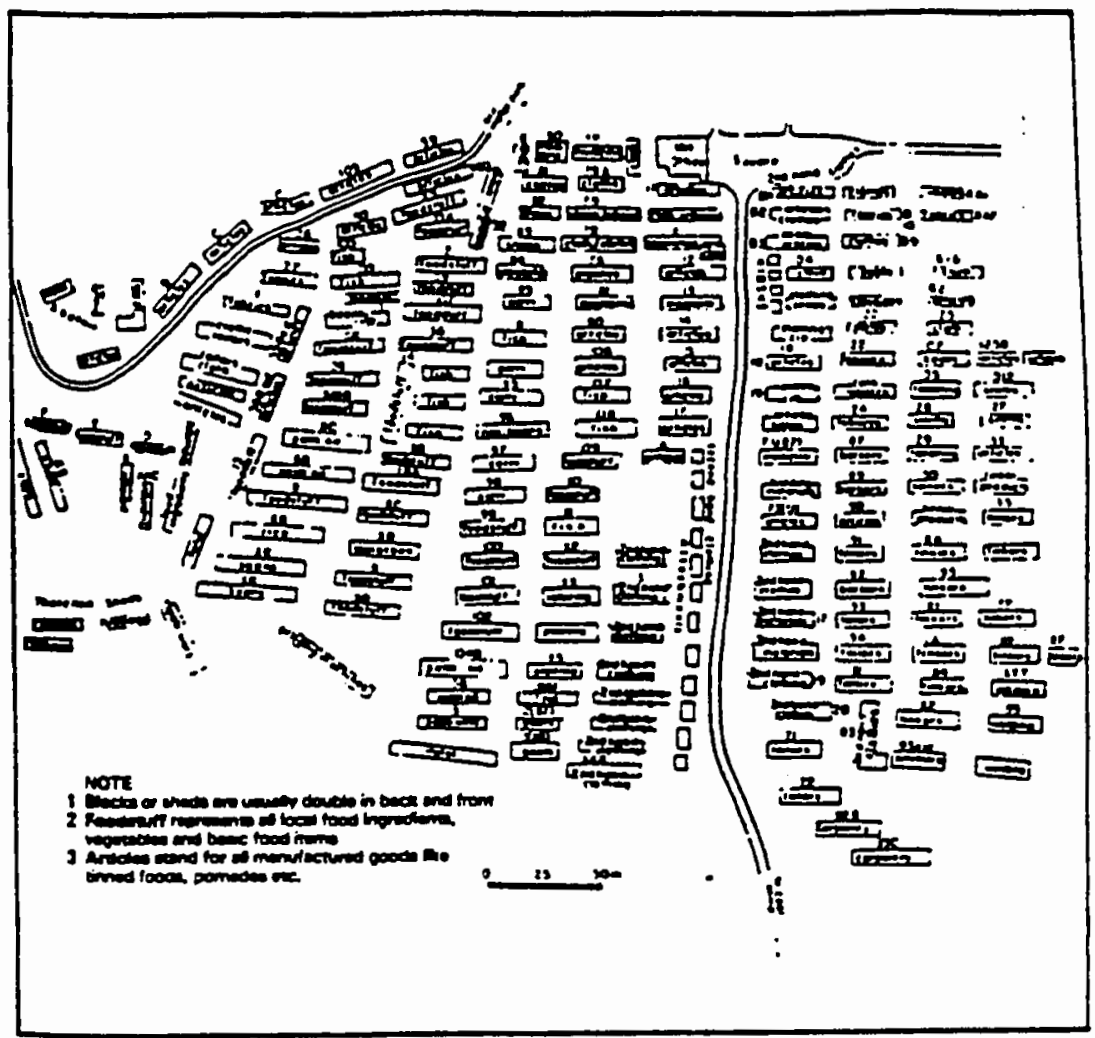

Eigure 6. Ogbete Market, Enugu, Nigeria, showing a typical arrangement of market stalls, Source: Okoye,1981.

an essential part of the variability of individual observations, and where it is therefore important that samples are representative of the full range of locational variability" (Hammond and McCullagh,1974:110). It should be added that all business premises in Onitsha are registered. Generally, due to the low vacancy rates for stalls, traders often rent and pay for stalls several months in advance to ensure undisrupted occupancy. The selection of three spatially-dispersed markets (in the $\mathrm{CBD}$ and the periphery) is more a question of experimental design than a sampling technique (Ebdon,1977:40). 
The selection of samples from the three markets was intended to facilitate the testing of the hypothesis based on location.

Apart from providing a stratification based on location, another form of stratification was achieved by selecting appropriate number of stalls from each of the markets. Table IX shows stall distribution, sample size and sampling interval, by market.

\section{TABLE IX}

MARKET LOCATION, TOTAL STALLS, SAMPLE SIZE AND SAMPLING INTERVAL

\begin{tabular}{ccccc} 
Market Location & $\begin{array}{l}\text { Total } \\
\text { Stalls }\end{array}$ & x of Total & $\begin{array}{l}\text { Sample } \\
\text { Size }\end{array}$ & $\begin{array}{l}\text { Sampling } \\
\text { Interval }\end{array}$ \\
Main Market & 3,264 & 33.7 & 83 & 39 \\
Ochanja Market & 2,984 & 35.4 & 87 & 34 \\
Headbridge Market & 2,620 & 30.9 & 76 & 34 \\
\multicolumn{1}{c}{ Total } & 8,868 & 100.0 & 246 & 36
\end{tabular}

All the required number of stalls were selected systematically following the identification of a random starting point. This methodology has not produced any bias which would render the results of the survey suspect. This is because there is no inherent periodicity in the arrangement of renters. Traders are randomly assigned stalls within their respective commodity zones. The assignment is conducted by street level bureaucrats using stall identification numbers, often in a lottery system. This notwithstanding, the sampling methodology is not equivalent to random sampling because once 
the first stall was chosen, all the others were fixed (Dixon and Leach,1978). According to Hammond and Mecullagh (1974:115), this type of bias in systematic samples is small and may be a price worth paying for the time saved. Moreover, the application of this sampling methodology has not created any computational problems above and beyond those generally associated with transport studies. Indeed, we are usually safe in considering a systematic sample as equivalent to a simple random sample (Blalock, 1979:595).

Being familiar with the physical structure of the markets, I realized the numbers identifying each stall would not be visible to a casual observer, including an interviewer. I was aware that any attempts to verify stall numbers would create an undue amount of suspicion from traders, irrespective of any assurances that the survey was unconnected with the Nigerian government, or any other government. Naturally, since traders may be unaware of survey methods, they would perceive surveying as merely interviewing any number of eager, and perhaps, curious volunteers without necessarily attempting to identify their stall numbers. For each stall selected, all individuals or a minimum of one individual were interviewed. It is my conviction that the statistical information obtained from the interviews are adequate for analyzing and explaining the overall movement geography of the (trader) population, at least for those doing business in the markets (because travel data were eventually obtained from 513 individuals, a statistically large sample).

The interviews focused only on the previous day's trips during daylight hours. Markets are permitted, by military order, to operate from 7:00 am to $6: 00 \mathrm{pm}$ daily, except on Sundays when the markets are closed. Security guards are posted around each market to interrogate individuals 
sighted within the market areas outside government-permitted market hours. The strict enforcement resulted from a rash of fires which damaged parts of the Main Market structures in December 1984 and again in April 1987 ( A N 2.5 m contract was awarded in March 1987 for repairs, but work had not started on the reconstruction as of July 1988). These measures are being taken to forestall future fires. Focusing on trips completed during the previous day and conducting the interviews at the workplace (Dunphy,1979:26-29) minimized the tendency to underreport movement? (cf: Meyburg and Brog, 1981).

There have been attempts (Marble,1967; Hoorn,1979) to explain the travel behavior of individuals. Recently, Burnett and Hanson (1982) have provided an added dimension to the debate. They argue persuasively that travel patterns may be a résult of constraints, environmental and economic, or the avoidance of other choices for similar reasons. In order to evaluate its relevance to the present study, a non-structured interview of $5 \%$ of the sample was conducted. The interview probed participants to explore to what degree, for example, congestion affects travel behavior, including trip purpose and destination, or, for short, the propensity to make trips. It also provided an opportunity to examine whether there were other reasons for tripmaking which the questionnaire failed to capture. An additional purpose was to evaluate the extent to which multiple tripmaking characterized market operations and whether trip-substitution was a possibility, assuming a telephone was installed in the stall.

\footnotetext{
7 Due to many unknowns, several studies (in the West) have recorded high under-reporting levels with the exception of the Washington, D.C. , 1968, home interview which focussed on non-work transit trips (Dunphy, 1979:220-260).
} 
Finally, it should be emphasized that samples were not drawn from shop traders who generally locate outside the markets. Generally, they tend to rent and occupy large spaces for storage and display of merchandise, unlike stall traders. The relatively large spaces consumed by this group. usually at higher rents, may mean trade-offs for trips which small (stall) traders would ordinarily undertake.

The other groups not included were peddlers and hawkers. Simply put, these groups have been proscribed by a military order in 1986. It is now illegal to peddle goods on city streets and offenders are liable for a fine of $\mathrm{N} 50.00$. Realizing that goods offered for sale by these itinerant traders are often valued less than the total cost associated with an arrest, harassment, fine and a possible detention in jail, potential peddlers have sought other activities which would literally "keep them off the street."

The markets ${ }^{8}$ selected for study are located in the central business district and in the periphery of town, along the Express Road. The road runs in an east-westerly direction and passes through the southeastern section of town. It connects Onitsha with Enugu, (the state capital), Lagos, and with other major Nigerian population centers.

8 The markets located along the express road are not the typical ribbon development as it is usually known in the West where the terms applies to street or highvay development.without further retail development in the side streets (Kellerman,1981). The markets along the express way do not conform either to Berry. (1963), which argues that ribbon developments serve the highway user and often are single purpose establishments. 


\section{DATA CHARACTERISTICS}

The characteristics and types of data collected to assist in answering the research questions, testing the hypotheses and providing an insight into the travel characteristics of traders in the stall are examined in this section. Our focus is on explaining the sources of data, the collection instrument, the types of data and the limitations of data collected. By presenting these features the survey analyses presented later will be better understood.

\section{Source and Collection Instrument}

The travel survey material (questionnaire) constituted the primary source of data. It was formatted to allow for pre-coding. It contained the data collection instrument and was administered to respondents by the researcher. (A copy of the questionnaire is included in the Appendix). It was constructed to reflect traders' understanding of local market and trading conditions to facilitate interpretation of survey questions without sacrificing quality.

The present-day traders are relatively better-educated than their pre-war counterparts. The war and the economic boom of the 1970s' have combined to make trading an attractive career choice for those who are not high school dropouts and illiterates because traditionally "Many people who did not finish secondary school see it (trading) as the route to success" (Peil and Sada,1984:255). What may not be clear, however, is whether the new breed of traders have embraced paper work as a primary medium for record-keeping because the tendency to evade taxes is still very high. It is certainly true that a significant percentage of traders still detest paper work 
so that the application of self-administered survey material in those circumstances was not advisable. Moreover, a majority of traders consider a survey an academic exercise if they are requested to fill out questionnaires on their own time especially when they perceive that there is no immediate reward. For these reasons, and in order to better control the consistency and the completeness of the survey process, the data were collected through face-to-face interviews.

It has been shown that the percentage return of travel-related questionnaires is dependent upon (i) the degree of simplicity of the questionnaire, (ii) the kind of questions asked, and (iii) the mode of contact with respondents (Kansky,1967:283). As a result, this study developed the usual but simplified transportation survey form and included only travelrelated, non-personal questions which would advance the goal of the research. These precautions ensured the highest response rate 9 and helped reduce standard errors due to interviewer effect.

Some secondary data are also used. This is limited to relevant data on markets available from the Ministries of Land and Survey, Finance and Economic Planning and the Local Government Offices. The data and information include land use maps, socio-economic data, census data and information from the Onitsha Master Plan prepared by a team of consultants and published in 1979.

Two important problems associated with collecting the primary data are the inherent characteristics of traders and the market environment.

9 In their study of markets and vendors in Lusaka, Zambia, for ezample, Todd. Mulenga and Mupimpila (1979) write "The arrival of several people armed with questionnaires ...... vas greeted $\nabla$ ith reactions varying from suspicion to instant flight. One market, Matero", they continue, "vas abandoned after half a day as a large proportion of vendors deserted their stalls, while others refused to be interviewed or gave patently false answers." 
Culturally, traders may be considered conservative in terms of providing business (secret or guarded) information. The harsh and very competitive trading environment may have exacerbated the tendencies to withhold private information. Moreover, since haggling is practiced, a trader may be consumed by an attempt to complete a deal most of the time. This would be more problematic for stalls occupied by single persons. Under those circumstances, surveys might be conducted away from the shed or during non-peak (trading) hours. The latter option was selected by this researcher. Each interview lasted no longer than 30 minutes. Moreover, in order to improve rapport, appropriate permissions were obtained from OMATA - the Onitsha Market Traders Association (see, Appendix). The trader population was also notified (in a newspaper article, see, Appendix) regarding the purpose, the starting time and the duration of the survey. Irrespective of these, it is reasonable to assume there were some elements of mistrust and/or over-statements as indicated by the presence of an insignificant number of outliers in the survey results. There were also a few nonresponses and/or refusals. According to those who did not co-operate, the reasons they cited most often were that they were not interested because the survey would not diminish the amount of suffering associated with trading; the government was always sponsoring these surveys in one way or the other and they had no reason to co-operate with those (referring to the researcher) in cahoots with the government; and finally, they confessed they could not fathom why this researcher traveled all the way from the United States just to study market traders. Lastly, the relevant secondary data and information, where available, were used to complement the field data. They were applied after their validity and accuracy were determined to be 
acceptable through comparison with field data and personal observation (where possible).

\section{Types of Data Collected}

Ten areas were emphasized in data collection (see, Appendix, Frequency Summary) and they are examined here in order to relate their relevance to model building, analysis and interpretation of survey results. The areas include: the sex of respondent, stall location, type of goods sold, number of employees/males/females, type of trader, number of vehicles available, internal trip report, the age of the trader, the number of adequate sheds and a comment section for respondents.

The sex of the respondent has no relevance and was not analyzed. It was originally included to assist in checking the accuracy of responses, assuming field assistants were utilized in data collection. For example, it could have been applied to check how the proportion of the sex of respondents compared with the results in the total sample. Since this researcher collected all the data, it was not analyzed any further.

The location of the shed yielded data for the same attribute for the type of good (broken down into five components) sold in the stall. Both attributes are used in analyzing trip generation rates. The total number of occupants, NEMP, was used to relate the attribute to TOTKPS. In two separate models considering the number of stalls exclusively occupied by males, NMALES, and the number occupied by females, NFEMS, but excluding NEMP, the effect of each attribute on trip generation was compared. Where a stall scored on both attributes, a fourth model was developed to evaluate the combined effect on trip making by stalls occupied by both males and females, MAFEMS. The size of a stall, measured as an ordinal variable - small 
(1-2 occupants), medium ( 3 occupants) and large ( $4^{+}$occupants) was also explored. The purpose of collapsing NEMP into three (nominal) categories was to evaluate whether trip making rates varied depending on the level of measurement of the variable.

Traders can be labelled as either trader-in-training, an assistant, owner/co-owner, or temporary help. (1) Traders-in-training are apprentices undergoing training; (2) Assistants are apprentices who have completed their normal training, but have not separated from the master; (3) Owner/Co-owner is the owner/co-owner of the shed; and, (4) Temporary Help is a trader who is intermittently doing business in the market. The inclusion of the last category was based on the assumption that school children or other adults could be employed to assist the primary traders. What was found was that an adult trader whose spouse occupied the same stall tended to classify the spouse as a "temporary trader," perhaps in an attempt to avoid any potential head tax in the future on all (adult) full-time occupants. The data from the trader category was used to compare their contributory effect on trip generation. In addition, trader groups were crosstabuiated with trip purpose and mode choice to assess the extent trader categories are related to trip purpose and mode selected. To assist the tabulation, traders were classified into two broad categories - masters and non-masters. Non-masters include trader-in-training and assistants, while masters include owners/co-owners and temporary help.

Data and information gathered on the number of vehicles served several purposes. First, it helped in analyzing whether there was any statistical significance between stalls with and without a means of personal transportation, PETRPS. Secondly, it was used in evaluating the relationship 
between TOTRPS and the number of vehicles, VEHAVA, available to the stall. The purpose was to determine whether stalls with a greater number of vehicles generated a greater number of trips.

The internal trip report included information on the number of trips completed the previous day, the origin, the destination, the time started, time ended, trip purpose and the mode selected. The origin-destination data assisted respondents in tracking reported trips. It also helped to satisfy the researcher that reported trips were non home-based, occurred while the trader was conducting daily business activities, and that the trip had a destination outside the geographically-defined markets. This requirement was necessary since the focus of the study is to evaluate the impact of stallgenerated trips on the existing transportation system. The summation of all trips from each stall comprise the dependent variable, total trips, TOTRPS. Detailed data on trip destination was not collected because of the difficulty in retrieving, in the view of our conservative traders, such personal information (cf:Sada and McNulty, 1981; Davis, 1973). Trip purpose and trip mode data were collected and analyzed to evaluate to what degree traders' trip activities are business-related and the frequency of favored modes, respectively. To assist the analysis, trip purpose was collapsed into four categories: Financial - buy stock, go to the bank; Personal Business pay/collect debt, run errand, pick up/deliver goods; Eat Meal; and Others travel-out-of-town, socialize, go to government offices. Mode choice was also collapsed into four areas: Walking; Transit - bus, taxi; Cycle - bicycle, motorcycle; and Auto - van/truck, driver, passenger, driver with passenger. The broad categories will make the data more consistent with categories often encountered in Western studies. 
The age of the trader (in five-year intervals) and the number of years a trader has been in business are germane in explaining the sociology of urban market trading. Finally, the last item in the questionnaire was included to elicit additional information the researcher failed to include which could affect the propensity of traders to make intraurban trips.

\section{Limitations of the Data}

The data was collected at the stall (macro) level for stall-level analysis. As a result, individual level analysis which is typical in most travel behavior studies in the West could not be conducted.

Another limitation concerns the temporal and trip destination data. The nature of the am-pm data precluded analysis of the characteristics of the peak hour and/or hourly trip pattern. Although attempts were made to collect some information on trip destinations, it was mainly intended to act as a check to verify and assist both the respondent and the interviewer in tracking trips. As a result, detailed trip destination or trip length data was not collected or analyzed.

There are few stalls occupied by both males and female traders. As a result, the travel behavior analysis based on the attribute (MAFEMS) is only exploratory. Additional analysis based on a large sample data must be attempted before we can make any definitive statements about the effects of mixed-sex stalls on trip generation rates. The results of such an analysis could be compared with the present study to expand our knowledge about the travel behavior of urban market traders. 


\section{SAMPLE SIZE}

The following were considered a priori in selecting the desirable sample size: (i) the homogeneity of the population, (ii) the length of the survey period, (iii) the probability of recruiting a sufficient number of field assistants from local schools, (iv) available training time for assistants, (v) remunerations for assistants and interview logistics, (vi) the sampling methodology used, and (vii) the anticipated high response rate (Sheskin,1985). These did not discount the fact that a sample of an acceptable minimum size must be used to ensure that reasonably accurate estimates would be obtained from the analysis (Dixon and Leach,1984:15).

What this researcher realized in the field was an apparent unwillingness of college students to participate in the survey because the timing of the survey conflicted with their preparation for the end of term/year examinations. Reinforced by a desire to tightly control and monitor the survey, this researcher decided to administer all the survey materials to respondents in the markets. As a result, the survey lasted from May 9 to June 24, 1988.

In the developing countries several authors, including Stopher and Meyburg (1979:87) have recognized the difficulty associated with determining the ideal size of samples because the relevant population parameters are rarely available. The recommendation is that guesstimates or a "rule of thumb" be applied in those circumstances (See, Tessler, O'Barr and Spain, eds. 1973, for a further discussion of survey research problems in Africa). My assumption was that a majority of traders have stalls or conduct business from shops, given existing laws and market operations. It was 
further assumed that about 80 per cent of all traders are located within defined markets and occupy stalls. This was confirmed through interviews with the Market Masters at the Main Market (May 5,1988) and the Headbridge Market (June 10,1988). By applying a rule of thumb, and considering the constraints and requirement to achieve a reasonable sample size, I selected and interviewed traders in 246 stalls from the three markets.

Sheskin (1985) has provided a relevant guide for selecting sample sizes based on different confidence levels and confidence intervals. The following formula is generally applied:

$$
n=\left(\frac{z \sqrt{P Q}}{c}\right)^{2}
$$

where $Z=1.96$, for $95 \%$ confidence that a result lies within a given confidence interval;

P - the percentage about which a confidence interval is computed, expressed as a proportion;

$Q=1-P$

C - the desired size of the confidence interval, expressed as a decimal number.

Applying a $P=0.8$, for traders who have the attribute, i.e. stalls, and $Q=0.2$, a confidence interval of $5 \%$ yielded 245 stalls, while a confidence interval of $8 \%$ yielded only 96 stalls. However, a confidence interval of $6 \%$ produced 170 stalls. Applying a rule of thumb, 234 stalls were considered adequate, and by accepting a $5 \%$ rejection level, 246 stalls were finally sampled, (implicitly, 
the confidence interval was, therefore, set at $5 \%$ ). A low rate of rejection was applied because this was an interviewer-administered, face-to-face survey. The number of stalls selected represents $2.8 \%$ of stalls in the three large markets. It excludes other traders in the urban area who are scattered in small shops, neighborhood markets, roadside kiosks, in residential areas and along business strips. They were excluded because of logistical problems and to assist in reducing the amount of within-group variations. The assumption, however, is that their travel behavior would not be any different from those of traders in the sampling frame, given the similarity in size and operational characteristics of these enterprises. (See also Chapter VII).

The practical limits on the sample size, the coverage of the population studies, accuracy levels and hence the level of generality of the survey (Diron and Leach,1984) did not pose any problems with the hypotheses tests or the results of the survey. Finally, the low values of standard errors obtained from the computer runs for appropriate statistical values confirm the robustness of the sample statistics.

In the next our efforts will focus on explaining the characteristics of movement and how they contribute to the character of existing stall activities. Ultimately we will evaluate to which extent a pattern exists in the tripmaking behavior of traders as they conduct daily business activities. 


\section{CHAPTER V}

\section{ANALYSIS OF SURVEY RESULTS}

The results of the survey show that the mean number of trips generated by a stall is 2.7 trips although the number of trips varied between zero and ten trips. This should be interpreted bearing in mind that when respondents are subjected to an interview situation and forced to recall travel history, under-reporting and poor reporting tend to be the rule. As a result, at least 10 per cent of actual trips often go unreported (Meyburg and Brog,1981), implying that the mean trips in this study should be assumed to be higher. This would make our results even more policyrelevant. Excluding the ten per cent error factor reported above, we found that characteristically, $61.8 \%$ of stalls generate less than three trips while $22.0 \%$ generate three or four trips and $16.3 \%$ of stalls generate five or more trips in a typical business day. Moreover, for every one female trader in the market, there are at least three male traders. Finally, a majority $(89.4 \%)$ of stalls are occupied exclusively by either males or females, and 70 percent of the stalls are occupied by either one or two traders.

The characteristics of travel behavior will be examined at the aggregate (stall) level using identifying strata of size, location, type of good sold, males, females, the type of trader, presence/absence of and the number of a means of personal transportation, as the basis of analysis. The attributes specified in the previous chapter were modeled using a multiple linear 
regression model and the results interpreted as presented below (cf: Nelson:1984).

\section{EFFECT OF LOCATION}

The prediction was that stalls located along the express road will generate a greater number of trips than stalls in the CBD. The resulting model for this attribute is:

$$
\begin{aligned}
& \text { TOTRPS }=1.618959-1.007257 \mathrm{LOC}+.535140 \mathrm{NEMP}+1.342905 \\
& (12.8)^{*} \\
& (20.9)^{x} \\
& \text { VEHAVA }+.365711 \text { FOODS }-.065537 \text { TEXT1 }+.188003 \\
& (27.3)^{*} \\
& \text { READY + .568586 HARD } \\
& R^{2}=.6044 \quad F=10.77 \quad \operatorname{Sig} F=.0012 \quad N=246 \\
& { }^{*} \text { significant at the } .001 \text { level (1-tailed) } \\
& \text { * significant at the } .1 \text { level (1-tailed) } \\
& F \text { values of regression coefficient shown in parentheses }
\end{aligned}
$$

As expected, the variables are not highly multicollinear (see, Appendix), the $\mathrm{R}^{2}=.6044$, and the model is statistically significant at the .001 level. However, the expected sign of the regression coefficient of LOC is opposite of the predicted sign, meaning that CBD stalls generate a greater number of trips than stalls located along the express road (CBD is coded 0 ; express road is coded 1). In addition, the regression coefficient of VEHAVA indicates that with a unit increase in TOTRPS, for example, stalls which have a means of 
personal transportation will increase their trip rates by 1.34 , while the increase will only be 0.54 for NEMP. In the commodity group, only for stalls selling hardwares would we encounter a significant increase of 0.57 trips for a unit increase in TOTRPS. In terms of trips produced, in equation (i) CBD stalls generate a mean of 4.4 trips while stalls along the express road generated a mean of 2.1 trips (standard deviation for $L O C=.47$ ).

Realizing that a difference occurred in the propensity of stalls to generate trips, given the spatial location of the stalls, to further evaluate the effect of each location on the dependent variable, two additional models, equations (ii) and (iii) were developed, using only samples from each of the two locations - the CBD and the periphery. The results enabled us to evaluate the differences in the resulting means and coefficients. The resulting models are:

For the CBD location:

$$
\begin{aligned}
& \text { TOTRPS }=1.320975+1.669072 \text { VEHAVA }+.808183 \text { NEMP }-.104151 \\
& (19.33)^{*} \\
& (22.0)^{*} \\
& \text { TEXTI - 084232 FOODS - } 1.208509 \text { READY }-.671877 \text { HARD } \\
& (3.3)^{* *} \\
& R^{2}=.6724 \quad F=4.04 \quad \mathrm{Sig} F=.05 \quad N=83 \\
& \text { * significant at the } .0000 \text { level ( } 1 \text {-tailed) } \\
& \text { ** significant at the } .06 \text { level ( } 1 \text {-tailed); and } \\
& F \text { values of regression coefficient in parentheses }
\end{aligned}
$$

For the Express Road location: 
TOTRPS $=.942537+.960118$ VEHAVA +.420864 NEMP -.715578

$(8.67)^{*}$

$(6.52)^{*}$

TEXTI +.146635 FOODS +.352009 READY + .917665 HARD

$(1.83)^{* *}$

$(4.59)^{* * *}$

(iii)

$R^{2}=.4780 \quad F=3.69 \quad$ Sig F $=.05 \quad N=163$

* significant at the 01 level (1-tailed)

* significant at the .1 level (1-tailed)

*** significant at the .03 level (1-tailed)

$F$ values of regression coefficient in parentheses

Both models are statistically-significant at the .05 level but a prediction based on the CBD model (equation ii) would be $67.2 \times$ accurate while a prediction based on equation (iii) would produce only $47.8 \%$ accuracy level. Moreover, not only are the regression coefficient values for VEHAVA and NEMP larger in the CBD model, we also have a much smaller critical region for the variables. For 2 unit increase in TOTRPS, there would be an induced change in VEHAVA of 1.70 units and .96 in NEMP in the CBD model compared with much smaller changes in equation (iii), the Express Road model. In the commodity group, notice that except for the READY group, other commodity categories, however, have a larger coefficient value in the second model than in the first suggesting that their effects on trip generation would be greater in stalls located along the express road than in the central business district. The values, however, are not large enough to diminish the higher over all significance of the CBD model which has an $\mathrm{R}^{2}$ value of .6724 . Finally, while the mean TOTRPS value for the CBD model is 3.96 (standard deviation $=2.41$ ), the mean value for the express road model is only 2.12 (standard deviation - 2.05). What these confirm is that, in general, stalls in the central business district, despite the high concentration of activities and 
associated congestion, tend to have a greater propensity to generate trips than stalls located along the express road, contrary to intuitive expectations and our hypothesis. How do we further account for this phenomenon in the context of, at least, our study area, especially when we realize that in the initial model, the attribute, LOC, has a negative value for the regression coefficient? We will defer answering this question until we discuss the significance of the findings later in the chapter.

\section{EFFECT OF STALL SIZE}

NEMP was used to model the size attribute and the resulting regression model shown below:

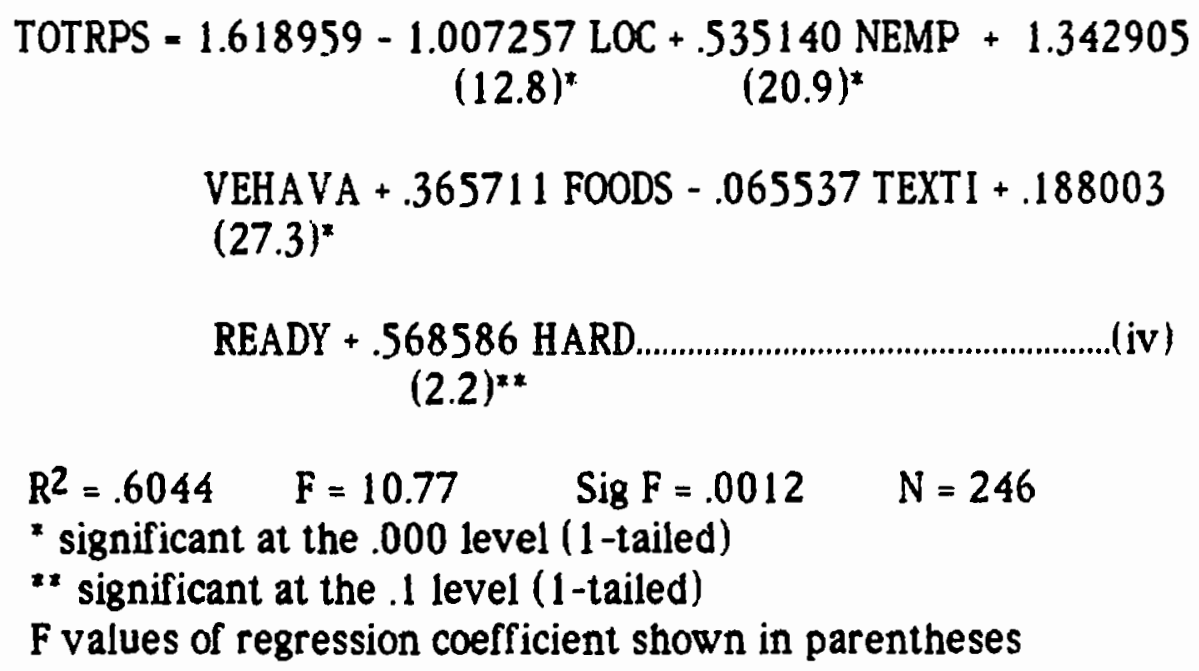

$R^{2}=.6044 \quad F=10.77 \quad$ Sig $F=.0012 \quad N=246$

* significant at the .000 level (1-tailed)

" significant at the .1 level (1-tailed)

$F$ values of regression coefficient shown in parentheses

The $\mathrm{R}^{2}$ for this model is .6044 and the $\mathrm{F}-10.77$, and as expected NEMP has a (positive) direct relationship with TOTRPS. In addition, multicollinearity 
does not pose a problem (see, Appendir). Also, the model is significant at the .001 level, meaning that the null hypothesis must be rejected.

The frequency results show that over one half (56.1\%) of stalls sampled generate either two or four trips while only four per cent generate either one or three trips daily. This suggests that a majority of traders who leave their business locations during business hours also return to the stall. Note, however, that $83.3 \%$ of stalls generate four or less trips per day. Irrespective of this, trip frequency decreases appreciably beyond four trips per day since only $16.6 \%$ of stalls generate five to ten trips per business day.

It is, perhaps, safe to assume that for practical purposes there may be only two categories of stall size in Onitsha markets; namely, small and large. For example, there is a preponderance, $70.3 \%$, of stalls occupied by either one or two traders, while stalls occupied by the three, or the four or over category is roughly similar, $15.5 \%$ vs $14.2 \%$. (NOTE: The number of occupants is synonymous with the number of employees).

Two slightly different results of trip characteristics were obtained when stall size was measured at an interval level scale only (without collapsing the results into three sizes - small, medium, large) and when size was measured as an ordinal level data. Table $\mathrm{X}$ shows the relationship between stall size (ordinal level measurement) and trips produced. There is a dramatic increase in trips produced between the small and the medium/large stall sizes.

The data suggest that as stall size increases, the number of trips tends to increase. In fact, the number of trips doubles as we encounter a marginal increase in the size of a stall beyond a minimum of two occupants (small size). When the measurement was limited to the interval level (by applying the absolute number of stall occupants), the results (shown in Table XI) are 
TABLE $X$

MEAN TRIPS OF ST ALLS AND STALL SIZE

$\begin{array}{lccc}\text { Stall Size } & \text { Mean Trips } & \text { Standard Error } & 95 \% \mathrm{CI}^{*} \\ \text { Small (1 -2 traders) } & 2.0 & .1422 & 1.8 \text { to } 2.3 \\ \text { Medium (3 traders) } & 4.3 & .3867 & 3.5 \text { to } 5.1 \\ \text { Large (4+ traders) } & 4.5 & .4627 & 3.6 \text { to } 5.4 \\ { }^{*} \mathrm{CI} \text { Confidence interval for mean } & & \\ \mathrm{N}=246\end{array}$

even more representative of intuitive expectations.

\section{TABLE XI}

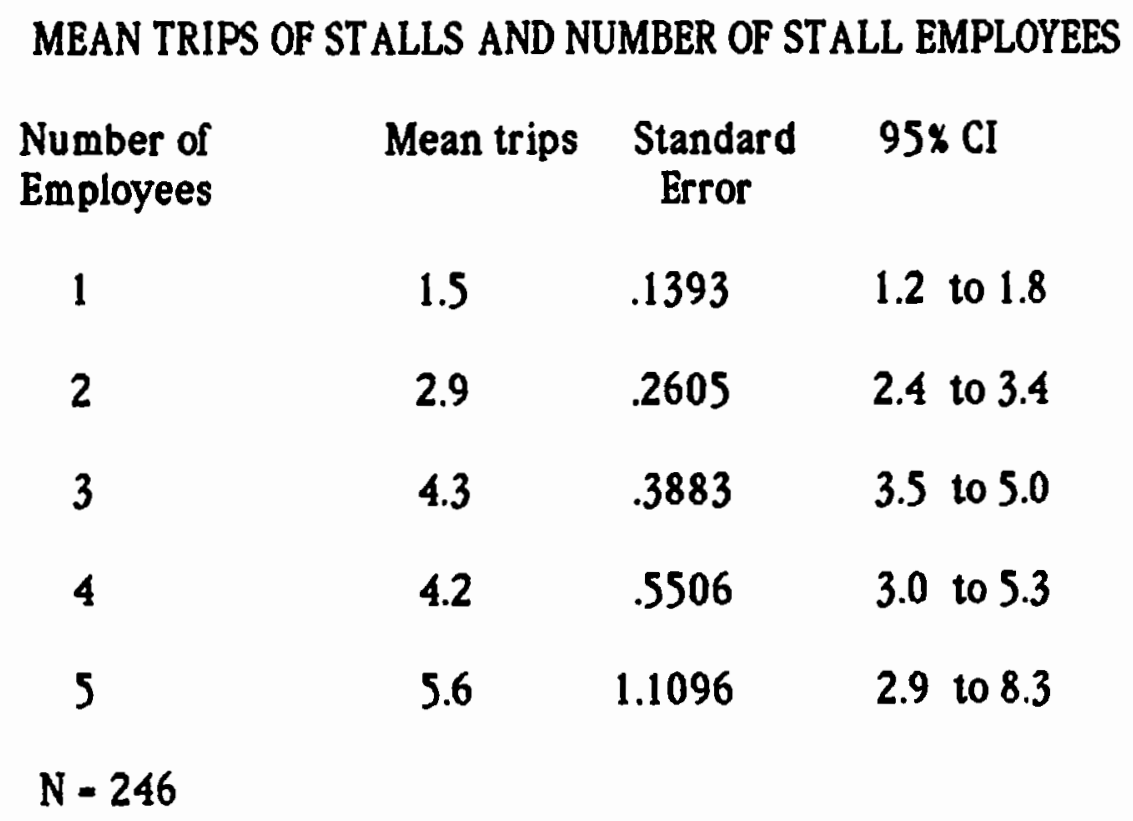

It appears the third occupant has a relatively large disproportionate 
marginal effect on total trips produced. We can assume that generally, should the average size of stalls increase from present average levels of one or two occupants to three and over, the transportaticn system in the commercial center of Onitsha should be expected to experience a significant increase in level of use (with associated wear and tear on the system).

There is a strong positive correlation between the number of trips generated and the number of occupants in a shed, Pearson's $R=.42774$ (size of stall measured as an ordinal level variable) and .4699 (size of stall measured as an interval level variable). The significant marginal increase in the number of trips produced as stall size increases from two to three may suggest that in ordinary conditions of market operations, a third individual may in deed turn out to be a "crowd" and, therefore, may be expected to undertake more trips than the original occupants to help decongest the stall. It could also suggest that a minimum of two individuals is sufficient to satisfy on-site needs of the stall, in terms of an efficient operation while the addition of a third individual, or, for that matter a fourth trader helps fulfill the stall's requirements for maintaining effective business contacts.

Another plausible explanation for the existence of a sharp increase in number of trips produced when stall size increases from two to three could be that trips are taken because of the utility available at the destination. Moreover, it appears the findings are consistent with expectations regarding the linear relationship between non residential (business) trips and the size of an establishment. 


\section{EFFECT OF THE AVAILABILITY OF \\ A MEANS OF PERSONAL TRANSPORTATION}

The first model (equation v) was an attempt to evaluate whether there was any statistical difference in trip production rates between stalls with and without a means of a personal means of transportation, PETRPS. Note that PETRPS is used as a dummy variable and is different from the variable NVEH (which will be applied in a later model) which measures the number of vehicles available in a stall, including zero vehicle. Also in equation (v) NMALES, NFEMS and MAFEMS (which describe gender) are used to substitute for NEMP which is applied in equation (iv) and in a subsequent model. The resulting model:

$$
\begin{aligned}
& \text { TOTRPS }=1.850317+1.813394 \text { PETRPS }+.787967 \text { NMALES }+.413245 \\
& (27.0)^{*} \\
& (18.6)^{*} \\
& \text { NFEMS }+.388881 \text { MAFEMS }-1.027891 \text { LOC }-.308740 \text { TEXTI } \\
& (9.8)^{* *} \quad(5.9)^{* * *} \quad(12.9)^{*} \\
& +.383943 \text { HARD }-.048502 \text { FOODS + .117010 READY } \\
& R^{2}=.6020 \quad F=13.42 \quad \text { Sig } F=.0003 \quad N=246 \\
& \text { " significant at the } .000 \text { level (1-tailed) } \\
& \text { * significant at the } .002 \text { level ( } 1 \text {-tailed) } \\
& \text { *** significant at the } .01 \text { level (1-tailed) } \\
& F \text { values of regression coefficient shown in parentheses }
\end{aligned}
$$

confirms that there is a statistical difference $(\rho=.0003)$ in trip generation rates between stalls when a means of personal transportation is present and when it is unavailable. The $F$ value confirms that the null hypothesis is 
falsified and we will conclude that the population coefficient of variation is indeed greater than zero. The expected sign of the regression coefficient was also obtained and the variables have low correlation coefficient values (Appendir). Additionally, empirical data indicate that while stalls with a means of personal transportation generated a mean of 4.5 trips in a typical business day, stalls without a means of personal transportation produced only a mean of 2.0 trips (standard deviation PETRPS $=.45$ ). Moreover, PETRPS shows the largest increase (of 1.80 trips) in $b_{i}$ values for all attributes for a unit change of an increase in TOTRPS.

Having established a statistical difference in the tripmaking capacity between stalls with and without a means of personal transportation, a model considering the impact of the number of a means of personal transportation was then evaluated. Incidentally, the best model depicting this attribute is similar to and coincidental with the NEMP model and need not be repeated. Rather, the implications of the regression coefficients and the results of the frequency data will be further examined. But, note that the positive unstandardized beta value for NEMP confirms the direct relationship between the attribute and TOTRPS, meaning that stalls with a greater number of a means of personal transportation will generate a greater number of trips.

The total trips generated and the number of vehicles available to a stall are strongly correlated (Pearson's $R=.48575$ ). However, almost 70 per cent of stalls have no vehicles available for making business trips. In other words, there is one vehicle available to every thirty stalls or about one vehicle to every one hundred-sizty traders in the sample. Relatively, this is an excellent record given that in Nigeria there is about one car for every one 
thousand individuals. Moreover, the results show that the maximum number of vehicles available to a stall is two, Table XII.

The results confirm hypothetical expectations of an increase in total trips as the number of vehicles increases, contrary to findings by Van Der Hoor (1979) in a Dutch study alluded to elsewhere. Additionally, the data show that there is a significant increase in mean number of trips from 2.0 to 4.3 as a stall acquires its first means of personal transportation. In other words, limiting the number of vehicles available to a stall would limit the number of trips generated from the stall.

Another significant fact provided by the data is the observed

TABLE XII

MEAN TRIPS OF ST ALLS BY NUMBER OF VEHICLES

$\begin{array}{cccc}\begin{array}{l}\text { Number } \\ \text { Vehicles }\end{array} & \begin{array}{c}\text { Mean } \\ \text { Trips }\end{array} & \begin{array}{c}\text { Standard } \\ \text { Error }\end{array} & 95 \% \mathrm{CI} \\ 0 & 2.0 & .1396 & 1.7 \text { to } 2.3 \\ 1 & 4.3 & .2965 & 3.7 \text { to } 4.9 \\ 2 & 5.6 & 1.0456 & 3.2 \text { to } 8.0 \\ \mathrm{~N}=246 & & & \end{array}$

dramatic increase in the number of trips as the number of vehicles increases from zero to two. The mean number of trips increases almost three times from 2.0 to 5.6. This is instructive because no other variable selected for this study has demonstrated such a strong influence on total trips generated. The result also confirms that not only do stalls with a means of personal 
transportation marimize the use of those vehicles, perhaps in response to the "socio-auto fact," but vehicle owners also disproportionately impact the existing transportation infrastructure and urban transport operation, given the frequency of their contact with the system in a typical business day.

A Westerner in Onitsha may not resist observing the magnitude of what I will describe as the domineering influence on other road users (un)consciously exerted by automobile operators. There is also the incessant use of horns by the same group to warn other users to relinquish their rights of way. Often, recalcitrant pedestrians and motorcyclists may, for example, be verbally abused and sometimes forced off the road. Eventually, auto operators have come to expect these "rights" to be respected by other road users. By usurping the rights of other road users (motorcycle operators belong to another hierarchy which intimidates pedestrians) those who own mechanized means of transportation will implicitly be predisposed to use the transport system at a greater rate relative to other road users. This may produce incentives for a vehicle owner to engage in tripmaking. The result is that stalls with a greater number of vehicles generate trips at a greater rate than stalls without any means of personal transportation.

It is also plausible that owning a means of personal transportation could correlate with an ability to afford additional outlets away from the (market) stall. The establishment of additional outlets would create the need for additional trips either to supply the outlet or provide relevant business information to employees. Most often the latter activity must be accomplished in a face-to-face manner. Implicitly, these types of activity affect and impact the urban transport system in a manner an average trader may not have imagined. 


\section{THE EFFECT OF GENDER - MALES AND FEMALES}

As originally predicted, the hypothesis for this attribute was that for any given stall occupied by both males and females, the greater the number of males, the greater the number of trips generated from the stall. A pretest of the survey material confirmed that in Onitsha markets, stalls are not "integrated," rather, both sexes appear to be naturally "segregated," with males occupying $58.5 \%$ of all stalls while females occupy $30.9 \%$ in our samples while only $10.6 \%$ (26 stalls) were occupied by both males and females. As a result, a decision was made to reevaluate and extend the hypothesis without changing its thrust. Generally, stalls occupied by males will generate a greater number of trips than stalls occupied by females. The selected method for recording the number of females and the number of males was maintained. However, the number of males and females was recorded on an interval level scale and not as dummy yariables since analysis will be conducted at the stall level. Otherwise, it would be difficult statistically to score a stall with more than one male or female.

Three models were developed in order to assess the effect on tripmaking when stalls are occupied exclusively by (1) males, NMALES (2) by females, NFEMS (3) by both males and females, MAFEMS. Because the sample (26) occupied by both males and females was not statistically large, the result from the model (equation viii) considering MAFEMS would only provide exploratory information and should be interpreted with caution.

In order to evaluate whether there is any statistical difference in trip rates between stall samples exclusively occupied by males and females, the coefficients of the two models were compared. This was accomplished by 
first running a model with NMALES only (equation vi), then a second model (equation vii) considering only NFEMS. The regression runs show the following results:

For NMALES

$$
\begin{aligned}
& \text { TOTRPS }=2.681600+.571397 \text { NMALES }-1.358978 \mathrm{LOC}+1.925919 \\
& (11.3)^{*} \\
& (21.5)^{*} \\
& \text { VEHAVA }-.282002 \text { FOODS }+.620066 \text { HARD }-.511478 \text { TEXTI } \\
& (49.0)^{*} \\
& +.263348 \text { READY } \\
& R^{2}=.5754 \quad F=41.22 \quad \operatorname{Sig} F=.0000 \quad N=144
\end{aligned}
$$

and for NFEMS:

$$
\begin{aligned}
& \text { TOTRPS }=2.383537+1.524533 \text { VEHAVA }-1.324510 \text { LOC }+.199823 \\
& \text { (24.7)* } \\
& (18.7)^{*} \\
& \text { NFEMS + .602420 FOODS }+.776162 \text { HARD }+.487450 \text { READY } \\
& (2.5)^{* *} \\
& +.049845 \text { TEXTI } \\
& \mathrm{R}^{2}=.5509 \quad \mathrm{~F}=21.07 \text { Sig } \mathrm{F}=.0000 \quad \mathrm{~N}=76 \\
& \text { * significant at the } .0001 \text { level (1-tailed) } \\
& \text { ** significant at the } .1 \text { level (1-tailed) } \\
& F \text { values of regression coefficient in parentheses }
\end{aligned}
$$

The results of the two models are strikingly different. NFEMS contributes to a reduction in the values of the regression coefficient for $L O C$ 
and VEHAVA and in overall $F$ and $R^{2}$ values. The model for NMALES (equation vi) has larger values for those elements. As expected, the regression coefficient value for NMALES is larger than the regression coefficient for NFEMS, although both models are statistically significant at the .0001 level. The larger value of $b_{i}$ for NMALES confirms that the attribute contributes more to the propensity of a stall to generate trips than the attribute NFEMS. Moreover, with a unit increase in TOTRPS, what the coefficients suggests is that a stall occupied exclusively by males will increase its trip rate by 0.6 while another stall occupied exclusively by females will increase its trip rate only by 0.2 trips.

A third model (equation viii) considered only stalls occupied by both males and females, MAFEM and the resulting regression model is shown below:

$$
\begin{aligned}
& \text { TOTRPS }=3.010393+.113854 \text { MAFEMS }+\begin{array}{c}
1.681974 \text { VEHAVA } \\
(43.2)^{*}
\end{array} \\
& \begin{array}{l}
1.365345 \mathrm{LOC}-.291508 \mathrm{TEXTI}+.344856 \mathrm{HARD}+.010605 \\
(23.0)^{*}
\end{array} \\
& \mathrm{READY}+.028157 \text { FOODS..........................................(viii) } \\
& \mathrm{R}^{2}=.5583 \quad \mathrm{~F}=56.76 \quad \mathrm{Sig} \mathrm{F}=.0000 \quad \mathrm{~N}=26 \\
& \quad \text { significant at the .0001 level }(1-\text { tailed }) \\
& \text { F values of regression coefficients shown in parentheses }
\end{aligned}
$$

Notice that the regression coefficient for MAFEMS is not statistically significant even though the over all model is significant at the .0000 level. The model has an $\mathrm{R}^{2}=.5583$ and an $\mathrm{F}=56.76$. It is plausible that the small sample size for MAFEMS has contributed to the statistical insignificance of 
the $b_{i}$ value. Otherwise, the result could be interpreted to mean that miring both sexes in the stalls does not produce any statistical difference in total trips generated. Put differently, it means that the amount of variation in TOTRPS accounted for by stalls occupied by both males and females is only 11.4x as compared with 57.1\% for NMALES (equation vi) or $20 \times$ for NFEMS (equation vii). This notwithstanding, the mean trips produced by the MAFEM attribute is 3.8 trips (standard deviation $=1.00$ ) even though one stall produced 8.0 trips while sir stalls produced a mean of 4.7 trips. Based on the sample size, we can not make a definitive statement about the sample or the implications of the mean trips produced. In all the three models, though, multicollinearity posed no statistical problems (Appendix).

We will continue the analysis by focusing on the differences between stalls exclusively occupied by either males or females. The confirmed difference in trip generation rates between the two sample categories is instructive because it appears that even though males and females sell similar types of goods and are subjected to similar operating conditions prevailing in the marketplace, females tend not to respond similarly to inherent operational needs in the marketplace by making a sufficient number of business contacts (for economic survivability). The opposite of this is that, perhaps, males may naturally tend to overproduce trips in response to existing mode of operation. Put differently, females appear not to impact the urban transportation system at rates similar to those of males even though the expectation is that both males and females, for example, would seek out and attempt to acquire stocks from similar sources and respond to other demands placed upon marketeers in order to maintain respectable profits. 
Additional empirical evidence suggest that while a stall exclusively occupied by males generates a mean number of about 3.0 trips (standard deviation $=.89$ ) in a typical business day, a stall exclusively occupied by females generates only a mean number of 2.0 trips (standard deviation = 1.44). Moreover, while the Pearson's $R$ for NMALES is .35956, the Pearson's $R$ value for NFEMS is .03908 , meaning that NMALES has a stronger (positive) relationship with TOTRPS than NFEMS.

It may be plausible that female stall occupants have developed alternate arrangements to service the needs of the stall without actually leaving the stall, say, by hiring outside laborers. We know for a fact, for example, that female traders whose spouses are also located in the same market tend to receive assistance from their husbands in the daily operation of the stall. The husband, for instance, would make lunch available for the spouse and would also make arrangements to have merchandise delivered to the spouse's stall. This is a norm since both husband and wife are attempting to capture a larger market by locating at different spots in the same market.

Another possible explanation why stalls occupied by females appear to generate fewer trips is because females, due to the cultural environment, may be perceiving the potential difficulties in tripmaking differently from their male counterparts. Discussing the state of the transport system in Onitsha, for example, Barrett (1988:102), writes: "Most roads are narrow, in very poor state of repair and heavily congested. The poor road traffic conditions are exacerbated by indescriminate (sic) loading and unloading of trucks and buses." He continues, "On a number of four-lane roads traffic is reduced to one lane because of parking and potholes." In fact, the Onitsha Master Plan aptly notes that the traffic congestion points affecting the whole town include the three market areas: the Main Market, the Bridge Head 
(Market) Approach and the Upper Iweka Roundabout where the Relief Market is located (Onitsha Master Plan, Vol.2,1979:137). It should be added that this type of congestion may not be peculiar to Onitsha (see, for example, Olayemi, 1980 for a description of road conditions in another Nigerian urban center of Ile-Ife). What Barrett fails to mention is that apart from the structural problems, there are also problems associated with transport and the transit services in Onitsha. For instance, buses are known to exceed designated and acceptable crush load factors and as traders told this researcher, a significant number of taxi cabs are decrepit. As a result, for example, female traders who may also be nursing their babies may prefer not to make a lot of trips, given the potential enervating/psychological strain on the traveler. Ultimately, female traders may prefer to limit the amount of contacts they would prefer to have with the transport system (thereby limiting the total volume of trips from stalls occupied by this category) and choose to stay in the stall and improve revenues to assist them to support their families.

Finally, examined from a different perspective, the low rate of trips by women may coincide with society's expectation of women's behavior, even for business purposes. Although men's attitude, for example, may be changing, they may perceive female business operators who often leave the stall as engaging in other than business trips. As a matter of fact, adjacent female stall operators could be the first suspicious observers in those circumstances. It, therefore, appears female stall occupants, cognizant of societal expectations, may tend to react accordingly and deliberately cut down on potential trips. 


\section{EFFECT OF TYPE OF COMMODITY SOLD}

As a result of the scoring system used for the components of the type of good sold, the regression coefficient of each commodity can be interpreted as the difference in the intercepts between the commodity and the provision category. In other words, the intercept represents, in causal terms, the increments or decrements in the number of trips that would be generated if traders selling provisions were to reestablish themselves in that commodity line (Blalock, 1979:536). Let us illustrate with the foodstuffs group what the resulting model for a commodity would look like. First, the model for the attribute, type of good sold is:

$$
\begin{aligned}
& \text { TOTRPS }=1.592166+1.386491 \mathrm{NVEH}+.525884 \mathrm{NEMP}+.598784 \\
& (29.15)^{*} \\
& (20.26)^{*} \\
& \text { HARD }+.227701 \text { READY }+.407032 \text { FOODS }-.027671 \text { TEXTI } \\
& (2.5)^{* *} \\
& -1.012450 \mathrm{LOC} \\
& (13.01)^{*} \\
& \mathrm{R}^{2}=.6080 \quad \mathrm{~F}=10.470 \quad \mathrm{Sig} F=.0014 \quad \mathrm{~N}=246 \\
& \text { * significant at the } .000 \text { level (1-tailed) } \\
& \text { ** significant at the } .1 \text { level (1-tailed) } \\
& F \text { values of regression coefficient shown in parentheses }
\end{aligned}
$$




$$
\begin{aligned}
& \text { TOTRPS }=(1.592116+.407032)+1.386491 \mathrm{NVEH}+.525884 \text { NEMP } \\
& -1.012450 \mathrm{LOC}
\end{aligned}
$$

since each attribute in the commodity group would score 0 while the foodstuffs category would score 1 . The $R^{2}$ value is .6080 and the model is significant at the .001 level. Only in the hardware group does an appreciable change occur (0.6) for a unit value change in the dependent variable. Otherwise, all different types of good sold do not appear to undergo any reasonable changes for a unit change in TOTRPS. Realizing that a majority of the attributes (in type of good sold) have not shown any reasonable degree of statistical significance, the preceding model example (for FOODS) will suffice so we can undertake an analysis to assess the propensity of the groups to affect total trips produced by a stall.

The analysis of other empirical data indicate that a typical stall selling provision goods will generate about 3.3 (standard deviation $=2.51$ ) trips in a typical business day while a stall specializing in foodstuffs generates about 2.1 trips (standard deviation $=2.09$ ). Intermediate results exist for other categories. This information helps us to better understand the differences in the propensity of each commodity group to affect the number of trips generated. In fact, apart from stalls stocking provision goods and those selling hardwares, other commodity groups appear to generate less than the mean number of trips for the population. The implication is that hardware and provision goods stalls are relative over-producers of trips while stalls in other three categories appear to be under-producers, Table XIII.

Additional empirical data, for example, indicate that when the comparison is limited to evaluating the differences in the proportion of stalls in each commodity group for trips produced, there is evidence to show that 
stalls specializing in foodstuffs (48.8\%) and stalls stocking readymade materials (47.0\%) tend to generate more travel (two trips) on a daily basis. However, the result is quite different when we focus our attention on stalls

\section{TABLE XIII}

MEAN STALL TRIPS BY TYPE OF GOOD SOLD

$\begin{array}{lclc}\begin{array}{l}\text { Commodity } \\ \text { Group }\end{array} & \begin{array}{l}\text { Mean } \\ \text { Trips }\end{array} & \begin{array}{l}\text { Standard } \\ \text { Error }\end{array} & 95 \% \mathrm{Cl} \\ \text { Foodstuffs } & 2.1 & .2969 & 1.5 \text { to } 2.7 \\ \text { Hardware } & 3.3 & .3324 & 2.6 \text { to } 3.9 \\ \text { Readymade } & 2.6 & .3324 & 1.9 \text { to } 3.3 \\ \text { Textiles } & 2.4 & .3427 & 1.7 \text { to } 3.1 \\ \text { Provisions } & 3.3 & .1496 & 2.6 \text { to } 3.9 \\ \mathrm{~N}=246 & & & \end{array}$

generating four trips. For example, a greater percentage of stalls selling provision goods $(24.5 \%)$ tend to lead the pack. Stalls associated with textile goods appear not to show any distinct characteristics even though the reason(s) may not be apparent. Moreover, there appear to be twice as many stalls selling provision goods which produce four trips as there are stalls stocking foodstuffs (12.0\%), Table XIV.

Notice that a majority of stalls do not produce three trips. apart from four per cent of stalls selling hardware and about two per cent of stalls stocking provisions. What these show is that trips which begin in the stall tend to have their final destination in the stall. Furthermore, only a small percentage of stalls appear to produce either one or no trips per day. Notice 
also that it is mainly among hardware and provision goods sellers do we find a match between the proportion of stalls generating two trips with those producing four trips. Furthermore, a relatively large proportion of stalls stocking textiles (32.6x) fail to generate any trips compared with only about three per cent of stalls specializing in foodstuffs. We, therefore, have evidence to show that a majority of foodstuffs sellers are forced to make daily contacts. One of the possible explanations is the absence of refrigeration equipments suggesting that only small quantities of (fresh) food must be bought and sold every business day. This is further

TABLE XIV

TRADER STALL TRIPS BY TYPE OF GOOD SOLD Foodstuffs Hardware Readymade Textiles Provisions

Total

$\xi^{*} \quad \xi^{*} \quad \xi^{*} \quad z^{*} \quad \xi^{*}$

Trips

$\begin{array}{lrrrrr}0 & 30.0 & 15.7 & 22.5 & 32.6 & 17.0 \\ 1 & 0.0 & 4.0 & 0.0 & 2.3 & 7.6 \\ 2 & 48.0 & 27.5 & 47.5 & 30.2 & 24.5 \\ 3 & 0.0 & 4.0 & 0.0 & 0.0 & 1.9 \\ 4 & 12.0 & 27.5 & 18.4 & 21.0 & 24.5 \\ 5-10 & 10.0 & 21.6 & 12.3 & 14.0 & 24.4 \\ \mathrm{~N}=246 & * \text { Percentage of total stalls sampled } & & \end{array}$


confirmed because it is within this group that we have the lowest proportion (25.0\%) of stalls generating four trips but the largest proportion (48.0x) producing two trips.

Stalls selling tertiles have the highest zero-trip generation rate in a typical day which may suggest a low turnover rate for that merchandise or there may be an existence of alternate arrangements for maintaining contacts unique to textiles good traders. We should not, therefore, be very surprised about a similar trend for stalls selling readymade goods since it serves as a substitute and/or a complementary good. Apparently, market factors affecting one category could be expected to significantly affect the other group. And, indeed there is no appreciable difference in proportion of stalls generating four trips for the two categories, viz, $18.4 \mathrm{~K}$ for readymade clothing against $21.0 \%$ for tertiles good.

A common practice in this marketplace by traders who sell provision goods is the establishment of shops in residential areas so sales could continue following a trader's return at the close of official business day. The neighborhood shops readily stock convenience goods, locally known as "provision." In fact, these neighborhood shops are locally known as "Provision Stores." A stall whose owner operates a neighborhood shop could generate day-time trips to restock the neighborhood shop. As a result, we will expect stalls stocking provision goods to produce additional trips, thereby increasing their mean daily trips, and explicitly pointing out the leadership role of this group in influencing trips generated from a stall. 


\section{CHARACTERISTICS OF TRIP PURPOSE}

So far the assumption is that out-of-stall trips completed by traders during normal business hours are business- related. To assess the veracity of the statement, we examine the distribution of trip purposes. Table $\mathrm{XV}$ is a display of trip purposes by percent of stalls producing trips connected with or not connected with identified purposes.

\section{TABLE XV}

\section{STALLS PRODUCING TRIPS BY TRIP PURPOSE}

Trip Purpose

Percent of Stalls Producing Trips

Not connected with Connected with

Financial

69.8

30.2

Personal Business

58.9

41.1

Eat Meal

88.7

11.3

Others

82.6

17.4

At the macro (collapsed, trip purpose data) level, the data suggest that for all daily activities associated with operating a stall, a relatively greater number of stalls generate trips associated with personal business (41.1\%) pay/collect debt, run errand, pickup/deliver goods; and finance-related activities (30.2x) - buy additional goods, 80 to the bank. On the other hand, a greater number of stalls fail to generate trips associated with eating a meal or for Other purposes - travel-out-of-town, socialize or go to a government 
office. The implication is that traders take their business seriously. (The following observations are based on uncollapsed trip purpose data see Appendix, in order to provide the proper insight into the reasons why traders may leave their stalls after arriving in the stall at the beginning of the business day).

The results show that either traders do not extend credit to their customers, or if they do, debtors are required to come in to make payments, since traders do not appear to be interested in deploying useful business hours chasing down debtors. This suggests that in order to be allowed to make additional purchases, debtors (customers) would be required to pay for previous merchandise. Moreover, traders tend to stay away from government offices. What we learn from this is that traders may not consider the existence of those offices essential to daily business operation. Contrast this with the fact that everyday, for example, a relatively large proportion of stalls, 28 per cent, generate trips associated with acquiring additional supplies for the shed.

Generally, while 10.2 per cent of all stalls would have contacts with the banks in a typical day, a similar proportion would have its occupants make out-of-town trips. Moreover, while only $9.8 \%$ of stalls generate trips associated with socializing, $14.2 \%$ of the stalls produce trips involving eating a meal. This should not be surprising since a majority of traders either buy their meals from mobile foodsellers in the markets, or bring their lunch from home or have it delivered by a family member. Finally, while $22.4 \mathrm{~K}$ of stalls engage their occupants in running errands, a similar proportion is involved with purposes related to picking up or delivering goods while a paltry $7.3 \%$ generate trips whose purpose is either to pay or collect debt. The preceding data make us believe that a majority of trips generated 
from stalls during business hours are business-related. This conclusion is confirmed by the fact that when traders were asked to suggest other reasons which could induce trip-making behavior the responses this researcher obtained appeared only semantically different from possible trip purposes already listed in the survey material.

\section{Multi-Purpose vs Single Purpose Trios}

Another relevant area worthy of elaboration is whether traders plan their trips so that several purposes are fulfilled as part of a trip chain or whether traders are averse to multi-purpose trips, as they engage in activities associated with accomplishing daily commercial activities.

According to the survey results, only $28.0 \%$ of stalls generate multipurpose trips even though "multiple activity journeys would seem more economical and efficient than single activity journeys," according to Lathrop (1970). Should it fail to materialize, as Hurst (1970:171) argues, it suggests that the "behavioral" and not the "economic" person is operative in those circumstances as the trader attempts to satisfice his/her daily business needs. This further confirms that engaging in multiple purpose trips is a "luxury" practice in which the affluent of ten indulge (Bently, et al, 1977). On the other hand, the findings tend to affirm the hypothesis that the proportion of multi-stage journeys made by an individual increases as his/her total number of journeys increase, as Bently, et al, (ibid), have confirmed. Despite this, the finding should be surprising given the characteristics of market operation. However, when it became clear to this researcher that it did not appear traders were interested in multi-purpose trips, the matter was pursued further with respondents, (mostly stall 
owners/co-owners). The question posed to them was simply: Why do traders prefer single purpose trips?

Traders believe a lot of time could be wasted completing multipurpose trips. They argue it would be cost-effective to truncate trips to minimize aggregate trip times. This rationalization is quite hard to understand but perhaps serves as a pretext for spending additional time in the stall to actually provide the constantly-needed supervision of stall activities. Otherwise, it would be mathematically difficult to justify how returning to the stall prior to initiating an additional trip would reasonably lead to time savings.

In responding to the question, traders indicated that it would create a poor impression on colleagues in adjacent stalls and on customers if a trader is rarely available in the stall. Apart from losing valuable customers, a trader could be perceived as an unreliable business-person. The implication that neighbors should assist in making business decisions in his/her behalf, and, perhaps coach any abandoned trainees, would not sit well with adjacent traders. Traders wish that colleagues "baby sit" their stalls only when it is absolutely necessary, for example, in an emergency, and preferably for a short duration. Engaging in multi-purpose trips would produce opposite and undesirable results, they emphasized.

To effectively impart acquired business skills and knowledge to apprentices and assistants, and to maintain an orderly stall operation, the presence of an owner in the stall is essential. Taking single purpose or multi-single purpose trips is better than engaging in multi-purpose trips, traders would argue. This would free them to provide for additional stall activities, including an opportunity to discharge expected management 
responsibilities, coordinating business activities, supervising trainees and planning and executing logistics to improve revenues and profits.

A majority of stalls are not equipped with a modern means of communication. In (family-related) emergencies, a family member should be satisfied he would have sufficient information about where to locate the head of the household, assuming he/she is away from the shed. This means that should the trader engage in several trips at one stretch, it could be difficult to trace and locate the tripmaker in the link. Moreover, the tripmaker does not have the luxury of phoning other stall members to report if a transaction is taking longer than expected. By engaging in single purpose trips, members could better understand and/or anticipate the source of any delays.

Finally, since a majority of business trips could involve acquiring additional stock or delivering merchandise, it would be unreasonable for a tripmaker to move the merchandise from one trip origin to another trip destination before returning to the shed. Even a bank visit to deposit or withdraw money would better be accomplished in a single trip, given the amount of time traders consume at the bank. For trips involving running errands (which we would expect a majority of trainees and/or assistants to complete), they are expected to return promptly to the shed to report the outcome to the master. All these combine to position Onitsha traders as averse to generating multi-purpose trips.

\section{Trip Purpose and the Category of Trader}

There was a possibility that the trip purpose of the master category could be different from the trip purpose of the non-master group because of the social structure of the market. To evaluate the differences in the 
relationships, the trader groups were cross-tabulated with trip purposes. It is anticipated that the cross-tabulation of the collapsed data would enhance the usability of the result for comparative purposes, Table XVI.

\section{TABLE XVI}

\section{CATEGORY OF TRADERS BY TRIP PURPOSE}

Trader Category

$\mathbf{x}$ of Trip Purpose by Stall

Financial $\begin{gathered}\text { Personal Eat Meal Others } \\ \text { Business }\end{gathered}$

Master

The results tend to confirm hypothetical expectations and are consistent with the empirical evidence discussed above. An appreciable proportion of trips by the master category appears to be associated with financial affairs. Typically, bank customers are known to spend a disproportionate amount of time at the bank in an attempt make withdrawals or deposit cash, so non-masters are expected to engage in more trips to the banks. Moreover, a majority of errands are run by the nonmasters, often at the request of the masters and these are classified as "personal business." As a result, we observe a relatively greater proportion of trip purpose of the non-master groups associated with personal business. For example, non-masters would be expected to have a greater proportion of their trip purposes associated with eating a meal since such trips would also include buying meals for the masters. 


\section{CHARACTERISTICS OF MODE CHOICE}

We will now turn our attention to mode choice. Commenting on factors which determine mode choice, Brog, et al, (1977:27), argue that the predominant factors would be the purpose of the journey, the frequency or the speed of the mode or, factors which the authors characterize as habitual, trusting or induced (by publicity) (p.30). In Onitsha, it could simply be habitual, given the socio-economic background of tripmakers and the need to constantly balance business and familial financial needs. The empirical evidence is that a majority of traders rely on the walking mode to complete a significant proportion of business-related trips. Table XVII shows the percent distribution of stalls producing trips completed or not completed by selecting an identified type of mode, collapsed into four broad areas.

On a macro (collapsed, mode choice data) level, walking ( $41.1 \%$ ) and transit (23.6\%) - bus and taxi - are most of ten selected while the bicycle and motorcycie mode $(3.9 \%)$ and the auto mode $(0.1 \%)$ constitute miniscule proportions. This finding does not contradict the earlier result that the number of vehicles available to the stall is a significant attribute. This is because it appears that despite the limited number of vehicles available, stalls where vehicles are available tend to produce a greater number of trips. Recall that vehicles, modeled as VEHAVA, include autos, motorcycles and bicycles.

Over 40 per cent of all stalls generate trips which depend on the walking mode. This is partly due to congestion because negotiating city streets could best be performed by an individual as a pedestrian, and 
TABLE XVII

TYPE OF MODE SELECTED BY STALLS PRODUCING TRIPS

Type of Mode

Transit

Cycle

Auto

\section{Walking}

Percent of Stalls Producing Trips

Not Completed by Completed by
58.9

76.4

96.1

99.9
41.1

23.6

3.9

0.1

perhaps the distance covered may be perceived as short; but, mainly because other modes may not be available or affordable. As a part of the cost of doing business, we do not have sufficient information to evaluate whether the disproportionate dependence on the walking mode translates to reduced total intraurban transport costs to the stall. Our suspicion is that over all, it could contribute to reduced total operating cost (see, for example, Anambra State of Nigeria, August,1985, Chapter 7). Given the structure of the market place, we will continue our discussion based on the uncollapsed, mode choice data, to provide depth to our understanding of choices made by traders as they make contacts in completing normal business activities.

It is interesting to observe that the bicycle was never mentioned as a preferred mode for any of the trips while the taxi mode appears to be the next most preferred mode and the van the second least preferred mode. Third in the order of preference is the bus mode, despite similarity in base fare with the taxi mode. Traders indicated to me that they ride the taxi more often than the bus because, to some degree, it provides a door-to-door 
service; it is not subjected to frequent stops to let off or pickup passengers; it is more convenient and, as a shared ride, it reduces a patron's exposure to the number and type of strangers during a trip. In his study of out-of-stall contacts of entrepreneurs in Zaria, Gihring (op cit:24) found that "for the 84 percent of surveyed entrepreneurs who engage in pick-up trips, the majority (54x) travel by public transport." The preference of the tari mode over the bus mode may also show a high value of time among those traders even though, as Koenigsberger, et al (1970:217-218), found in their Kenya studies, it may not necessarily reflect a higher earning power but could be attributed to a cultural disposition to impatience. In Onitsha, the implication may indeed be different because traders traditionally believe that time is money. (Some of them even use slogans such as "Time is Money" as aliases or as a stall name identification). The assumption is that those who prefer the tari mode may indeed attach a greater value to time than their counterparts and may as well be relatively more prosperous. In fact, we will conclude that the findings on mode choice tend to "support the hypothesis that mode choices are (in deed) made largely on the basis of of time and cost," as Thomas (1983) found in Malaysia. He found, in addition, that "Over 80 per cent of regular bus users mentioned cost as a factor in their choice of mode while 95 per cent of taxi users emphasized speed." Since the single-hop fare for bus and taxi is the same in Onitsha, we will begin to to appreciate why a majority of (rational) traders select the tari over the bus mode. Indeed, the Malaysian study also showed that users rated taxi (58.0\%) as being more comfortable than bus (33.0x).

Notice that only $11.0 \%$ auto drivers travel alone but only in about 1 out of 33 times would they travel with a passenger. The motorcycle mode was mentioned by traders in $7.7 \%$ of the stalls, perhaps, due to an increasing 
awareness by the public about the tendency of riders to be involved in (fatal) accidents,(see, for example, Anambra State of Nigeria, Digest of Social Statistics, December 1987,Section 4). Perhaps the escalating acquisition cost of the vehicle is placing this mode outside the reach of a significant proportion of traders.

The bicycle, touted in the West as non-polluting, easy-to-maintain and operate, and suitable for short distance trips (2-5 miles), appears to be out of favor amongst traders. One would expect, though, that this will be untrue for a majority of urban centers in Southeast Asia (Cheng,1970). We have already referred to the "socio-auto fact" and it becomes easier to understand why a majority of traders would rather walk than ride a bicycle. Moreover, street and traffic conditions, in addition to the probability that small packages could be moved while making a trip, combine to diminish the attractiveness of this mode. Besides, due to current economic conditions, acquiring a bicycle would involve a higher opportunity cost.

In conclusion, while $41.1 \%$ of stalls generate trips completed on foot, only $28.0 \%$ generate trips in which the tari mode is selected while $19.1 \%$ generate trips which depend on the bus mode. As expected, the three modes constitute the principal means of intraurban movement for a majority of traders and together account for $76.7 \%$ of trips generated from market stalls in Onitsha in a typical business day.

Mode Choice and the Category of Trader

Table XVIII is a display of the relationship between the category of a trader and the mode of ten selected by the group. The numbers represent the proportion of times a given mode was selected to complete trips.

The results show that most often masters choose to walk (39.4\%) or 
take a transit mode $(38.2 \%$ ). They rarely ride a cycle $(7.2 x)$. The possible explanation is that it might appear too dangerous to the group, given the makeup of the group - usually, older adults and females. On the contrary, non-masters tend to select the cycle mode more frequently would also take a bus or a taxi and, surprisingly, use the auto mode more often than the master group. One of the main reasons why a greater proportion of their

\section{TABLE XVIII}

CATEGORY OF TRADERS BY MODE CHOICE

Category of Trader

Master

Non-Master
Percent of Mode Choice by Stalls

Walking Auto Transit Cycle

$\begin{array}{llll}39.4 & 15.3 & 38.2 & 7.2\end{array}$

$\begin{array}{llll}24.8 & 22.7 & 41.1 & 11.4\end{array}$

trips is associated with the auto mode is that often the group doubles as servants or chauffeurs. As a result, even when they may not be driving the master to a destination, they may be required to make irips requiring the use of the auto mode since traders may tend to believe they could save travel times by using the mode. Non-masters also have a higher score for transit - an indication that as the group members engage in delivering/picking up stock (which we will expect them to do more often than masters), it is conceivable they would opt for a taxi or a bus to facilitate their movement. Even though the Master group appears to select the walking mode more often than the non-master group, it does not conflict with the former group being interested in saving time (the-time-is-money-attitude). This is because sample data does not allow a detailed analysis of trip 
distances so the master group might be making shorter trips often completed on foot to maximize limited stall resources.

\section{CONSTRAINTS ON TRAVEL BEHAVIOR}

There is an on-going debate in the field of transportation studies concerning the extent to which the environment is an important attribute in choice behavior of urban tripmakers. Burnett and Hanson (op cit), in dealing with this issue elect to focus on modeling problems facing an analyst attempting to compare travel behavior based on environmental constraints , avoidance behaviors and habits. The authors are interested in measurement problems inherent in identifying modeling parameters. Hertz (op cit) eramines daily travel activity patterns as they are influenced by concrete physical environment. Both studies deal with whether a subgroup or the individual should be the focus of trip observation and analysis. Supernak lop cit:51-51) has also expressed a similar concern.

Our focus here is not an attempt to settle the debate; rather, we will evaluate the extent, based on a non-structured interview, to which daily travel behavior is influenced by a number of location-specific environmental constraints. The relevant constraints include (perceived/real) congestion (operational constraint), limited mode choice (system constraint), out-of-pocket cost for riding a bus or a taxi cab (economic constraint), and presence/absence of a telephone service (technological constraint), Table XIX.

The non-structured interview attempted to evaluate to what degree Factors A - E would limit the propensity of traders to undertake business trips. 
The defined environmental factors appear not to be playing any appreciable roles in dissuading traders from making trips. Respondents were interviewed to evaluate whether they would be dissuaded from making trips by the fact that:

1. the intraurban bus service connects mainly the markets;

\section{TABLE XIX}

\section{RESPONSE RATE OF STALLS ON ENVIRONMENTAL} CONSTRAINTS ON TRAVEL BEHAVIOR

Factors Considered

A. Limited modal choice

(i) Circular bus route

(ii) Not enough taxi cabs

(iii) No other means of transport

B. Out-of-pocket cost

C. Effects of traffic congestion

D. Bad road conditions (potholes, etc)

B. Telephone services

Source: Field Study by Author
Response Rate

(Percentages) 
(the result reflects proportion of respondents who answered yes to the three variables);

4. the roads are basically unmaintained and full of potholes; The other areas explored were:

5. Would the installation of a telephone in the shed force a respondent to substitute trips?

6. Whether respondent believed there is an insufficient number of taxicabs?

7. Whether respondent believed the base fare (of $50 \mathrm{kobo}$ ) is too steep to affect respondent's decision to take a trip?

It appears from Table XIX that a majority of respondents do not believe that the effect of each selected environmental factor was sufficient to force a trader to forgo a trip.

Perhaps, traders have accepted these factors as intractable, especially if traders perceive the individual as incapable of inducing meaningful changes. For example, the public transportation service is a seller's market partly because a majority of traders may not have an access to an alternative (personal) means of transportation. This breeds a situation in which, despite the operational characteristic of the transit system, patrons appear not to be concerned enough to organize and seek to initiate improvements. Traders, as transit-captive users are apathetic because their type of business requires that during most trips a trader depends on the system to move some type of commodity. The unintended side effect is that traders may be paying undue attention to what they perceive has a direct relationship to their business - the need to move goods and information via the system - than to complementary attributes, such as comfort and 
convenience. In essence, instead of fleeing from the poor transport system, the trader fights back by internalizing any negative impacts due to Factors $\mathrm{A}$ - E and completes relevant business trips.

One direct implication of this is that we would assume that a majority of traders consider trips taken in the course of conducting daily business as obligatory rather than discretionary (Supernak,op cit:52-53), or what Bland (1983) describes as "Less Elastic" rather than "More Elastic" trips. Ordinarily, a tripmaker could be more easily dissuaded from taking a discretionary trip should the transport system present even a limited number of environmental constraints (Brog:1977:32). Given the intense competition and limited profit margins prevalent in these areas (Mueller,1982), the decision not to make essential business trips could separate economic survival from economic annihilation. To a rational trader the decision would be to discount all and any unfavorable factors and complete all obligatory trips. It is my opinion, though, that the high negative scores recorded for Factors A - E should not be construed as an indication of traders' unwillingness to accept a better transportation system.

Regarding the response offered on the presence/absence of telephone services, it appears that technology could assist traders in substituting business trips and reducing tripmakers' impact on the system while improving efficiency in market operation. As indicated earlier, to assess technology's potential for trip substitution, traders were asked whether the installation of telephone services would mean a reduction in the number of daily business trips completed. Although it may appear from the survey result that opinion is almost evenly divided, it is highly questionable whether trips could be substituted due to availability of telephone services in the stall. Part of the reason is the inherent need for face-to-face contact in 
business transactions in these areas. It would certainly be fair to suggest that the similarity in the proportion of positive and negative responses is attributable to a trader's perception that he/she could improve his/her social status if the service is available in the shed than a reflection of how telephone services would influence trip making behavior. Lamberton and Mandeville (1982:162-169), for instance, in discussing what is generally referred to as $T^{3}$, the telecommunication-transportation-tradeoff, for office workers in the West, sound skeptical about the virtues of the concept and warn that if the transition from working in the office to working at home (telecommuting) were to occur, it would be gradual. In fact Salomon (1986:226), in citing Miller (1980) maintains that all in all substitution (or telecommuting) "is more (often) quoted than tested," see also Salomon and Schofer, 1988. Incidentally, this assertion is made about workers in an environment where face-to-face contact is not the standard mode of operation. Accordingly, we would infer that the installation of telephone services would not compel traders to conduct business contacts from the shed to a degree that total daily trips could be reduced significantly.

In summary, what traders appear to reflect in those responses is that they need to support their families so that irrespective of existing conditions in the transport system, essential business trips must be completed. This suggests a hypothesis that opportunities, rather than other environmental variables, tend to be one of the controlling factor on trips produced and on trip frequency in this urban market. Moreover, traders would appreciate improvements in the transportation system: some traders, wrongly perceiving that this researcher had access to public policy makers, implored him to communicate the magnitude of traders' misery due to the transport 
system, and to emphasize that an improvement in the system would improve market efficiency and revenues.

\section{Constraints and the Category of Trader}

What was not stated about the responses was that they were provided mainly by stall owners who of ten are older than either traders-intraining or assistants. A skeptic knowledgeable about African social conditions may demur at the responses because the expectation is that older traders may not actually comprise the greater proportion of individuals who engage in tripmaking. In other words, as assistants and apprentices are socialized into a trading career (Peil and Sada,1984:254; The United Nations, 1981:78), there is the general understanding that they would make the required trips (irrespective of existing conditions), as long as the older trader makes the decision, just as the authority of an older adult is rarely questioned in managing the affairs of an West African household (Basden,1966:194; Uchendu,1965:85). Implicitly, the potential adverse effects of Factors A - E would actually fall on non-masters who, given the cultural background of participants, would be expected to make a majority of intra-urban trips. One could, therefore, argue that as a result, there may not be any reasons to take the responses seriously. However, survey results from this study indicate that the masters, who provided the responses, actually participate in tripmaking at a greater rate than the other group of traders, the non-masters, Table XX, thereby affirming the validity of the results in Table XIX.

The results do not support the argument that older adults, often including owners/co-owners and the so-called temporary help (categorized as "Master)" would not make trips at frequencies greater than those of non- 
masters. In fact, Table XXI confirms that masters tend to produce almost twice the rate of trips produced by non-masters. Our concern becomes, therefore, why, contrary to intuition, would non-masters make relatively fewer trips than the masters?

\begin{tabular}{lccc}
\multicolumn{4}{c}{ TABLE XX } \\
MEAN TRIPS BY CATEGORY OF TRADERS \\
Category of Trader & Mean Trip & Standard Error & $95 \% \mathrm{CI}$ \\
Master & 4.2 & .4527 & 3.3 to 5.2 \\
Non-Master & 2.3 & .3292 & 1.7 to 3.0
\end{tabular}

A majority of traders in the master category may have business experience other stall members lack, meaning that the owner is better equipped to deal, for instance, with the banks and suppliers than any other stall member. The group also may have a better understanding of the complexities of business operation, including negotiating deals, dealing with competitors and pricing. The members of the group are also rightlypositioned to sign business documents in behalf of the business because they can produce the required collateral and can make informed decisions about which lines of good would produce the highest turnover rate. Finally, being more knowledgeable about the overall financial status of the business (balanced against the needs of the family), members of the group are in a better position to make on-the-spot decisions about the quantity of goods to purchase from the suppliers. A trainee, for example, due to inexperience, would not be delegated to discharge those responsibilities. The trainee could relate better to non-monetary (business) matters, like running errands or 
picking up/delivering goods - responsibilities the master group are often willing and prepared to delegate to trainees without risking business losses.

On the other hand, apprentices are typically expected and required to spend more time in the stall to learn what is considered the mainstay of trading - understanding customer behavior and how to persuade them to buy. This constitutes part of the socialization process. For example, commenting on African urban markets and the apprenticeship system, Peil and Sada (op cit:254) argue that the large number of assistants in the markets are not exploited youngsters but learners who are being adapted to the nuances of the trading profession. A trainee, therefore, has to earn his/her wings. Trainees need to understand the virtues of perseverance and hard work, especially in a marketplace characterized by frequent fluctuations. They are expected to understand, practice and perfect the market's equivalent of a "filibuster" - a process whereby one trader tactfully delays a customer while the other trader sources a merchandise for sale to the customer. The practice, apart from producing an immediate financial reward, produces a tripartite effect - it satisfies the needs of a customer, makes the stall owner look good and, if the merchandise is in short supply, impresses the customer who is expected to return for additional future purchases. It also demonstrates and solidifies the spirit of camaraderie inherently existing between these friendly competitors in the marketplace.

Usually, a trainee or an assistant is expected to demonstrate tenacity in consummating a significant number of sales maintaining expected relationships with adjacent stall occupants, and recording sales efficiently. The successful and satisfactory discharge of such responsibilities contributes to how quickly he/she graduates from apprenticeship, and, for obvious 
reasons is a relevant factor in deciding the amount of monetary settlement he/she is awarded (by the master) at completion of his/her training. Spending the extra time in the shed is one of the persuasive methods an apprentice would apply to demonstrate his/her willingness and preparedness to acquire these relevant business skills and experience.

Finally, the longer the amount of business hours a trainee or an assistant spends in the stall, the better the chance the trainee would understand and appreciate the nuances involved in manipulating the pricing process, including price discrimination; develop an aptitude for taking initiatives, and understand general stall management - essential skills which a trainee would transfer and deploy when he/she becomes an independent operator. So, an implicit division of labor exists in the stall which appears to put a limit on the number of trips produced by different categories of trader. Eventually, we have obtained trip results which appear contrary to intuitive expectations based on our knowledge about African family life, some relevant characteristics which are often transferred to the marketplace and influence the volume and characteristics of trips produced from the stall.

\section{SIGNIFICANCE OF FINDINGS}

To sum marize, our survey results show that

1. Stall traders make trips outside geographically-defined markets as part of doing business and, therefore, affect the existing transportation system;

2. Location is a significant factor in affecting total trips produced by a stall: 
3. Stalls which have a means of personal transportation produce a greater number of trips than stalls where none exist;

4. The greater the number of vehicles available to the stall, the greater the number of trips produced;

5. Large stalls produce a greater number of trips than small stalls;

6. Stalls occupied exclusively by males generate a greater number of trips than stalls occupied exclusively by females;

7. The number of trips produced by stalls occupied exclusively by both males and females is not statistically significant; and,

8. The type of good sold in a stall has no statistically significant effect on the number of trips produced by a stall, even though, in absolute terms, provision good stalls tend to generate a greater number of trips.

The findings are significant because we have information to assist us in an attempt to fill the gap in the literature regarding traders and traders' travel behavior. Secondly, the findings provide us with information and data to assist in an intelligent transportation planning process in order to foster urban development in the study area. Except in one instance (where we found that CBD stalls actually generated a greater number of trips than stalls located along the periphery) the survey results confirmed our hypothetical expectations. As a result, we failed to reject the other hypotheses we set out to test in the study.

We realized that in evaluating the model for location, we obtained results contrary to our expectations. We shall briefly consider some plausible explanations why we obtained such results. First is what I shall denote as the factor of inertia or the habit of shoppers. The Main Market, to many local and non-local shoppers, is synonymous with Onitsha market, for which the center is known throughout West Africa. Coupled with its mall character, 
more shoppers may be attracted to it than to the relatively new and open markets in the periphery. The assumption is that this would translate into increased sales with the attending need to restock the shed or even to cater to the needs of customers. One of the results is the relative increase in the number of mean trips generated from the stall over and beyond those for similar stalls along the express road.

There is also the locational factor. The emphasis here is the location of distributors and urban institutions. The $\mathrm{CBD}$ is the original site of early European trading and distribution houses. The tradition has survived into the 20th Century so that a majority of distributors (who consume relatively large business spaces), including importers, are usually found closer to the $\mathrm{CBD}$ market. The arrival of new merchandise, for example, could trigger a number of successive trips to distributors and because of prorimity, stall traders could be expected to seek and maintain close (daily) contacts with these invaluable suppliers. Finally, it is reasonable to assume that the former could "run an errand" to these nearby shops to "check out merchandise," place orders, or just discuss business. It should be emphasized that these shops are located outside the geographically-defined markets. The combined effect of these is to increase the trip frequency of $C B D$ traders.

Another dimension of location relates to urban institutions, including churches, medical facilities and financial houses. These amenities are historically located closer to the CBD market because of early urban land use patterns. As a result, there is a high concentration of these activity centers within the CBD or to the north/northeast of it. Taking advantage of their closeness and forced by the need to attend to and fulfill pressing familial responsibilities in addition to business requirements during official business hours, the CBD trader (and hence CBD stalls) would tend to 
produce more trips than those along the express road. In other words, CBD traders appear to be faced with more intervening opportunities than peripheral traders. As a result, this appears to be a stronger trip generating factor than one would intuitively expect.

Finally, for those who select the bus and tari mode, the difference in street patterns and traffic systems in the CBD and peripheral markets is another factor. The Main Market is bounded by two local streets served by transit vehicles. The express road markets lack this quality, with the express road serving as the major transit street abutting those markets. During layover, operators also use the time to load passengers. At the CBD location, this occurs next to the market where the traffic speed is quite low. At the express road markets, not only are operators often harassed by the traffic police, there is no sheltered area for this operation. Moreover, to drop or pick up a passenger along the busy express road, where traffic speed is quite high, is not only unsafe but has to be completed quickly to maintain traffic flow. In addition, the traffic mir includes trailers, big buses and (14wheeler) goods trucks. So, while the waiting time at the express road markets may be shorter, it appears that actually boarding a vehicle may be a more difficult exercise at the express road markets which might affect the frequency, and hence, the mean trip rate of stalls. As a result, $\mathrm{CBD}$ traders are likely to utilize public transit services more of ten thereby contributing to current empirical results.

It is clear from the findings that using the mean average trip value per stall, it would mean that total trips produced in the three markets selected for study could increase from about 25,700 to 38,100 trips daily, should the number of stall occupants increase from two to three; or, there would be an increase of about $48.3 \%$ in total daily trips produced. These trips 
should not be expected to be confined within the markets' periphery because the questionnaire was developed to record only those trips whose destinations were outside the market to enable us understand the impact of those trips on the transportation system. As a result the rate of change in average stall size would determine how quickly the transportation system would be impacted. The results obtained from the two methods of scoring the size of a stall have provided an additional information to assist in interpretation of trip making and marketing activities by establishing the linear relationship between trips produced and the number of employees/occupants.

For planning purposes the results are instructive should planners strive to assist traders in maintaining an optimal stall operation, based on mean trips generated from the stall. The purpose will be to assist in minimizing investment in urban transportation infrastructure by monitoring the number of occupants in a stall and determining whether additional stalls ought to be provided in lieu of increasing the amount of investment in urban transportation facilities to service expected increases in system use. Whether planners would succeed in controlling the size of the stall is open for debate. Nevertheless, our knowledge about the eristence of this threshold could facilitate our effort to develop strategies aimed at evolving a meaningf ul balance between this class of users and the urban transportation system. For (West) African traders who substitute labor for capital, assuming capital is infused into the system (through some government program) and stalls grow larger a potential (in)direct effect is an increase in trip rates, ceteris paribus Assuming that the urban transportation system is not upgraded to absorb the impact of the change, there could be a further deterioration in the traffic system which could hurt business activities and impede further 
growth in the urban economy.

Earlier on we discussed the poor transportation system in Onitsha. One significant phenomenon is that it does not appear that those directly affected by the bad condition of the transportation system care enough to band together and seek redress or even openly complain and demand action from the government. In his Houston study of residents' propensity to contact the government and seek action about unacceptable municipal services, Mladenka (1977) shows that blacks are less likely to bother to contact the government. As I have argued elsewhere (Ochia,1984), segregation and discrimination (in the US) against blacks is a plausible explanation which denied those citizens the opportunity to acquire proper socialization to deal with such human needs. But because this is also occurring in Onitsha where one would strongly argue that the sins of segregation and discrimination are absent, the plausible explanation is the early apathy citizens developed against the government, which to the typical Nigerian, belonged to the white man (the colonialists). As a result people tended to perceive urban services and facilities as belonging to and fulfilling the needs of the foreigners. Any meaningful development and improvement are only those which occurred in the urban individual's place of origin. Apparently, it is taking quite a long time for urban residents to realize that they also have a stake in a good government and that they have an important role to play in demanding for and being provided with adequate urban services and facilities, regardless of who is producing and/or providing them.

Regarding our goal of providing some information to begin to fill the void in current literature about the travel behavior of traders, we have empirical evidence to show that traders do not spend the entire business day in the shed consum mating sales. They engage in intraurban trips which 
impact the transportation system. Westerners familiar with retail business practices might be surprised with the results since consumers, and not retailers, are expected to constitute trip makers in an urban retail environment. Therefore, planners should consider the travel behavior of traders in evolving urban transportation plans in order to formulate an intelligent and a comprehensive urban development plan, considering that traders constitute the major participants in the urban economy.

The findings also suggests a renewed emphasis on another area of study in urban transportation - non home-based trip behavior, especially in the developing areas. Often, researchers tend to emphasize home-based trips - a carry-over from studies with Western perspective which tend to emphasize similar areas of interest even though land use controls, urbanization levels, occupational characteristics and motorization levels may be quite dissimilar in the two areas. More important, the difference in the land use-transport dichotomy and transport characteristics in the developed and the developing have contributed to the diversity of non home-based trips in Onitsha. The diversity would mean that trips associated with non home-based activities would contribute to off-peak traffic in these areas to a level not quite understood or even considered relevant enough to attract the attention of researchers. It is anticipated that the results of this research would alert other researchers to the need for similar studies to assist in enhancing over all urban development in these areas.

Where stall occupants have available to them a personal means of transportation during business hours, such stalls tend to generate a greater number of trips than stalls without a means of personal transportation. Related to this is the disproportionate contribution of a third occupant of a stall to total trips generated. Both attributes tend to impact the 
transportation system intensively and to a degree, perhaps, astonishing to the average trader. The relevance is that traders interested in showing their business success by purchasing automobiles or their interest in assisting relatives by accepting them into the stall, for example, as apprentices, are unaware of the deleterious impacts these actions have on the transportation system. That such rational choices could cost the society additional investment in the upkeep of the urban transportation system, is a fact traders (in Onitsha or similar areas in West Africa), or for that matter, other small scale operators in other developing areas may not be willing to accept or contemplate paying for from their meager incomes. What this suggests is that there is a need to incorporate traders in the development and implementation of transport policy and programs which would provide a basis for educating traders about the impact of their behavior on the transport system. Eventually, this would facilitate an efficient delivery of urban transport services and programs.

The myth that older adults always lord it over the youth appears not to hold water when the consideration is focused on completing business contacts. For example, at the household level, the younger members would be expected to run a majority of household errands but in market operation, it appears there is a tight rein by older adults in this area. Because the older adults, as owners/co-owners, generate more trips than the younger members of the stall, the older adults still have the responsibility for the more difficult and money-related decisions for the stall. The tendency of older adults to dominate completion of these errands is because market deals require face-to-face contacts so that trust is continuously renewed. The goal is to ensure an efficient stall operation while utilizing the oppportunity, to the advantage of the head of the household, to balance 
familial with business financial needs.

Finally, a majority of goods sold by traders are not statistically significant attributes in stall trip-generation rates. In other words, even though the absolute number of trips due to attributes in this category may compare favorably with trip rates of other attributes studied, the suggestion is that the type of good sold in a stall may not be an important variable to consider, should planners engage in spatial distribution of operators to minimize their impact on the transportation system. Moreover, based on our findings that the CBD stalls, and not stalls located in the periphery location, generate a greater number of intraurban trips, perhaps, a more important factor would be whether to encourage central versus peripheral locations of urban activities. This would constitute a relevant urban development issue, especially as populations continue to grow at rapid rates in these areas. Despite the trends in the West, the central business district may not be declining in importance, rather, it may still remain a more attractive location, especially when motorization levels may continue to be low and the transit system poorly planned and operated to the disadvantage of peripheral locations. Any costs associated with occurrence of traffic congestion are discounted heavily by consumers who patronize traders whose increased sales in the CBD would prompt additional trips from the stalls.

Additionally, it seems the environment does not constrain the propensity of traders to engage in business trips. The implication is that, to our small-scale operators, it is obvious that no matter how severe intraurban travel constraints may appear, such constraints may actually be considered trivial since economic survival is at stake. This is particularly significant because in terms of Western business standards, a small business operator who faces similar environmental constraints would seek alternative means 
of movement or else significantly reduce their propensity to make trips (and revenues).

Overall, we may not have conclusive evidence for proposing a series of all-inclusive theories about the tripmaking behavior of urban market traders, but we do have empirical evidence, so far lacking in the literature, which suggests that stalls with a large number of occupants tend to produce more trips than stalls with fewer occupants. Moreover, it appears that in (West) African market conditions, the greater the number of occupants, the greater the propensity of a market stall to generate business trips.

Secondly, we now know that there is a statistically significant difference in trip production rates of stalls where a means of personal transportation is available and where none exist. Furthermore, stalls which have a greater number of a means of personal transportation available for completing business contacts tend to generate a greater number of trips in a typical business day than stalls with fewer number of means of personal transportation.

West African (urban) markets are typically dominated by women. In major (urban) markets in Onitsha, however, men tend to predominate. The survey data suggest that stalls exclusively occupied by males generate a greater number of trips than stalls occupied exclusively by females. We do not, however, have a large sample of stalls occupied by both males and females to permit us to make any statistically valid statement about that group.

Finally, the com modity sold in a stall tends not to exert any significant influence on the propensity of a stall to generate trips. We do know, however, that in general terms, stalls stocking either provision or hardware goods tend to lead the pack in daily trip production rates while stalls selling 
foodstuffs tend to be at the bottom of the pack. In conclusion, it is anticipated that the preceding information on urban traders, trading activities and trip making contribute to our knowledge on the travel behavior of urban market traders, hitherto lacking in the literature, at least, in Onitsha. 


\section{CHAPTER VI}

\section{TRANSPORT POLICY IMPLICATIONS}

In order to propose meaningful transport-related policy alternatives aimed at promoting an efficient market operation, we will focus mainly on the resulting values of the slope coefficients for each independent variable since they are the useful tools in identifying policy (Hanushek and Kain, 1972:136).

In their work for the World Bank examining urbanization trend in the less developed countries and policies for meaningful management, Beier. Churchill, et al (1976:373) write: "Overall, it seems reasonable to postulate that, starting with a low urban base, the growth rate for African cities will continue to be the highest in the world for several years." The same urban centers may, therefore, continue to be inefficient in absorbing the urban labor force into the wage economy. The implication is that increasingly, the informal sector will continue to dominate the urban economic scene. especially in the service sector. The World Bank experts (fn 409) find this trend consistent with a similar period (1870-1910) in the US urbanization process, when, approximately $50 \%$ of urban employment was in the service sector.

Elsewhere, we provided data confirming the importance of commerce in the tertiary sector. Given the level of poverty in these areas (Renaud,1979) and the small capital required to enter into trading, "The large urban markets (will continue to) have an important role in the 
economic and social organization of the (African) town and countryside, linking urban and rural consumers and ensuring that foodstuffs and craft products from one area are available for distribution in another," according to Peil and Sada (1984:253). This is confirmed in a recent study in which Rondinelli (1987) characterizes cities in the developing areas as "agricultural markets" for similar purposes. Moreover, it is not likely the modern (Western) super-market system may soon replace today's collective markets (Handwerker, 1979). As a result, the trip character of traders may not undergo any rapid changes in the near future. From the supply side, the methods for acquiring merchandise for sale may not alter, either (Simms and Dumar, 1976/77). There is no reason to believe the empirical data obtained from this study would not apply to traders well into the next Century (Lawson, 1971) to assist in providing relevant transportation services and facilities. The urban market trader in the developing areas is not an endangered species.

Based on the survey results, we have established that the sample statistics are no different from the population statistic at the $95 \%$ confidence level. Moreover, our sample produced responses from an equivalent of 513 traders which far exceeds the number suggested by Sheskin (1985:35) or by Dixon and Leach $(1978: 10)$ at the five per cent confidence interval. The cumulative effect of these is that policy statements applicable to the sample will also apply to the entire trader population (Norusis,1983).

We have determined that Onitsha is characterized by an intense, mixed land use, a transport system in which road users are not separated by traffic type and, a high traffic density with one mile of a poorly-maintained urban road system (see, for example, The World Bank, Road Deterioration in Developing Countries, June, 1988) serves about 8,750 urban residents. As a 
result, the relevant policy discussion should, in the opinion of this researcher, emphasize transportation systems management (cf:Brown West,1984) and, perhaps, a limited amount of new capital improvement projects. This alternative is preferred because a majority of traders depend either on walking, taxi or the bus mode (in that order) to complete intraurban trips associated with buying additional stock to resupply the shed, picking up or delivering goods or running personal/business errand. This population also prefers single purpose trips and about 70 per cent of stalls have no personal means of transport available for facilitating business contacts. The other reason for de-emphasizing new capital projects is that this is a built-up urban center whose existing infrastructure should be brought up to minimum engineering standards and properly maintained. These notwithstanding, it must be emphasized that as Hawkins' study in East Africa shows, there is a need for a change in the attitude of traders if sufficient improvements in market operations are expected from implementation of transport policies affecting the group (Hawkins, 1965:142143).

The number of vehicles available to the stall has been demonstrated empirically to be one of the most important variables affecting the number of trips generated from a stall. We learned from the mode choice analysis that a majority of traders, however, either walk, ride the taxi or take a bus. The emphasis, therefore, appears to point to the need to develop policies and programs which would encourage traders to use existing transport system conveniently and efficiently, but without explicitly encouraging additional use of a personal means of transportation. This is because stalls which have a personal means of transportation (30x) tend to generate a disproportionate amount (49\%) of urban business trips. This would suggest charging 
reasonable fees for parking in the $\mathrm{CBD}$ and increasing the parking fees in publicly-owned parking structures to begin to recover part of the cost of developing and implementing market-area parking policies and enforcing parking regulations.

An attempt should be made to assist pedestrians since $41 \%$ of all stallbased trips depend on the walking mode. On an average business day, this would translate into an equivalent of about 9,800 trips from all markets selected for study. An incremental approach, using each market as a focus, is not only recommended but desirable to emphasize each market's commercial and economic nodality. For a start, there is a need to institute a minimal road maintenance policy which could include providing adequate shoulders to encourage pedestrian movement. A discussion with the City Engineer for Onitsha revealed that currently the Ministry of Works does not build additional roads because no new residential areas are being developed. This is consistent with the national government policy (instituted since the 1981-85 development plan period) to re-emphasize maintenance. Given the present condition of urban roads, the Ministry obviously has a tremendous amount of backlog of unmaintained streets in order to match the policy statement with appropriate programs (see Barrett, 1988).

Finally, traders who sell provisions and hardware goods tend to engage in more trips (average $=3.3$ trips) than traders in other categories who average about 2.6 trips. We now have empirical evidence that a majority of stalls (42.7\%) in Onitsha markets produce trips associated with restocking the stall. Traders indicated that recent warket fires have intensified their fears of losing their merchandise in future fires. As an insurance policy against future losses, they tend to store goods away from the stall. This suggests that should adequate storage facilities be provided, 
preferably within the markets, together with proper security measures (OMATA currently provides security guards for its members for a fee), it would contribute to the reduction of the demand placed on the urban transport system and perhaps provide additional travel opportunities to consumers, thereby further strengthening the commercial importance of Onitsha in the Ibo country (and in Nigeria). To complement the preceding land use/transportation policy, attempts could be made at controlling the mean number of stall occupants, i.e., the stall size, (by increasing the number of rentable stalls and complemented by providing seed money to encourage new entrepreneurs to occupy those stalls) which would contribute to controlling total trips generated from a stall during a typical business day. After all, as Filani and Osayimewese (1979:20) observe, "the most important impact of transportation on the growth and pattern of a city results from the journeys which begin and end within it," and the preceding policy proposals are aimed at managing the cost of friction associated with completing those trips. 


\section{CHAPTER VII}

\section{FURTHER RESEARCH}

In order to suggest areas for additional research, we will first discuss the limitations of findings in current research and the transferability of the research results. The survey excluded stalls and traders scattered in residences, in small neighborhood markets, and along the commercial strips. Traders in big shops were also excluded mainly because they are typically more affluent than small-scale traders. Some skeptics may argue that the sampling frame was limited but in the opinion of this researcher, it does not appear that the travel behavior of economically-similar traders, irrespective of their spatial location, would differ any significantly from those of traders actually considered in the sampling frame. This would be true in Onitsha and applicable to other West African commercial urban centers. As a result, the survey findings could be relevant in understanding the travel behavior of stall traders in other centers of commerce in West Africa.

Another area for examination is the implication of the limited analyses of travel data on individual tripmakers. For example, we have not included detailed information on trip distance, hourly trip distribution or trip destination of individuals. In addition, we would have gained additional information assuming the trip purpose of individuals were broken into components under the category "to run errand." However, it was my conviction that the entire survey could have been hampered assuming traders were asked to divulge information about exact location of trip destination or what they actually did under the to-run-errand category. 
Even though the extraction of such information would further assist us in understanding the travel behavior of traders, the inherent conservatism of traders in the developing areas in volunteering what they consider personal information suggest that the absence of the foregoing information could limit the compatibility of our results with studies based on individual tripmakers.

Typically, by conducting trip studies at the individual level, relevant information on how far the trader travels from the trip origin, the time of travel, broken down by the hour of the day, and the exact trip destination would be evaluated. For urban market traders, the information would assist planners to further determine the spatial distribution of trips with reference to market locations, trip linkages, vis-a-vis other activity centers, and trip/time density. Eventually, we will begin to evaluate the relationship between trading activities and traffic congestion, and establish the nature of inter- and intra-trader relationships traders have with suppliers and other institutions. Therefore, additional studies would be needed to complement current results in our research to answer such questions.

We have indicated that females tend to dominate trading and markets in West Africa. However, in Onitsha, male traders tend to dominate because of historical factors outlined in Chapter II. The male dominance might have contributed to over all results of travel behavior of traders. Perhaps, Onitsha has evolved faster than other urban areas in West Africa or Onitsha could eventually reverse its course and resemble other commercial centers as more women enter the business. Whatever the case, the empirical results showing that males make more trips than females is consistent with the literature; therefore, our results could be relevant in other West African urban areas, irrespective of the gender of markeeters. The preceding analysis notwithstanding. Onitsha markets present 
characteristics found in other West African urban markets where traders sell different commodities in defined market zones, are typically small-scale, labor-intensive operators, and a majority have no mechanically-assisted means of personal transportation so that tripmakers must depend on walking, bus or the tari mode to complete business contacts. Furthermore, since our small-scale entrepreneurs rarely separate business from personal finance, it is the masters, and not the non-masters, who would make more complez trips. Such trips would relate to financial matters since it would provide an opportunity for making on-the-spot decisions on expenditures without necessarily jeopardizing the financial status of either the family or the business.

Now, turning to the need for further research, let me emphasize that additional variables could be identified and applied in studying trip production from market stalls. Using data from sales volumes and revenues, it could be relevant to assess which market location(s) reward entrepreneurs the most. Based on that it could be necessary to evaluate whether locations with heaviest sales volume (and income) also produce the greatest number of trips. This could provide some needed guidelines in assessing potential sites for future markets.

This research has analyzed trips at the stall level but a future study could address a similar problem at the individual trader's level to provide a balance in our understanding of tripmaking behavior. It could help us to further understand the interrelationship between markets/traders and other urban activity centers, and identify trip destinations, vis-a-vis traders' sourcing pattern of stall goods. I believe this would help us to understand what activities are conducted at trip destinations when traders indicate trip purpose as "to run errand." 
Women and men appear to occupy separate stalls. Women tend to produce fewer number of trips than men in a typical business day. At our current level of knowledge about tripmaking behavior of urban traders, we can only speculate about the implications of the phenomenon. We do not know whether there are any economic benefits from the arrangements or the effect on trip characteristics, assuming the sexes are fully integrated. A related area of further interest would be to study a large sample of stalls currently occupied by both sexes and to compare the results with those discussed in this study.

Finally, it might be relevant to evaluate factors which could induce traders to substitute for some business trips, in light of our knowledge about T3 studies in the West. We are not suggesting that researchers explore methods to induce traders to stay home and conduct business; rather, we are suggesting an investigation to uncover a body of knowledge which would enable us to intelligently evaluate how traders could engage in business operations assisted by modern telecommunication technology! including any effects on the interrelationship of traders with other traders, customers and suppliers, the dyadic relationships. 


\section{A SELECTED BIBLIOGRAPHY}

Abler, R., J. S. Adams and P. Gould. 1971. Spatial Organization. Prentice-Hall, Englewood Cliffs, N.J.

Achen, Christopher H. 1982. Interpreting and Using Regression Sage University Press, Beverly Hills.

Adeniji, Kunle. 1983. "Nigerian Municipal Bus Operations," Transportation Quarterly, 37, \#1, 135-143.

Ahonsi, Babatunde A. 1988. "Deliberate Falsification and Census data in Nigeria," African Affairs. 87, 553-562.

Ajaegbu, H. I. 1976. Urban and Rural Development in Nigeria. Heinemann, Edingburgh.

Allison, P. D. 1977. "Testing for Interaction in Multiple Regression," American lournal of Sociology 83, 144-153.

Anambra State of Nigeria. 1985. A Report on the Survey of Distributive Trades and Related Services. Ministry of Economic Development and Planning, Statistics Division, Enugu.

Anthonia, Q. B. O. and J. A. Akinwumi. 1971. "The Supply and Distribution of Smoked Fish in Ibadan Markets." The Nigerian Journal of Economic and Social Sciences, 14, 151-164.

Armstrong-Wright, Allan. 1986. Urban Transport Systems. Guidelines for Examining Options. Technical Paper \#52. The World Bank. Washington. D.C.

Ayeni, M. A. 0. 1975. "Some Determinants of the Propensity to Interact in an Urban System: A Case Study of Jos, Nigeria," The Nigerian Geographical lournal, 14.151-164.

Baker, P. T. 1965. "Marketing in Nigeria," Journal of Marketing.29, 40-48. 
Barrett, Richard. 1988. Urban Transport in West Africa. World Bank Technical Paper \#81, The World Bank, Washington, D.C.

Basden, G. T. 1966. Niger Ibos, Frank Cass and Co. Ltd. London.

Bauer, P. T. 1965. West African Trade. Routledge and Kegan Paul, Ltd.

Bier, G., Anthony Churchill, et al. 1971. "The Task ahead of the Cities in the Developing Countries," World Development. 4,363-409.

Beaujeu-Garnier, J and Annie Delobez. 1979. Geography of Marketing. Longman, Translated by S. H. Beaver.

Ben, C.,R. J. Bouchard and C. E. Sweet, Jr. 1965. "An Evaluation of Simplified Procedure for Determining Travel Patterns in a small Urban Area." Highway Research Record \#88.

Bentley, G. A., Alex Bruce and David R. Jones. "Intra-urban Journeys and Activity Linkages," Socio-Economic Planning Sciences 11, 213-220.

Beveridge, A. A., and Anthony Oberschall. 1979. African Business and Development in Zambia. Princeton University Press, Princeton.

Berry, B. J. L. 1963. Commercial Structures and Commercial Blight. Department of Geography, Research paper \#85. University of Chicago, Chicago. Illinois.

Berry, B. J. L. and Duane F. Marble, eds. 1968. Spatial Analysis:A Reader in Statistical Geography.Princetice-Hall, Englewood Cliffs.

Blalock, H. M. 1963. "Correlated Independent Variables: The Problem of Collinearity," Social Forces 42,233-236.

Blalock, H. M. Jr. 1979. Social Statistics, MoGraw Hill.

Bland, B. H. 1983. Land Use Patterns and Travel. TRRL, Crowthorne, Berkshire.

Bohannan, P and George Dalton, eds. 1962. Markets in Africa, Northwestern University Press. 
Breman,Jane. 1985. "A Dualistic Labour System? A Critique of the Informal Sector' Concept." In Ray Bromley. Planning for Small Enterorises in Third World Cities Pergamon Press, Exerter

Brindley, J. 1972. "Passenger Transport Demand in West Africa: Submarkets and their Spatial Structure," Economic Geography, 48, 258-283.

Bromley, R. J. 1971. "Markets in Developing Countries - A Review," Geography 56, 124-132.

Bromley, R. J. 1974. "The Organization of Quito's Urban Markets: Towards a Reinterpretation of Periodic Central Places," Transactions: The Institute of British Geographers, 62, 45-70.

Brog, Werner, et al. 1977. Psychological Determinants of User Behaviour. Economic Research Center, OECD, Paris.

Brog, Werner, Erhard Erl, et al. "Problems of Nonreported Trips in Surveys of Nonhome Activity Patterns," Transportation Research Record 891. TRB, Washington, D. C.

Brown-West, Orikaye G. 1984. "A Comparative Analysis of Traffic Management Performance in Developing Countries," Transportation Quarterly 38, $33,459-469$.

Brunso, Joanna M and David T. Hartgen. 1984. "An Update on HouseholdReported Trip Generation Rates," Transportation Research Record 987 TRB, Washington, D.C.

Bunge, W. 1962. "Towards a General Theory of Movement," in William Bunge, ed. Theoretical Geography. (lund Studies in Geography. Series C). CWK Gleerup, Lund, Sweden, Chapter 5.

Burnett, P. and Susan Hanson. 1982. "The Analysis of Travel as an Example of Complex Human Behavior in Spatially-Constrained Situations: Definition and Measurement Issues," Transportation Research. 16A,87-102.

Chalmer, Bruce J. 1987. Understanding Statistics, Marcel Dekker, Inc, N.Y.

Chang, Sen-Don. 1970. "Land Use and Intra-urban Travel in Tai-pei," Proceedings. Association of American Geographers, 2,40-45. 
Chapin, Stuart, Jr. and Edward J. Kaiser. 1979. Urban Land Use Planning. University of Illinois Press, Urbana, Chicago.

Chapin, Stuart F. Jr. 1968. "Activity Systems and Urban Structure," Journal of American Institute of Planners 34, 11-18.

Clark, W. A. V. and P. L. Hosking. 1986. Statistical Methods for Geographers, John Wiley and Sons, New York.

Connell, John and Richard Curtain. 1982. "The Political Economy of Urbanization in Melanesia," Singapore Journal of Tropical Geography $3, \# 2,119-136$.

Crowther, M. 1966. A Short History of Nigeria, Frederick and Praeger, N. Y.

Crowther, S. A. 1970. Journal of the Expedition up the Niger and Tshadda Rivers, Frank Cass and Co., Ltd. Reprint of Ist Edition, London, Seeley, Jackson and Holliday, 1855.

Dannhaeuser, N. 1977. "Distribution and Structure of Retail Trade in a Philippine Commercial-Setting," Economic Development and Cultural Change, 25, 471-503.

Daniels, P. W. and A. M. Warnes. 1980. Movement in Cities,Metheun, N. Y.

Davis, W. G. 1973. Social Relations in a Philippine Market. University of California Press.

Diandas, J. 1984. "Alternative Approaches to Transport in Third World Cities: Issues in Equity and Accessibility," Ekistics. 306, 197-210.

Dike, Azuka A. 1982. "Urban Migrants and Rural Development," African Studies Review. XXV. 85-94.

Dixon C. and B. Leach. 1978. Sampling Methods for Geographical Research. CATMOG \#17, Geo Abstracts, Norwich.

Dixon, C and B. Leach. 1984. Survey Research in Underdeveloped Countries. CATMOG \#39, Geo Abstracts, Norwich.

Dunphy, R. T. 1979. "Workplace Interviews as an Effective Source of Travel Surveys," Highway Research Record \#701. TRB, Washington, D. C. 
Eades, J. S. 1985. "If You Can't Beat 'em, Join 'em: State Regulation of Small Enterprises," In. Ray Bromley, op cit.

Ebdon, David. 1977. Statistics in Geography Basil Blackwell, Oxford.

Etim, B. A. and F. N. Erontimi. 1976. "Personal Income Distribution in Nigeria," In, Poverty In Nigeria. Proceedings, 1975 Annual Conference, Nigerian Economic Society, University Press, Ibadan, 295-312.

Fajana, 0. 1976. "The Distribution of Personal Income in Nigeria," In, Poverty In Nigeria, ibid, 277-294.

Federal Republic of Nigeria. 1957. Handbook of Commerce and Industry in Nigeria. Department of Commerce and Industry, Lagos, Nigeria.

Ferguson, R. 1977. Linear Regression in Geography, CATMOG \#15, Geo Abstracts, Norwich.

Filani, M. O. and Iz Osayimwese. 1970. "Intra-city Traffic Flow and Problems in Nigeria:The Case of Ibadan Metropolitan Area," The Nigerian Geographical Journal. 22, 17-31.

Floyd, B. 1969. Eastern Nigeria. Praeger Publishers.

Forrest, J. 1977. "Business Trip Activity Patterns" New Zealand Geographer. 33. 50-59.

G \& G International (Nig) Ltd and Intergroup Architects. 1979. Onitsha Master Plan. Vol. 2. Survey Data for Ministry of Economic Development, Anambra State of Nigeria, Enugu, Nigeria.

Garlick, P. C. 1971. African Traders and Economic Development in Ghana. Clarendon Press.

Gelman, David and Mary Hager. 1988. "Body and Soul," Newsweek, November 7.

Gihring, Thomas. 1984. "Intraurban Activity Patterns Among Entrepreneurs in a West African Setting," Geografiska Annaler. 66B, 17-27.

Gihring, T.A. 1982. "Accessibility Choice and Opportunities in Zaria, Nigeria," Third World Planning Review 4, 387-379. 
Hammond K. and McCullagh. 1974. Quantitative Techniques in Geography Clarendon Press, Oxford.

Hanna W. J. and J. L. Hanna. 1977. Urban Dynamics in Black Africa. AldineAtherton, N. Y.

Handwerker, W. P. 1979. "Daily Markets and Urban Economic Development," Human Organization. 38, 366-376.

Hanushek, Eric, A. and John F. Kain. 1972. "On the Value of Equality of Educational Opportunity as a Guide to Public Policy," In: Frederick Mosteller and Daniel P. Moynihan, eds. On Equality of Educational Qpoortunity Random House, N. Y., 230-342.

Hassall, B. B. 1974. "Pedestrian Traffic Generated by Retail Stores," Traffic Engineering and Control. 15, 566-570.

Hawkins, H. C. G. 1965. Wholesale and Retail Trade in Tanganyika. Frederick A. Praeger.

Hay, A. M. 1969. "The Importance of Passenger Transport in Nigeria," In: B. S. Boyle, ed. Transport and Development. MacMillan, 125-138.

Helmore, Kristine. 1987. "Children in Darkness: The Exploitation of Innocence. Child Labor Usage Still Widespread Scourge of World," The Oregenian. August 3.

Henderson, R. N. 1971. "Generalized Cultures and Evolutionary Adaptability," in: H. Wolpe, Nigeria Modernization and the Politics of Communalism. Ann Arbor.

Hertz, R. 1982. "The Influence of Environmental Factors on Daily Behavior," Environment and Planning A. 14, 1175-1193.

Highway Research Board. 1971. Urban Commodity Flow, Special Report \#120. Washington, D. C.

Hill, Polly. 1966. "Notes on Traditional Market Authority and Market Periodicity in West Africa," Journal of African History, vii, 295-311.

Hill, Polly. 1970. Studies in Rural Capitalism in West Africa Cambridge at the University Press. 
Hodder , B. W. and UkwU I. Ukwu. 1969. Markets in West Africa Ibadan University Press.

Hodder, B. W. and Roger Lee. 1974. Economic Geography St Martins Press.

Hoorn. Toon ver Der. 1979. "Travel Bahaviour and the Total Activity Pattern," Transportation. 8, 309-328.

Hope, K. R. 1983. "Some Problems of Administering Development in Developing Nations," The Indian Journal of Public Administration, 9, 110.

Hunter, G. 1962. New Societies of Tropical Africa Oxford University Press.

Hurst, M. E. 1970. "An Approach to the Study of non-residential Land Use Traffic Generation," Annals. Association of American Geographers. 2, 40-45.

Isichei, E. 1976. A History of the Igbo People St Martins Press.

Iversen, $G$ and Helmut Norpoth. 1982. Analysis of Variance, Sage Publications, Beverly Hills, CA.

Kalton, G. 1984. Introduction to Survey Sampling, Sage Publications \#35, Beverly Hills, CA.

Kansky, K. J. 1967. "Travel Patterns of Urban Residents," Transportation Science, 1,261-285.

Katzin, M. 1964. "The Role of the Small Entrepreneur," In: Melville J. Herskovits and Mitchell Harwitz, eds. Economic Transition in Africa. Routledge and Kegan Paul, Lid, London, 179-198.

Kellerman, A. 1981. "Retail Ribbon Development in the Industrial area of Haifa, Israel," Geoforum, 12, 371-375.

Kilby, P. 1969. Industralisation in an Open Economy: Nigeria 1945-1966. Cambridge at the University Press.

Koenigsberger, H. O., et al. 1970. Infrastructure Problems of the Cities of Developing Countries, The Ford Foundation, Washington, D. C. 
Kollo, Hanna P. H. and Charles L. Purvis. 1984. "Changes in Regional Travel Characteristics in the San Francisco Bay Area: 1960-1981," Transportportation Research Record \#987 TRB, Washington, D. C.

Kumar, Krishma T. 1975. "Multicollinearity in Regression Analysis," The Review of Economics and Statistics, LVII, \#3, 365-366.

Lamberton, D. M. and T D. Mandeville. 1982. "Substitution of Communication for Transportation," Singapore Journal of Tropical Geography 3. \#2, 162-1669.

Lawson, R. M. 1971. "The Supply Response of Retail Trading Services to Urban Population Growth in Ghana," In: Claude Meillassoux, ed. The Development of Indigenous Trade and Markets in West Africa. Oxford University Press, 377-396.

Lee, J. M. 1967. Colonial Develooment and Good Government: A Study of the Ideas Expressed by the British Classes in Planning Decolonisation. 1934-1964, Oxford, Clarendon Press.

Lemieux, P. H. 1978. "Note on the Detection of Multicollinearity," American Journal of Political Science, 22, 183-186.

Levison, Hebert S. 1978. "Characteristics of Urban Transportation Demand: A New Data Bank," Iransportation Research Record \#673, TRB, Washington. D.C.

Lewis-Beck, M. 1975. Apolied Regression, Sage Publications, Beverly Hills, Ca.

Linn, J. F. 1983. Cities in the Developing Areas. The World Bank, Oxford University Press.

Locklin, D. P. 1959. "Discussion: Transport and Economic Development," The American Economic Review, May, 198-200.

Lowder, Stella. 1986. The Geography of Third World Cities. Barnes and Noble Books, N.J.

Mabogunje, A. L. 1968. Urbanization in Nigeria. University of London Press.

Maltby, D. "Traffic at Manufacturing Plants," Traffic Engineering and Control. 12.72-77. 
Mathur, Vijay K. 1970. "An Economic Derivation of the 'Gravity Law' of Spatial Interaction: A Comment," Journal of Regional Science. 10, \#3, 403-405.

Marble, D.F. 1959. "Transport inputs at urban Residential Sites," Papers and Proceedings. Regional Science Association 5, 253-266.

Marble, D. F. 1967. "A Theoretical Explanation of Individual Travel Behavior," In: W. L. Garrison and D. F. Marble, eds. Quantitative Geography. Part I. Northwestern University, Evanston, Illinois.

Maunder, D. A. C. 1984. Trip Rates and Travel Patterns in Delhi. India. Transport and Road Research Laboratory, Research Report \#1, Crowthorne, Berkshire.

Mazumdar, D. 1976. "The Urban Informal Sector," World Develorment 4, 655-679.

Mathews, John A. 1981. Quantitative and Statistical Approaches in Geography Pergamon Press.

McNulty, M. L. 1970. "African Urban Centers and Markets," African Urban Notes, 5. 58-63.

Meyburg, Arnin, $\mathrm{H}$ and Werner Brog. 1981. "Validity Problems in Empirical Analysis of non home-activity Patterns," Iransportation Research Record 807 TRB, Washington, D. C.

Meyer, J. R. and Jose A. Gomez-Ibanez. 1981. Autos. Transit and Cities. Harvard University Press.

Mera, K. 1970. A Framework for Urban Transport Studies. The World Bank, WP \#73. Washington, D. C.

Mertz, William L. 1957. "A Study of Factors Related to Urban Travel," Public Roads, 29, \#7, 170-174.

Miller, C.E. 1980. "Telecommunication/Transportation Substitution: Some Empirical Findings," Socio-economic Planning Science 14, 163-166.

Mitchell, Robert B. and Chester Rapkin. 1954. Urban Traffic: A Function of Land Use, Columbia University Press, N.Y. 
Mladenka, K.R. 1977. "Citizen Demand and Bureaucratic Response. Direct Dialing Democracy in a Major American City," Urban Affairs Quarterly, $12,273-274$

Moser, C. Q. N. 1980. "Why the Poor Remain Poor, the Experience of Bogota Market Traders in the 1970's," Journal of Inter American Studies and World Affairs, 23, 365-387.

Muller, Maria S. 1982. "The Self-Employed in Kitale: No Easy Way to Success," African Urban Studies 12, 1-15.

Muller, Peter 0. 1976. "Social Transportation Geography," Progress in Geography, 8, 208-231.

Mushtaq, M. 1968. "The Pattern of Retail and Wholesale Trade in Lahore," Pakistan Geographical Review, 23, 37-53.

Nelson, Arthur, C. 1984. Evaluatine Urban Containment Programs Unpublished Ph.D. Dissertation, Center for Urban Studies, Portland State University, Portland, Oregon.

Nie, N. H., C. H. Hull, et al. 1975. Statistical Packages for Social Sciences. McGraw Hill.

Niedercorn, J. H. and B. V. Bechdolt. Jr. 1970. "An Economic Derivation of the 'Gravity Law' of Spatial Interaction: A Reply," Journal of Regional Science, 10, \#3, 407-410.

Nkambwe, Musisi. 1986. "Urban Transportation," In: Toyin Falola and S. A. Olarenwaju, Transport Systems in Nigeria Maxwell School of Citizenship and Public Affairs, Syracuse University.

Norusis, Marija, J. 1983. Introductory Statistical Guide: SPSSX. McGraw Hill.

Nysteun, J. D. 1967. "A Theory and Simulation of Intra-Urban Travel," In: W. L. Garrison, op cit.

Nzekwu, 0. 1967. "West Africa's Largest Market, Onitsha," Nigeria Magazine. \#65, 132-147.

Obadofin, Juwon and Bola Olowu. 1989. "The Wheels of Fortune," West Africa January 30 -February 5. 
O'Connor, A. 1983. The African City Africana Publishing Co., N.Y.

Ochia, Krys. 1984. "The Urban Environment and the Problem of Municipal Services in Nigeria: A Case Study of Onitsha," ARDHI: Journal of Land Development.3.66-76.

Ogunsanya, A. A. 1982. "Spatial Pattern of Urban Freight Transportation in Lagos Metropolis," Transportation Research, 16A, 289-300.

Ogunsanya, A. A. 1985. "Generating Urban Traffic Flow Data for Urban Transport Studies in Developing Countries: An Approach," Geoforum. $16,403-412$.

O'Hagan, John and Brendan McCabe. 1975. "Tests for the Severity of Multicollinearity in Regression Analysis," The Review of Economics and Statistics, Lvii, \#3, 368-370.

Okoye, T. 0. 1981. "The Structure of the Central Business District of Enugu," In: P. O. Sada and J. S. Oguntoyinbo, eds. Urbanization Process and Problems in Nigeria Ibadan University Press.

Okpala, D. C. I. 1981. "Car Ownership Attitudes to Mass Transit Use: A Nigerian Pilot Study," Geoforum. 12, 59-69.

Olak anpo, 0. n.d. A Preliminary Report on the Indigenous Enterprises in Distributive Trades in Nigeria NISER, Ibadan.

Olarenwaju, S. A. 1986. "Transportation in Nigeria's Economic Setting," In: Toyin Falola and S. A. Olarenwaju, op cit.

Olayemi, O. A. 1977. "Intra-City Travel in Metropolitan Lagos: A Study of Commuting in the Fast-Growing Capital in a Developing Country," Geoforum. 8, 19-27.

Olayemi, O. A. 1980, "Urban Roads in West Africa: Case Study of lle-lfe, Nigeria," Iraffic Quarterly 34, 129-142.

Onokerhoraye, A. 1977. "Urban Land Use in Nigeria: Problems and Implications for Policy," Town Planning Review 48, 59-72.

Onyemelukwe, J. O. C. 1970. "Aspects of Staple Food Trade in Onitsha Market," The Nigerian Geographical lournal, 13, 121-138. 
Onyemelukwe, J. O. C. 1974. "Factors in the Growth of West African Market Towns: The Example of Pre-Civil War Onitsha," Urban Studies. 11, 47-59.

Onyemelukwe, J. O. C. 1982. "Urban Population," In: K. M. Barbour, J. S. Oguntoyinbo, et al. eds. Nigeria in Maps. Hodder and Stoughton. London.

Ou, Fong-Lieh and Jason C. Yu. 1982. "Effects of Urban Character on Transferability of Travel Demand Models," Transportation Research Record 874. TRB, Washington, D. C.

Owen, W. 1959. "Transport and Economic Development," The American Economic Review, May, 179-187.

Owen, W. 1973. Automobile and Cities - Strategies for Developins Countries, The World Bank, WP $\# 162$, Washington, D. C.

Oyebanji, J. O. 1984. "Road Traffic Accidents and Wastage of Human Resources in Nigeria," Ekistics. 51, 242-250.

Pedler, F. J. 1955. Economic Geography of West Africa Longman.

Peil, Margaret and Pius 0. Sada. 1984. African Urban Society, John Wiley and Sons, Chichester.

Plumb, A.J. and P.G. Hill. 1981. Transport Policies in Sri Lanka and Some Consequences. TRRL, Crowthorne, Berkshire.

Poole, Michael A and Patrick N. Farrell. 1971. "The Assumptions of the Linear Regression Model," The Institute of British Geographers. Transactions. \#52, 141-158.

Prashker, John N. 1979. "Direct Analysis of the Perceived Importance of Attributes of Reliability of Travel Modes in Urban Travel," Transportation, 8, 329-346.

Reed, $M$ and Stanley C Hollander, eds. 1968. Markets and Marketing in Developing Economies, Richard D. Irwin, Homewood, Illinois.

Roberston. Clair. 1974. "Economic Women in Africa. Profit-making Techniques of Accra Market Women, Journal of Modern African Studies, 12, 657-664. 
Rondinelli. D. A. 1983. Development Projects as Policy Experiments. Methueun, N. Y.

Ross, C. G. 1982. "A Village level Study of Producer Grain Transactions in Rural Senegal," African Studies Review, 4, 65-84.

Sada, P. O. and M. L. McNulty. 1981. "The Market Traders in the City of Lagos," In: P. O. Sada and J. S. Oguntoyinbo, eds. Urbanization Processes and Problems in Nigeria. Ibadan University.

Salomon, Ilan. 1986. "Telecommunication and Travel Relationships: A Review," Transportation Research-A, 20A, 3, 223-238.

Salomon, Ilan and Joseph L Schofer. 1988. "Forecasting TelecommunicationsTravel Interactions:The Transportation Manager's Perspective," Transportation Research 22A, 3, 219-229.

Sarkar, J. 1980. "Letter from Calcutta," Far East Economic Review, 109, 92.

Savas, E.S. 1979. "How much do Government Services really Cost?" Urban Affairs Quarterly, 15, September.

Schaffer, Bernard and Huang Wen-Hsien. 1985. "Distribution and the Theory of Access." In Ray Bromley, op cit

Schwimmer, Brian. 1979. "Market Structure and Social Organization in a Ghananian Marketing System, American Ethnologist. 6, 682-701.

Sethurman, S. V. 1977. "The Urban Informal Sector in Africa," International Labour Review, 116, 343-352.

Sethurman, S.V. (ed.) 1981. The Urban Informal Sector in Developing Countries:Employment. Poverty and Environment, ILO, Geneva

Sheskin, Ira M. 1985. Survey Research for Geographers, Resources Publications in Geography.

Shuldiner, Paul W. 1965. Non-residential Trio Generation Analysis, Northwestern University, Department of Civil Engineering and Transportation Center, N.Y. 
Siddal, W. 1961. "Wholesale-retail Trader Ratios as Indices of Urban Centrality," Economic Geography. 37, 124-132.

Silberman, Leo. 1950. "Social Survey of the Old Town of Mombasa," Journal of African Administration 11, 14-21.

Silk, J. 1979. Statistiçi Concepts in Geography George Allen and Unwin, London.

Simmons, J. 1964. The Changing Patterns of Retail Location. Department of Geography Research Paper \#92. University of Chicago, Illinois.

Simms, Ruth and E. Dumar. 1976/77. "Women in the Urban Economy of Ghana. Associational Activity and the Enclave Economy," African Urban Notes 2, 43-64.

Sklar, R. L. 1963. Nigerian Political Parties: Power in an Emergent African Nation. Princeton University Press.

Smith, Marshall S. 1972. "Equality of Educational Opportunity: The Finding Reconsidered," In: Frederick Mosteller and Daniel P. Moynihan, eds. op cit: $230-342$.

Smith, R. H. T. 1970. "Concepts and Methods in Commodity Flow Analysis," Economic Analysis. 46, 404-416.

Smith, W. S. and Nai-Keong, et al. 1981. "Solving Urban Transportation Problems in Asia," Traffic Quarterly, XXXV, 216-247.

Sonenblum, S., et al. 1977. How Cities Provide Services, Ballinger Publishing Co., Cambridge-Mass.

Spielberg, Frank, Edward Weiner and Ulrich Ernst. 1981. "The Shape of the 1980s: Demography, Economic, and Travel Characteristics," Transportation Research Record. \#807 TRB, Washington, D.C.

Starkie, D. N. M. 1967. "Business Premises Traffic -Generation Studies," Lournal of the Town Planning Institute, 53, 232-234. 
Starkie, D. N. M. 1967. Traffic and Industry: A Study of Traffic Generation and Spatial Interaction. London School of Economics and Political Science, Geographical Paper \#3, Wembly, Midds

Stolper, Wolfang, F. 1966. Planning Without Facts, Harvard University Press, Mass.

Stouffer, S. A. 1940. "Intervening Opportunities: A Theory of Relating Mobility and Distance," American Sociological Review, 5. 845-867.

Stopher, Peter, R., Eric C Ohstrom, et al. 1984. "Logit Mode Choice Models for Non-Work Trips," Transportation Research Record 987 TRB, Washington, D. C.

Stopher, Peter R and Ira M. Sheskin. 1982. "Towards Improved Collection of 24-H Travel Records," Highway Research Record 891. TRB, Washington, D. C.

Stopher Peter R and A. H. Meyburg. 1979. Survey Sampling and Multivariate Analysis for Social Scientists and Engineers Lexington.

Stowers, J. R. and Edmond L. Kanwit. 1965. "The Use of Behavioral Surveys in Forecasting Transportation Requirements," Highway Research Record \#106.TRB, Washington, D. C.

Stuart A. 1964. Basic Ideas of Scientific Sampling, Charles Griffin and Co. Ltd, London.

Supernak, Janusz. 1984. "Travel Regularities and their Interpretations:A Discussion Paper," Highway Research Record 987 TRB, Washington, D.C.

Taaffee, E. J., R. L. Morrill, et al. 1972. "Transportation Expansion in UnderDeveloped Countries," In: B. S. Boyle, ed. Transport and Development. MacMillan, London.

Tait, D. 1961. The Kokomba of Northern Ghana Oxford.

Temple, P. 1969. "The Urban Markets of Greater Kampala," TESG, Journal of Social and Economic Geography LX, 346-359. 
Tessler, M. A., William M O'Barr and David H Spain, eds. 1973. Survey Research in Africa: Its Applications and Limits Northwestern University Press, Evanston, Illinois.

The United Nations. 1981. Youth. Tradition and Development in Africa. Regional Meetins on Youth in Africa Nairobi, Kenya, 17-22 December, 1979, UNESCO Press, Paris.

The United Nations. 1973. Urban Land Policies and Land Use Control Measures. Vol. 1. Africa. ST/ECA/167, N. Y.

Thomas, S. 1983. The Value of Time Savings in West Malaysia: Car. Bus and Taxi Occupants.TRRL, Crowthorne, Berkshire.

Thomas, Theodore. 1985. "Reorienting Bureaucratic Performance. A Social Learning Approach to Development Action." In Jean-Claude Garcia, ed., Public Participation in Development Planning and Management. West View Press, Colorado.

Thompson, Michael J. 1983. Toward Better Urban Transport Planning in Developins Countries. World Bank WP \#600, The World Bank, Washington, D. C.

Todd D., A. Mulenga and C. Mupimpila. 1979. "Market Vendors in Lusaka, Zambia," African Urban Studies 5, 45-70.

Trager, Lillian. 1976/77. "Market Women in the Urban Economy: The Role of Yoruba Intermediaries in a Medium-Sized City," African Urban Notes. 2. $1-11$.

Uchendu. Victor C. 1965. The Jgbe of Southeast Nigeria, Holt, Rinehart and Winston, N. Y.

Udo, R. K. 1970. Geographical Regions of Nizeria University of California Press.

Ullman, E. L. 1956. "The Role of Transportation and the Bases for Interaction," In: W. L. Thomas, Jr. ed. Man's Role in Changing the Face of the Barth. Univer sity of Chicago Press, Chicago, Illinois. 
Vagale, L. R. 1972. Anatomy of Traditional Markets in Nigeria. Focus on Ibadan. The Polytechnic. Ibadan.

Vickerman, R. 1972. "The Demand for Non-Work Travel," Journal of Transport Economics and Policy, VI, 176-210.

Walters. A. A. 1979. Costs and Scale of Bus Service, World Bank WP $\# 325$, The World Bank, Washington, D. C.

Wichers, C. R. 1975. "Detection of Multicollinearity: A Comment," Review of Economics and Statistics, 57. 366-368.

Wilms, G. J. and C. S. I. J. Lagerberg. 1974. Profile of Commercial Town in West Cameroons. Tilburg University Press, The Netherlands.

Wheeler, J. 0. 1969. "Some Effects of Occupational Status on Work Trips," Journal of Regional Science 9, 69-77.

Wilson, G. W. 1972. "Towards a Theory of Transport and Development," In: B. S. Boyle, op cit: Chapter 12.

Wing, Ho Chi and Sim Loo Lee. 1980. "The Characteristics and Locational Patterns of Wholesale Service Trades in the Central area of Singapore," Singapore Journal of Tropical Geography 1, 21-36.

Wigglesworth, E. F. and D. Brotan. 1966. "Retailing Trends in Thailand," Journal of Retailing, Summer, 41-51.

Wiseman, Robert F. 1975. "Location in the City as a Factor in Tripmaking Patterns, TESG. Journal of Economic and Social Geography LXVI, 3. 167-177

Wolpe, H. 1974. Urban Politics in Nigeria University of California Press.

Weisman, M. 1972. "Variables Influencing Transit Use," Iraffic Quarterly 35. $371-383$.

Werlin, Herbert H. 1984. "Urban Transportation Systems in the Developing World," Ekistics. 306, 192-196.

White, E. F. 1981. "Creole Women Traders in the Nineteenth Century." The International Journal of African Historical Studies. 14, 626-642. 
Wohl, M. 1970. "Users of Urban Transportation Services and their Income," Traffic Quarterly 24, 21-43.

Wong. S. T. 1969. "Multivariate Analysis of Urban Travel Behavior in Chicago," Transportation Research. 3, 345-363.

World Bank. 1975. Urban Transport Sector Policy Paper. Washington, D. C.

World Bank. 1986. Urban Transoortation: A World Bank Policy Study Washington, D.C.

Yusuf, A. B. 1975. "Capital Formation and Management among the Moslem Hausa Traders of Kano, Nigeria, Africa 45, 167-182.

Zahavi, Y. 1976. Travel Characteristics in Cities of Developing and Developed Countries.The World Bank WP \#230. The World Bank, Washington, D. C. 


\section{APPENDIX A}

SUMMARY OF ST ALL DATA AND RELATED FREQUENCIES 


\section{SAMPLE DATA}

\begin{tabular}{|c|c|}
\hline Observation & Sample Size \\
\hline \multicolumn{2}{|l|}{ Location } \\
\hline $\mathrm{CBD}$ & 83 \\
\hline \multirow[t]{2}{*}{ Express Road } & 163 \\
\hline & $n=246$ \\
\hline \multicolumn{2}{|l|}{ Type of Good Sold } \\
\hline Foodstuffs & 50 \\
\hline Hardware & 51 \\
\hline Readymade & 49 \\
\hline Textiles & 43 \\
\hline \multirow[t]{2}{*}{ Provisions } & 53 \\
\hline & $n=246$ \\
\hline \multicolumn{2}{|l|}{ Gender } \\
\hline Males & 144 \\
\hline Females & 76 \\
\hline \multirow[t]{2}{*}{ Males \& Females } & 26 \\
\hline & $n=246$ \\
\hline
\end{tabular}




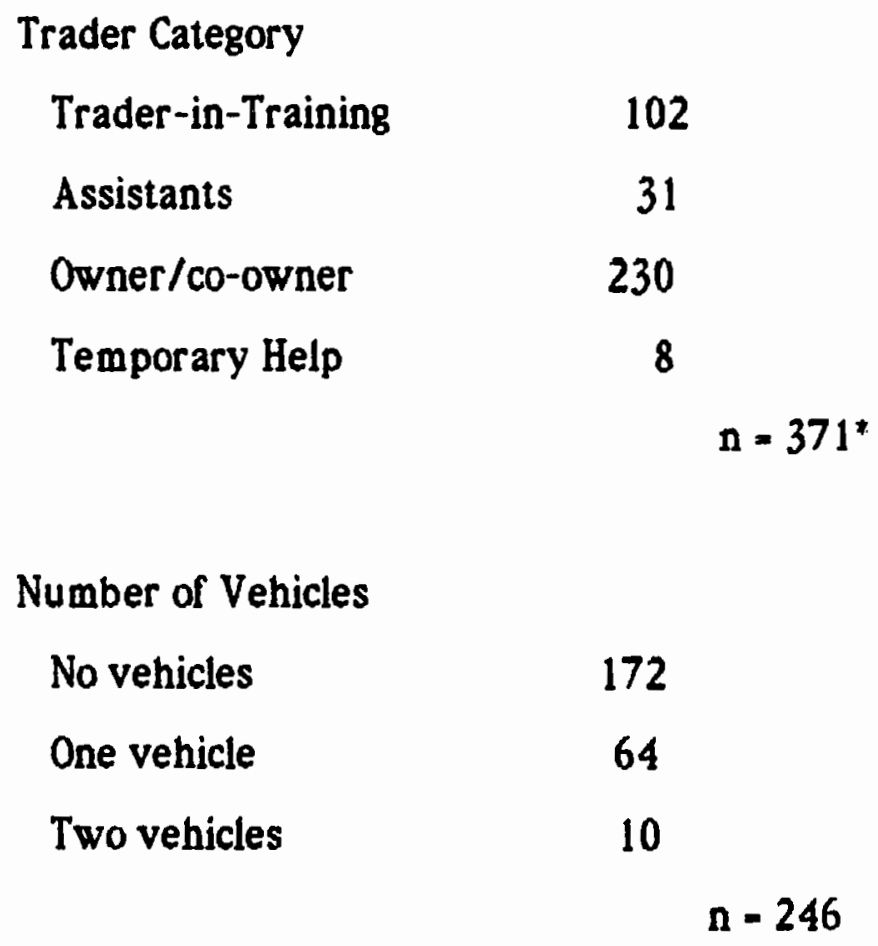

Trip Purpose

Pickup/deliver goods 55

Bank/post office 25

Eat meal 35

Government office 4

Travel-out-of-town 26

Pay/collect debt $\quad 18$

Run errand 55

$\begin{array}{ll}\text { Socialize } & 67\end{array}$

$n-285^{*}$ 


$\begin{array}{lr}\text { Mode Choice } & \\ \text { Walking } & 101 \\ \text { Bus } & 47 \\ \text { Taxi } & 69 \\ \text { Motorcycle } & 19 \\ \text { Van/truck } & 5 \\ \text { Autodriver alone } & 27 \\ \text { Autopassenger } & 8 \\ \text { Autodriver with passenger } & 7\end{array}$

$$
\mathrm{n}=283^{*}
$$

Adequate Number of sheds

Less than two

Two or three

Four and over
151

75

20

$$
\mathrm{n}=\mathbf{2 4 6}
$$

\section{Years in business}

$\begin{array}{cc}\text { Under } 5 & 186 \\ 5-9 & 104 \\ 10-14 & 67 \\ 15-19 & 62 \\ 20^{*} & 94 \\ & \quad n=513^{* *}\end{array}$


Age

$15 \&$ under $\quad 54$

$16-30 \quad 252$

$31-40 \quad 98$

$41^{+} \quad 109$

$\mathrm{n}-513^{* *}$

* Total is greater than 246 (stalls) because some stalls reported multiple responses.

** Based on total number of employees in the stall. 


\section{FREQUENCIES}

$\begin{array}{lrrc}\text { LOCATION } & & & \\ \text { Value Label } & \text { Frequency } & \text { Percent } & \text { Cumulative \% } \\ \text { CBD } & 83 & 33.7 & 33.7 \\ \text { Express Road } & 163 & 66.3 & 100.0 \\ \text { Total } & 246 & 100.0 & \end{array}$

TYPE OF GOOD SOLD

$\begin{array}{lcrc}\text { Value Label } & \text { Frequency } & \text { Percent } & \text { Cumulative \% } \\ \text { Foodstuffs } & 50 & 20.3 & 20.3 \\ \text { Hardware } & 51 & 20.7 & 41.1 \\ \text { Readymade } & 49 & 19.9 & 61.0 \\ \text { Textiles } & 43 & 17.5 & 78.5 \\ \text { Provisions } & 53 & 21.5 & 100.0 \\ \quad \text { Total } & 246 & 100.0 & \end{array}$


NUMBER OF MALES

$\begin{array}{ccrc}\text { Value } & \text { Frequency } & \text { Percent } & \text { Cumulative } \times \\ 0 & 72 & 29.3 & 29.3 \\ 1 & 61 & 24.8 & 54.1 \\ 2 & 56 & 22.8 & 76.8 \\ 3 & 32 & 13.0 & 89.8 \\ 4 & 18 & 7.3 & 97.2 \\ 5 & 5 & 2.0 & 99.2 \\ 6 & 1 & 0.4 & 99.4 \\ 7 & 1 & 0.4 & 100.0 \\ \text { Total } & 246 & 100.0 & \end{array}$

NUMBER OF FEMALES

$\begin{array}{cccc}\text { Value } & \text { Frequency } & \text { Percent } & \text { Cumulative \% } \\ 0 & 147 & 59.8 & 59.8 \\ 1 & 80 & 32.5 & 92.3 \\ 2 & 13 & 5.3 & 97.6 \\ 3 & 2 & 0.8 & 98.4 \\ 4 & 1 & 0.4 & 98.8 \\ 5 & 2 & 0.8 & 99.8 \\ 6 & 1 & 0.4 & 100.0 \\ \text { Total } & 246 & 100.0 & \end{array}$


TRADER CATEGORY

Trader-in-Training

$\begin{array}{crrc}\text { Value } & \text { Frequency } & \text { Percent } & \text { Cumulative \% } \\ 0 & 144 & 58.5 & 58.5 \\ 1 & 45 & 18.3 & 76.8 \\ 2 & 36 & 14.6 & 91.5 \\ 3 & 16 & 6.5 & 98.0 \\ 4 & 4 & 1.6 & 99.6 \\ 5 & 1 & 0.4 & 100.0 \\ \text { Total } & 246 & 100.0 & \end{array}$

Assistant

$\begin{array}{lrrr}\text { Value } & \text { Frequency } & \text { Percent } & \text { Cumulative } \% \\ 0 & 215 & 87.4 & 87.4 \\ 1 & 24 & 9.8 & 97.2 \\ 2 & 6 & 2.4 & 99.6 \\ 3 & 1 & 0.4 & 100.0 \\ \quad \text { Total } & 246 & 100.0 & \end{array}$


Owner/Co-owner

$\begin{array}{cccc}\text { Value } & \text { Frequency } & \text { Percent } & \text { Cumulative * } \\ 0 & 16 & 6.5 & 6.5 \\ 1 & 196 & 79.7 & 86.2 \\ 2 & 31 & 12.6 & 98.8 \\ 3 & 1 & 0.4 & 99.2 \\ 5 & 1 & 0.4 & 99.6 \\ 6 & 1 & 0.4 & 100.0 \\ \text { Total } & 246 & 100.0 & \end{array}$

Temporary Help

$\begin{array}{crrc}\text { Value } & \text { Frequency } & \text { Percent } & \text { Cumulative \% } \\ 0 & 238 & 96.7 & 96.7 \\ 1 & 7 & 2.8 & 99.6 \\ 2 & 1 & 0.4 & 100.0 \\ \text { Total } & 246 & 100.0 & \end{array}$

NUMBER OF VEHICLES

$\begin{array}{lccc}\text { Value Label } & \text { Frequency } & \text { Percent } & \text { Cumulative \% } \\ \text { No Vehicles } & 172 & 69.9 & 69.9 \\ \text { One Vehicle } & 64 & 26.0 & 95.9 \\ \text { Two Vehicles } & 10 & 4.1 & 100.0 \\ \quad \text { Total } & 246 & 100.0 & \end{array}$




\section{TRIP PURPOSE}

Number of Times to Pickup/Deliver Goods

$\begin{array}{cccc}\text { Value } & \text { Frequency } & \text { Percent } & \text { Cumulative \% } \\ 0 & 191 & 77.6 & 77.6 \\ 1 & 2 & 0.8 & 78.5 \\ 2 & 45 & 18.3 & 96.7 \\ 4 & 7 & 2.8 & 99.6 \\ 6 & 1 & 0.4 & 100.0 \\ \text { Total } & 246 & 100.0 & \end{array}$

Number of times to the Bank/Post Office

\begin{tabular}{|c|c|c|c|}
\hline Value & Frequency & Percent & Cumulative $\%$ \\
\hline 0 & 221 & 89.8 & 89.8 \\
\hline 1 & 1 & 0.4 & 90.2 \\
\hline 2 & 23 & 9.3 & 99.6 \\
\hline 4 & 1 & 0.4 & 100.0 \\
\hline Total & 246 & 100.0 & \\
\hline
\end{tabular}

Number of Times to Eat Meal

$\begin{array}{cccc}\text { Value } & \text { Frequency } & \text { Percent } & \text { Cumulative \% } \\ 0 & 211 & 85.8 & 85.8 \\ 1 & 1 & 0.4 & 86.2 \\ 2 & 30 & 12.2 & 98.4 \\ 3 & 1 & 0.4 & 98.8 \\ 4 & 3 & 1.2 & 100.0 \\ \quad \text { Total } & 246 & 100.0 & \end{array}$


Number of Times to Government Offices

\begin{tabular}{|c|c|c|c|}
\hline Value & Frequency & Percent & Cumulative $x$ \\
\hline 0 & 242 & 98.4 & 98.4 \\
\hline 1 & 1 & 0.4 & 98.8 \\
\hline 2 & 3 & 1.2 & 100.0 \\
\hline Total & 246 & 100.0 & \\
\hline
\end{tabular}

\begin{tabular}{|c|c|c|c|}
\hline \multicolumn{4}{|c|}{ Number of Times Travel-out-of-Town } \\
\hline Value & Frequency & Percent & Cumulative $x$ \\
\hline 0 & 220 & 89.4 & 89.4 \\
\hline 1 & 10 & 4.1 & 93.5 \\
\hline 2 & 15 & 6.1 & 99.6 \\
\hline 3 & 1 & 0.4 & 100.0 \\
\hline Total & 246 & 100.0 & \\
\hline
\end{tabular}

Number of Times to Pay/Collect Debt

$\begin{array}{cccc}\text { Value } & \text { Frequency } & \text { Percent } & \text { Cumulative \% } \\ 0 & 228 & 92.7 & 92.7 \\ 1 & 3 & 1.2 & 93.9 \\ 2 & 15 & 6.1 & 100.0 \\ \quad \text { Total } & 246 & 100.0 & \end{array}$


Number of Times to Run Errand

$\begin{array}{ccrc}\text { Value } & \text { Frequency } & \text { Percent } & \text { Cumulative * } \\ 0 & 191 & 77.6 & 77.6 \\ 1 & 9 & 3.7 & 81.3 \\ 2 & 32 & 13.0 & 94.3 \\ 3 & 6 & 2.4 & 96.7 \\ 4 & 6 & 2.4 & 99.2 \\ 6 & 1 & 0.4 & 99.6 \\ 7 & 1 & 0.4 & 100.0 \\ \text { Total } & 246 & 100.0 & \end{array}$

Number of Times to Socialize

$\begin{array}{cccc}\text { Value } & \text { Frequency } & \text { Percent } & \text { Cumulative \% } \\ 0 & 222 & 90.2 & 90.2 \\ 1 & 2 & 0.8 & 91.1 \\ 2 & 59 & 24.0 & 97.6 \\ 4 & 4 & 1.6 & 99.2 \\ 5 & 1 & 0.4 & 99.6 \\ 6 & 1 & 0.4 & 100.0 \\ \text { Total } & 246 & 100.0 & \end{array}$


MODE CHOICE

$\begin{array}{lccc}\text { Walking } & & & \\ \text { Value } & \text { Frequency } & \text { Percent } & \text { Cumulative \% } \\ 0 & 145 & 58.9 & 58.9 \\ 1 & 7 & 2.8 & 61.8 \\ 2 & 64 & 26.0 & 87.8 \\ 3 & 5 & 2.0 & 89.8 \\ 4 & 17 & 6.9 & 96.7 \\ 5 & 1 & 0.4 & 97.2 \\ 6 & 7 & 2.8 & 100.0 \\ \text { Total } & 246 & 100.0 & \end{array}$

$\begin{array}{lccc}\text { Bus } & & & \\ \text { Value } & \text { Frequency } & \text { Percent } & \text { Cumulative * } \\ 0 & 199 & 80.9 & 80.9 \\ 1 & 6 & 2.4 & 83.3 \\ 2 & 33 & 13.4 & 96.7 \\ 3 & 2 & 0.8 & 97.6 \\ 4 & 4 & 1.6 & 99.2 \\ 5 & 1 & 0.4 & 99.6 \\ 6 & 1 & 0.4 & 100.0 \\ \text { Total } & 246 & 100.0 & \end{array}$




$\begin{array}{lccc}\text { Taxi } & & & \\ \text { Value } & \text { Frequency } & \text { Percent } & \text { Cumulative * } \\ 0 & 177 & 72.0 & 72.0 \\ 1 & 12 & 4.9 & 76.8 \\ 2 & 47 & 19.1 & 95.9 \\ 3 & 3 & 1.2 & 97.2 \\ 4 & 5 & 2.0 & 98.2 \\ 6 & 2 & 0.8 & 100.0 \\ \text { Total } & 246 & 100.0 & \end{array}$

Motorcycle

\begin{tabular}{|c|c|c|c|}
\hline Value & Frequency & Percent & Cumulative $\%$ \\
\hline 0 & 227 & 92.3 & 92.3 \\
\hline 1 & 1 & 0.4 & 92.7 \\
\hline 2 & 10 & 4.1 & 96.7 \\
\hline 3 & 4 & 1.6 & 98.4 \\
\hline 4 & 3 & 1.2 & 99.6 \\
\hline 8 & 1 & 0.4 & 100.0 \\
\hline Total & 246 & 100.0 & \\
\hline
\end{tabular}

Van/Truck

$\begin{array}{lccc}\text { Value } & \text { Frequency } & \text { Percent } & \text { Cumulative } * \\ 0 & 241 & 98.0 & 98.0 \\ 2 & 5 & 2.0 & 100.0 \\ \text { Total } & 246 & 100.0 & \end{array}$


AutoDriver Alone

$\begin{array}{cccc}\text { Value } & \text { Frequency } & \text { Percent } & \text { Cumulative } x \\ 0 & 219 & 89.0 & 89.0 \\ 1 & 7 & 2.8 & 91.9 \\ 2 & 11 & 4.5 & 96.3 \\ 3 & 2 & 0.8 & 97.2 \\ 4 & 5 & 2.0 & 99.2 \\ 5 & 1 & 0.4 & 99.6 \\ 7 & 1 & 0.4 & 100.0 \\ \text { Total } & 246 & 100.0 & \end{array}$

Auto Passenger

$\begin{array}{lccc}\text { Value } & \text { Frequency } & \text { Percent } & \text { Cumulative * } \\ 0 & 238 & 96.7 & 96.7 \\ 1 & 7 & 2.8 & 99.6 \\ 2 & 1 & 0.4 & 100.0 \\ \text { Total } & 246 & 100.0 & \end{array}$

AutoDriver with Passenger

$\begin{array}{cccc}\text { Value } & \text { Frequency } & \text { Percent } & \text { Cumulative * } \\ 0 & 239 & 97.2 & 97.2 \\ 1 & 3 & 1.2 & 98.4 \\ 2 & 1 & 0.4 & 98.8 \\ 3 & 2 & 0.8 & 99.6 \\ 4 & 1 & 0.4 & 100.0 \\ \text { Total } & 246 & 100.0 & \end{array}$


NUMBER OF YEARS IN BUSINESS

$\begin{array}{cccc}\text { Value } & \text { Frequency } & \text { Percent } & \text { Cumulative * } \\ \text { Under } 5 & 186 & 36.4 & 36.4 \\ 5-9 & 104 & 20.3 & 56.7 \\ 10-14 & 67 & 13.0 & 69.7 \\ 15-19 & 62 & 12.0 & 81.7 \\ 20^{+} & 94 & 18.3 & 100.0 \\ \text { Total } & 513 & 100.0 & \end{array}$

AGE OF TRADERS

$\begin{array}{cccc}\text { Value } & \text { Frequency } & \text { Percent } & \text { Cumulative * } \\ 15 \text { \& Under } & 54 & 10.5 & 10.5 \\ 16-30 & 252 & 49.2 & 59.7 \\ 31-40 & 98 & 19.0 & 68.7 \\ 41^{+} & 109 & 21.3 & 100.0 \\ \text { Total } & 513 & 100.0 & \end{array}$

NUMBER OF ADEQUATE SHEDS

$\begin{array}{lccc}\text { Value Label } & \text { Frequency } & \text { Percent } & \text { Cumulative * } \\ \text { Less than two } & 151 & 61.4 & 61.4 \\ \text { Two or three } & 75 & 30.5 & 91.9 \\ \text { Four and over } & 20 & 8.1 & 100.0 \\ \quad \text { Total } & 246 & 100.0 & \end{array}$




\section{APPENDIX B}

CORRELATION MATRIX TABLES

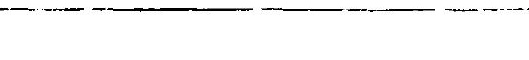


FOR LOCATION (SEe, MEMP)

FOR CBD LOCATION

\begin{tabular}{|c|c|c|c|c|c|c|c|}
\hline & $\varphi$ & $x_{1}$ & $x_{2}$ & $x_{3}$ & $x_{4}$ & $x_{5}$ & $x_{6}$ \\
\hline Totrps & 1,00 & .53 & .51 & .04 & -.11 & -.06 & -.09 \\
\hline UEHAUR & & 1.00 & .28 & -.06 & -.24 & .01 & .01 \\
\hline MEMP & & & 1.00 & -.01 & -.15 & .25 & -.10 \\
\hline TEXTI & & & & 1.00 & -.23 & -.28 & -.2 \\
\hline FOODS & & & & & 1.00 & -.20 & -.2 \\
\hline READY & & & & & & 1.00 & -.2 \\
\hline HARI & & & & & & & 1.0 \\
\hline
\end{tabular}

FOR EXPRESS ROAD LOCATION

\begin{tabular}{|c|c|c|c|c|c|c|c|}
\hline & $\psi$ & $x_{1}$ & $x_{2}$ & $x_{3}$ & $x_{4}$ & $x_{5}$ & $x_{6}$ \\
\hline Totrps & 1.00 & .37 & .33 & -.24 & -.09 & -.04 & .25 \\
\hline UEHAUA & & 1.00 & .43 & -.15 & -.15 & -.18 & .18 \\
\hline MEMP & & & 1.00 & -.12 & -.24 & -.17 & .09 \\
\hline TEXTI & & & & 1.00 & -.22 & -.19 & -.21 \\
\hline FOODS & & & & & 1.00 & -.28 & -.22 \\
\hline READY & & & & & & 1.00 & -.26 \\
\hline HARD & & & & & & & 1.00 \\
\hline
\end{tabular}


FOR MEMP

\begin{tabular}{|c|c|c|c|c|c|c|c|c|}
\hline & $Y$ & $x_{1}$ & $x_{2}$ & $x_{3}$ & $x_{4}$ & $x_{5}$ & $x_{6}$ & $x_{7}$ \\
\hline Totrps & 1.00 & -.12 & -.04 & .11 & -.06 & -.37 & .48 & .48 \\
\hline FOODS & & 1.00 & -.25 & -.25 & -.22 & .10 & -.23 & -.23 \\
\hline READY & & & 1.00 & -.25 & -.22 & -.00 & -.10 & -.10 \\
\hline HARD & & & & 1.00 & -.23 & .00 & .01 & 1 \\
\hline TEXTI & & & & & 1.00 & -.13 & -.02 & -.0 \\
\hline LOC & & & & & & 1.00 &,- 36 & -.2 \\
\hline HEMP & & & & & & & 1.00 & .4 \\
\hline$\pi$ & & & & & & & & \\
\hline
\end{tabular}




\section{FOR PETRPS}

$\begin{array}{llllllllll}y & x_{1} & x_{2} & x_{3} & x_{4} & x_{5} & x_{6} & x_{7} & x_{3} & x_{9}\end{array}$ $\begin{array}{lllllllllll}\text { Totrps } & 1.00 & -.12 & -.04 & .11 & -.06 & -.37 & .48 & .00 & .26 & .20\end{array}$ FOODS $\quad \begin{array}{lllllllll}1.00 & -.25 & -.25 & -.22 & .10 & -.27 & .41 & -.34 & -.14\end{array}$

RERDY $\begin{array}{lllllllll}1.00 & -.25 & -.22 & -.00 & -.09 & -.09 & -.03 & .05\end{array}$

HARD $\begin{array}{lllllll}1.00 & -.23 & .00 & .16 & -.17 & .07 & .06\end{array}$ TEXTI $\begin{array}{llllll}1.00 & -.13 & -.09 & .14 & -.07 & -.05\end{array}$

LOC $\begin{array}{lllll}1.00 & -.27 & .00 & -.14 & -.24\end{array}$

PETRPS $\begin{array}{llll}1.00 & -.31 & .44 & .27\end{array}$

MTRLES $1.00-.46-.16$

NFEMS

$1.00-.28$

MAFEMS 


\section{FOR MAFEMS}

$\begin{array}{llllllll}4 & x_{1} & x_{2} & x_{3} & x_{4} & x_{5} & x_{6} & x_{7}\end{array}$

\begin{tabular}{|c|c|c|c|c|c|c|c|c|}
\hline Totrps & 1.00 & -.13 & -.04 & .11 & -.06 & -.37 & .48 & .20 \\
\hline FOODS & & 1.00 & -.26 & -.26 & -.23 & .10 & -.24 & -.14 \\
\hline RERDY & & & 1.00 & -.26 & -.23 & -.00 & -.11 & -.06 \\
\hline HARD & & & & 1.00 & -.23 & .00 & .11 & .06 \\
\hline TEXTI & & & & & 1.00 & -.13 & -.08 & -.1 \\
\hline LOC & & & & & & 1.00 & -.23 & .24 \\
\hline UEHAUA & & & & & & & 1.00 & .2 \\
\hline MAFEK & & & & & & & & 1 \\
\hline
\end{tabular}

FOR MMRLES

$\begin{array}{llllllll}y & x_{1} & x_{2} & x_{3} & x_{4} & x_{5} & x_{6} & x_{7}\end{array}$

$\begin{array}{lllllllll}\text { Totrps } & 1.00 & -.09 & .45 & .13 & -.06 & -.35 & .03 & -.03\end{array}$

Foods $\quad \begin{array}{llllllll}1.00 & -.22 & -.26 & -.24 & .06 & .40 & -.26\end{array}$

$\begin{array}{lllllll}\text { UEHAUR } & 1.00 & .09 & -.06 & -.20 & -.30 & -.13\end{array}$

HARD

$\begin{array}{lllll}1.00 & -.22 & -.00 & -.17 & -.24\end{array}$

TEXTI

$\begin{array}{llll}1.00 & -.15 & .13 & -.23\end{array}$

LOC

$1.00 \quad-.03 \quad .03$

MMALES

$1.00--.10$

READY 


\section{APPENDIX C}

HSRRC MEMORANDUM 


\section{FOR MFEMS}

\begin{tabular}{|c|c|c|c|c|c|c|c|c|}
\hline & $Y$ & $x_{1}$ & $X_{2}$ & $x_{3}$ & $x_{4}$ & $x_{5}$ & $x_{6}$ & $x_{1}$ \\
\hline Totrps & 1.00 & -.09 & .45 & .36 & .13 & -.06 & -.36 & -.03 \\
\hline FOODS & & 1.00 & -.22 & -.41 & -.26 & -.24 & -.06 & -.26 \\
\hline UEHAUA & & & 1.00 & .56 & .09 & -.06 & -.20 & -.13 \\
\hline MFEHS & & & & 1.00 & .13 & -.09 & -.24 & -.02 \\
\hline HARD & & & & & 1.00 & -.22 & -.00 & -.24 \\
\hline TEXTI & & & & & & 1.00 & -.15 & -.23 \\
\hline LOC & & & & & & & 1.00 & .03 \\
\hline EHD & & & & & & & & 1.00 \\
\hline
\end{tabular}




\title{
Portland State University
}

\author{
MENORANUUMI
}

KUMAN SUBJECTS RESEARCH REVIEH COMAITTEE

1987-88

DATE: February 4, 1988

TO: Kkrys Ochia, USP

FROY: Robert C. Holloway, Chairperson Human Subjects Research Review Comittee (HSRRC)

RE: HSRRC APproval

In accordance with your request, the Human Subjecrs Research Review Committee has reviewed your proposal entitled Commercial Activities and che Geography of Movement for compliance with DHHS policies and regulations on the protection of human subjects.

The comrittee is sarisfied that your provisions for prozecting the rights and welfare of all subjects participaring in the research are adequate and therefore the project is approved. Any conditions relative to this approval

are noted below:

Conditions: None.

RH: 11

ce:Offlce of Grants and Coneracts 
APPENDIX D

SURVEY MATERIAL 
SCHOOL OF URBAN AND PUBLIC AEFAIRS

PORTLAND STATE UNIVERSITY

P.O. BOX 75I

PORTLAND, OREGON 97201

U.S.A.

TRANSPORTATION SÜRVEY OF ONITSHA TRADERS, 1988

Survey Date

Survey Time [in]

INTERVIEWER should answer Questions $1-3$
Sample Number by Market: RM

$\mathrm{HBM}$

MM

1. Respondent is

(0) Male

(1) Eemale

2. Shed is located

(0) In the Main Market

(1) Along the Express Road

3. What types of good are sold in this shed?

(I) Eoodstuifs

(2) Hardwares

(3) Ready-made clothing

(4) Textiles

(5) Provisions

4. How many traders are there in this shed?

Numbez

Male Female

5. How many are:

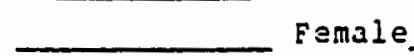

Number

(1) Tradez-in-training

(2) Assistants

(3) Owner/Co-owner

(4) Temporary heip

(5) Other: Specify

6. Means of transportation, for example, car, van, motorcycle, bicycle, etc; How many of each category are available to this shed for making trips during regular business hours?

Tyoe of Vehicle
(1) Bicycle
(2) Motorcycle
(3) Car
(4) van/truck
(E) other, Spec:




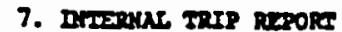

For all tripa and on HIY TH IS

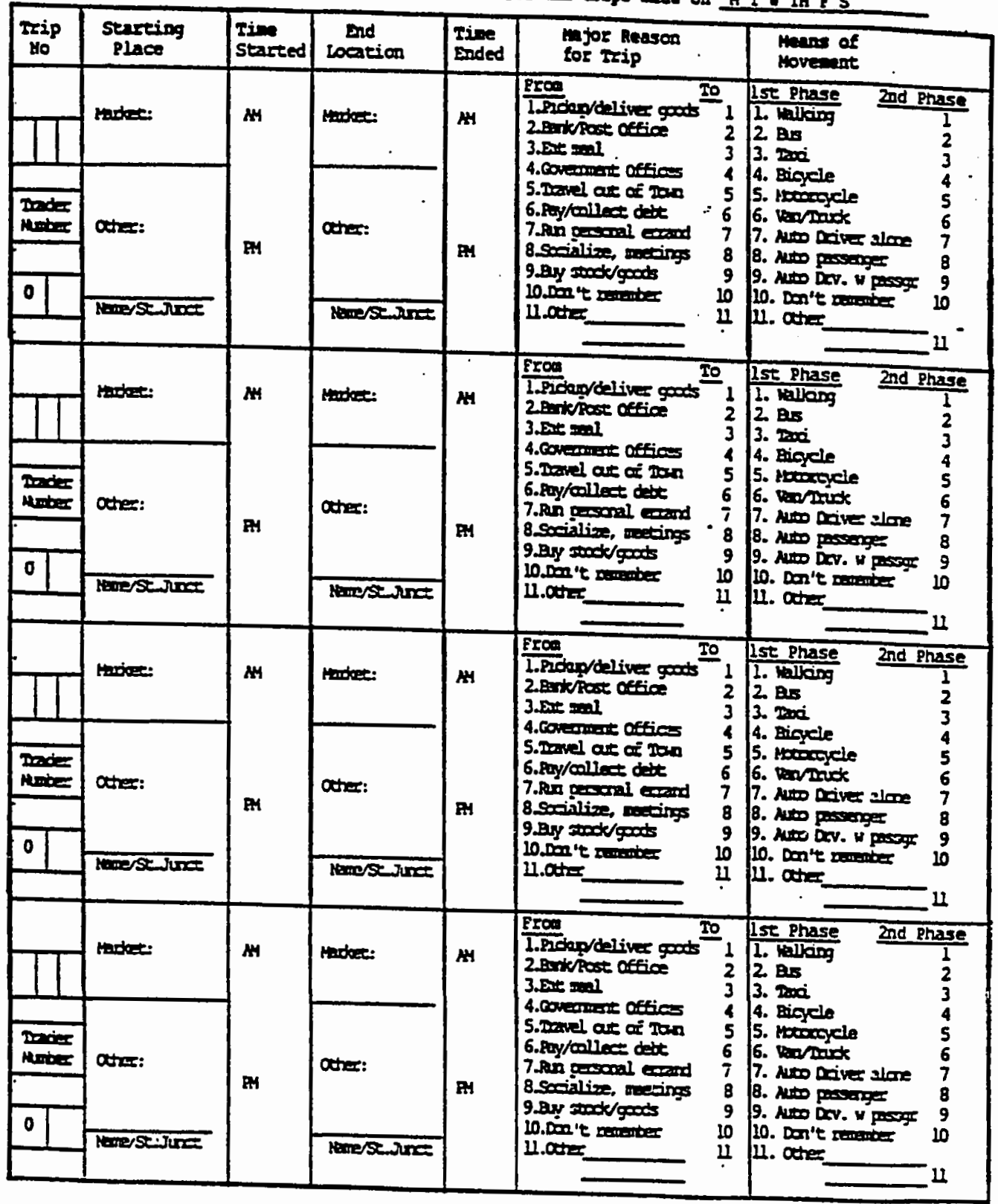

Please turn orer 
8. How long has each trader in this shed been in trading?

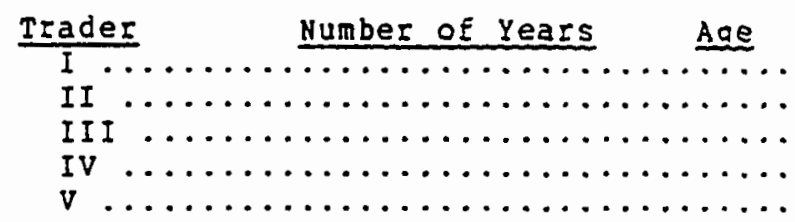

9. How many sheds do you consider adequate for a business person like you?

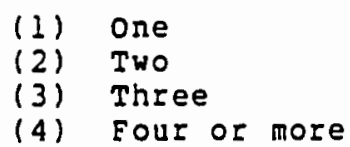

10. Are there any other factors we have not covered which you believe affect how ofter a trader from this shed will make a trip after arriving in the market in the moraing?

comments:

1 .

2 .

3 .

4.

5 .

Thank you very much and goodluck in your business. This will help us co undezsrand how and why traders use the urban eransporzation system in onitsina.

\section{END OF INTERVIEW}

TO INTERVIEWER: I hereby certify that I have completed this interview and recorded all responses accuracely.

Interviewer signature

Date 
APPENDIX E

NIGERIAN MIRROR 
7it is reported that ded to Nigerians of the four Ladies.

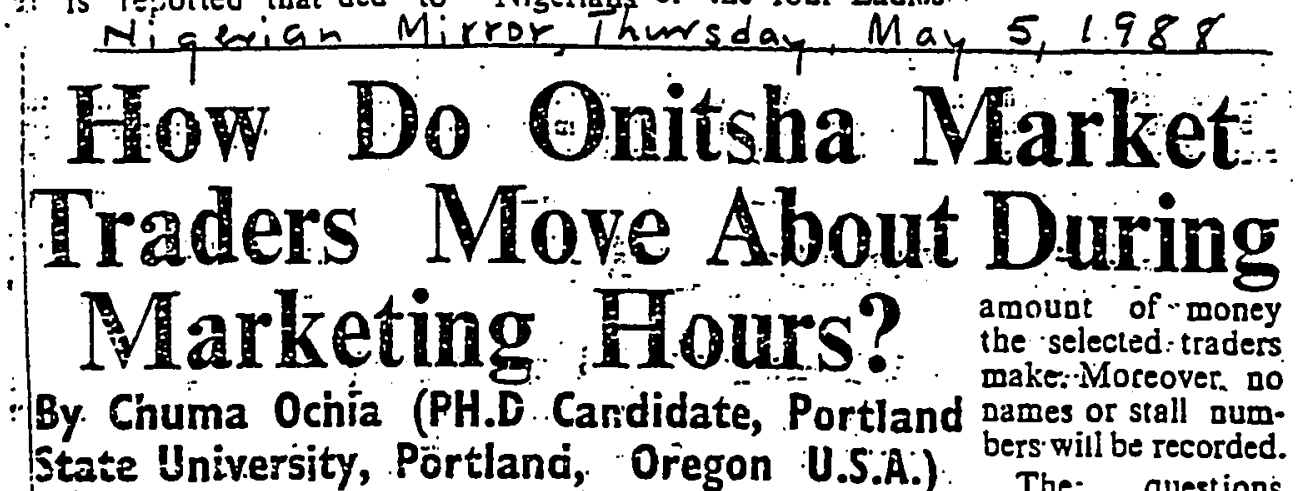
State University, Pörtland, Oregon U.S.A.) bers will be recorded.

If you area tra- vide the answers on leave the shed? Do will be answered der, you may want how traders. use the theygo to a number by the owner/co-

to answer this ques- existing traosporta- of places or, do they owner. of. the shed ion immediately. tion system. All the go "to orly. one or someone who is Well, you may soon sheds: will be located place beiore returniog innowledgeable - about bave an opportunity in either of the mar- to the shed? Ans- activities of all io do so. ke 1,5 mentioned wers to such ques- occupants in the It is reasorable to above. Only 63 sheds tions- will tell us shed. The time 3s iume - that there will be selected: from bow traders move spent answering the may be some level of each market. - about in town dur- questions will be diffrcuity involved Some traders-have ing marketing hours. short. Finally, if when an.average tra- private-cars, vans To an average we. understand bow der in a shed in and/or motorcycles trader these ques. traders use the either tine main which. they use to tions may appear to existing transportamarket, or the make all contacts have obvinus ans. tion system, then the Headbridge market, during normal.trad- wers. I will caution governmeni, workor the Relief ing hours. Other that even though ing : together with Market moves about traders, especially opinions may exist, iraders, transport in Onitsha to those selling fcod- no one is sure for owners and $/$ or make contact as stuff, - may not-be a fact, how often operators, will be part of the regular so fortunate. Those and why: every.in. a -. position. to trading activity. traders may have to other trader muves develop reasonabla To understand depend on. walking; about after: they ways-10: make $\cdots$ it traders' experience in buses, bicycles... or arrive in the. shed.. more convenient accomplishiog these taxi services as their Let me state that for.traders to make types of movement,.I means of transport- this survey- is not contarts during ofwill.be conducting a ation. The issue -is; interested in the ficial marketing bour:

survey this month for those traders

and the next. The who leave their :- survey will involve sheds to make-con:

i) visiting:the sheds: of tacts -..after they

si some - traders and arrive in the market

: asking - some ques- in:- the "morning

tions about; bow tra- where do they go?

iders move'about du- What . are -..their

ring offeial: : trading reasons: for:- going

bnurs. " The '. sbeds there? How -.. often

i. will be - selected in a do they lêve tia

lottery fashion. The shed in a typical

occupants of the se- day? What time ol

- lected sheds will pro- the day do they

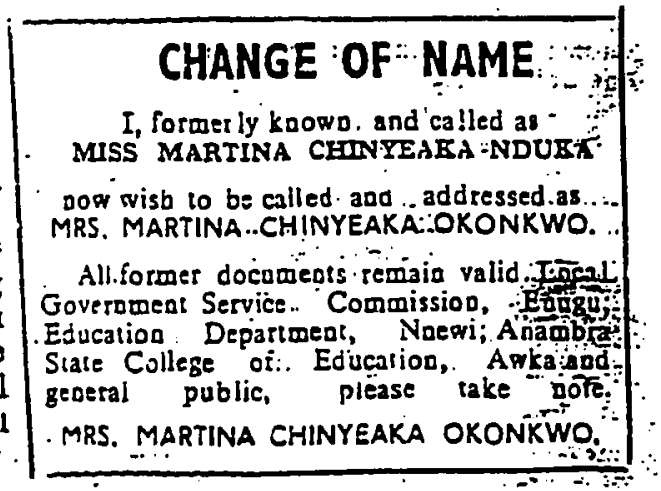


APPENDIX F

LETTER 
199

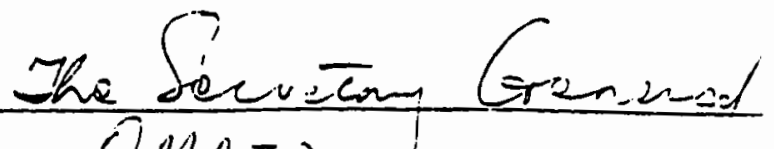
OMA-T

The 'weasm 23, New manuch ed: Mh. S.E. Anyanow.

$$
\text { Qsing }
$$
Had oridge mut.
Eshs.

$13 / 5 / 0^{2} 8$

Dear Mr. Angenure.

Pleare Kincy assict the Georer Mr. Chutionma Oehis Le is a sCusent at USA avi we will explaim nore of his vee thanks Len yew cos-oprenatis.

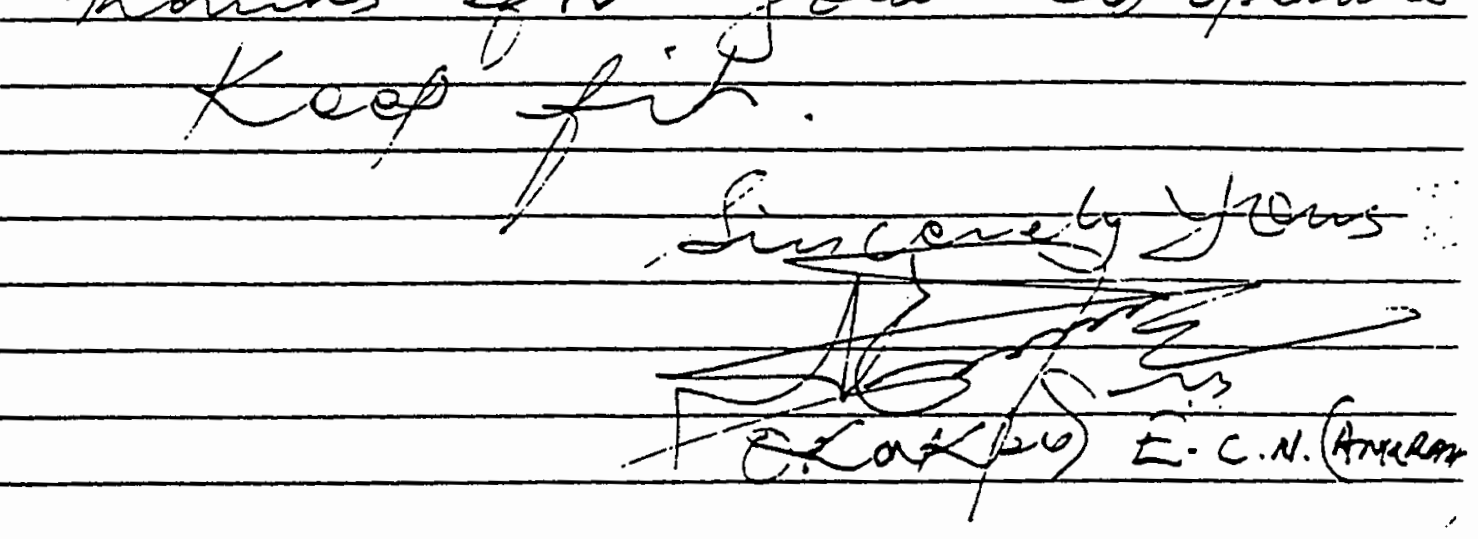

NB Pleave afte H/B. mowher driv hims $=0$ relizintht 